Carlos Carrasco Arbieto

\title{
Incorporação de informações secundárias para gerenciar o risco geológico no planejamento de lavra de curto-prazo
}

Dissertação apresentada à Escola Politécnica da Universidade de São Paulo para obtenção do Título de Mestre em Engenharia Mineral. 
Carlos Carrasco Arbieto

\section{Incorporação de informações secundárias para gerenciar o risco geológico no planejamento de lavra de curto-prazo}

Dissertação apresentada à Escola Politécnica da Universidade de São Paulo para obtenção do Título de Mestre em Engenharia Mineral.

Área de concentração:

Engenharia Mineral

Orientador:

Prof. Dr. Giorgio De Tomi 
Ficha Catalográfica

Carrasco Arbieto, Carlos

Incorporação de informações secundárias para gerenciar o risco geológico no planejamento de lavra de curto-prazo. São Paulo, 2006. 107 p.

Dissertação (Mestrado) - Escola Politécnica da Universidade de São Paulo. Departamento de Engenharia Mineral e Petróleo.

1. Planejamento de lavra. 2. Engenharia de mineral. I. Universidade de São Paulo. Escola Politécnica. Departamento de Engenharia Mineral e Petróleo. II. Título. 
A meus Pais por todo seu apoio e as pessoas que acreditaram neste trabalho... 


\section{Agradecimentos}

Gostaria de agradecer a inestimável ajuda do Prof. Dr. Giorgio de Tomi, não apenas como meu orientador, mas também como criador e responsável pelo LAPOL - Laboratório de Planejamento e Otimização de Lavra da EPUSP - que serviu de base para todo o trabalho aqui apresentado. Ao colega e exemplo de acreditar em coisas Agenor de Faria Junior da equipe de planejamento da Mina de Cajati do grupo Bunge S. A. Com especial reconhecimento ao Prof. Dr. João Felipe Costa, da Universidade Federal de Rio Grande do Sul, quem me deu a oportunidade de receber orientação adicional neste trabalho na própria UFRGS. Ao Prof. Dr. Marcelo Rocha (IG - USP) quem contribuiu com suas sugestões e experiência. A toda a equipe do nosso laboratório, o atual Professor e amigo, Ricardo Cabral Azebedo, Rondinelli Sousa, Sandro Lucerna, Fabricio Aragaki e, a todos os integrantes do time do Lapol. Ao Eng. Nelson Senhorinho, particularmente, no otimismo e motivação em temas de planejamento de lavra. Com muito carinho a Jenny Niño de Guzmam por todo o apoio e motivação. Indispensável agradecer, também, à Bunge S. A. e, finalmente, agradeço à CAPES, pelo grande incentivo e auxílio financeiro a esta e a tantas outras pesquisas nas mais diversas áreas. 


\section{Resumo}

O planejamento de lavra de curto prazo é normalmente executado utilizando-se número reduzido de informações de sondagem. Para aprimorar o gerenciamento de riscos geológicos no planejamento de lavra de curto prazo é necessário utilizar um universo maior de informações. Como é normalmente inviável obter novas informações de sondagem, esta dissertaçao propõe uma metodologia de utilizaçao de amostras de pó de perfuratriz (a partir de furos de desmonte) como uma fonte de informação secundária e assim aprimorar a qualidade das estimativas. Neste sentido, foi adotada uma técnica de co-estimativa da variável $P_{2} O_{5}$ das sondagens (variável primária) em conjunto com a variável $P_{2} O_{5}$ do desmonte (variável secundária) baseado no modelo Marcoviano MM2, pelo qual é possível combinar as duas informações (sondagem e desmonte) na estimativa de um modelo de blocos. Este processo permitiu a modelagem de atributos geológicos de forma mais detalhada o que contribuiu para uma melhor interface entre o planejamento de curto prazo e a operação da mina. A metodologia proposta também possibilitou acessar uma população maior de informações geológicas o que contribui para a criação de planos operacionais mais aderentes aos objetivos de produção mensal ou semanal, e, ao mesmo tempo, respeitando o seqüenciamento importado do planejamento de longo e médio prazo. Como resultado, foi demonstrado que é possível criar programas operacionais mais precisos com base em estimativas de áreas próximas à lavra mesmo quando apenas um pequeno número de informações primárias (sondagens) esteja disponível. 


\section{Abstract}

Short-term mine planning is normally carried out over a limited number of drillhole information. In order to improve the management of geological risks in mine planning, a larger population of samples is required. However, it is normally very difficult to obtain additional drillhole samples once mining takes place. This research addresses that issue by proposing a methodology for the incorporation of additional information from blastholes (secondary information) to the original drillhole samples (primary information). A co-estimation technique for using $P_{2} \mathrm{O}_{5}$ samples from the drillholes (primary variable) in conjunction with $\mathrm{P}_{2} \mathrm{O}_{5}$ from blastholes (secondary variable) based on the Markovian estimation model (MM2), through which is possible to combine both sources of information for a better estimation of mineable blocks. This process has allowed more detailed modeling of geological attributes and a better interface between short-term mine planning and mine operations. The proposed methodology also allowed the access to a larger sample population which meant more accurate mine plans for the daily and weekly mine schedules. As a result, it has been demonstrated that it is possible to crate operational plans that are more precise through the use of models that are properly estimated even in those areas where only a small amount of primary information (drillhole samples) is available. 


\section{Sumário}

\section{Lista de Figuras}

Lista de Tabelas

Lista de Abreviaturas

Convenções e Lista de Símbolos

1 Introdução $\quad 9$

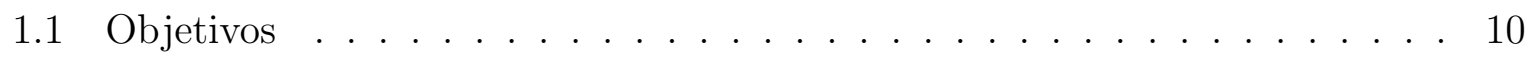

1.2 Justificativa . . . . . . . . . . . . . . . . . . 11

1.3 Organização da dissertação . . . . . . . . . . . . . . . . . . . . 12

2 Planejamento de Lavra $\quad 13$

2.1 Conceitos iniciais . . . . . . . . . . . . . . . . . 13

2.2 Parâmetros para o planejamento de lavra. . . . . . . . . . . . . . . . . . 18

2.2.1 Planejamento estratégico e de longo prazo . . . . . . . . . . . . . 19

2.2.2 Considerações gerais de cava final e o fluxo de caixa . . . . . . . . . 21

2.2.3 Seqüenciamento de lavra no planejamento de longo prazo. . . . . . 22

2.3 Planejamento de curto prazo . . . . . . . . . . . . . . . . 24

2.4 Planejamento de lavra operacional . . . . . . . . . . . . . . . . . . 26

2.4.1 Objetivos dos planos operacionais . . . . . . . . . . 26

2.5 Controle de teores na lavra . . . . . . . . . . . . . . . . . . . 28

2.5.1 Controle da qualidade do teor . . . . . . . . . . . . . 29 
3.1 Populações e domínios das amostragens . . . . . . . . . . . . . . . . . . 31

3.1.1 Amostragem georeferenciadas e estratégia de amostragem . . . . . . 32

3.1.2 Representatividade das amostras . . . . . . . . . . . . . 33

3.2 Amostragem na sondagem . . . . . . . . . . . . . . . . . 33

3.3 Amostragem nos furos para desmonte . . . . . . . . . . . . . . . . 36

3.4 Suporte amostral . . . . . . . . . . . . . . . . . . . . 37

3.4.1 Métodos de correção do suporte amostral . . . . . . . . . . . . . . . 39

4 Análise Geoestatística $\quad 41$

4.1 Estimativa da incerteza no planejamento de curto prazo . . . . . . . . . . . 41

4.1 .1 Métodos de desagrupamento . . . . . . . . . . . . . . . . . . . 42

4.1 .2 Correlação espacial . . . . . . . . . . . . . . . . . . . . . . 43

4.2 Anisotropia. . . . . . . . . . . . . . . . . . . 47

4.3 Modelos teóricos do variograma . . . . . . . . . . . . . . . . . 50

4.3.1 Modelos de variogramas teóricos . . . . . . . . . . . . . . . 50

4.4 Influência dos parâmetros do variograma na estimativa por krigagem . . . 52

4.4.1 Validação do modelo ajustado . . . . . . . . . . . . . . 54

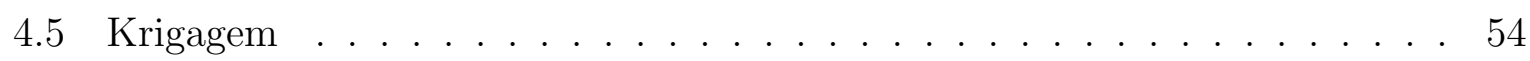

4.5.1 Definição do erro de estimativa bloco a bloco . . . . . . . . . . . . 55

4.6 Incorporação da informação secundária ao modelo existente . . . . . . . . . 57

4.7 Amálise da continuidade espacial de 2 variáveis . . . . . . . . . . . . . 57

4.7.1 Coeficiente de correlação e covariância cruzada . . . . . . . . . 57

4.7 .2 Variograma Cruzado . . . . . . . . . . . . . . . . 59

4.8 Co-estimativas por co-krigagem f . . . . . . . . . . . . . . . . 59

4.9 Estimativas por co-krigagem co-locada . . . . . . . . . . . . . . . 61 
4.10 Modelo de Markov $2($ MM2) . . . . . . . . . . . . . . . . . 62

4.11 Comparativo da krigagem simples a respeito a cokrigagem simples . . . . . 64

5 Metodologia

5.1 Metodologia proposta . . . . . . . . . . . . . . . 66

5.1.1 Mapeamento de atividades . . . . . . . . . . . . . . . . . 67

5.2 Localização da mina em estudo . . . . . . . . . . . . . . . . . . . . . 69

5.3 Geologia Regional e Local . . . . . . . . . . . . . . . . . . . . . . . . 69

5.4 Histórico . . . . . . . . . . . . . . . . . . . . . . . . . 71

5.5 Fluxograma dos processos de beneficiamento . . . . . . . . . . . . . 71

5.6 Análise e estimativa da incerteza geológica . . . . . . . . . . . . . . 73

5.6.1 Localização das amostras de teor de $P_{2} O_{5}$ do desmonte e sondagem 73

6 Resultados

6.1 Banco de dados da análise do pó do desmonte . . . . . . . . . . . . . . . . 74

6.1.1 Análise exploratória dos dados de desmonte e sondagem por bancadas 75

6.1.2 Mudança do suporte amostral . . . . . . . . . . . . . . . . 76

6.2 Análise da continuidade espacial do teor de $P_{2} O_{5}$ dos furos de desmonte . . 78

6.3 Banco de dados de sondagens . . . . . . . . . . . . . . . . . . . 82

6.3.1 Análise da continuidade e krigagem . . . . . . . . . . . . . . . 82

6.4 Deslocamento dos pontos . . . . . . . . . . . . . . . . . . 86

6.4.1 Cálculo dos índices de correlação . . . . . . . . . . . . . . . 87

6.4.2 Utilização do modelo Markoviano MM2 na construção do modelo 88

6.5 Aplicação no planejamento de curto prazo . . . . . . . . . . . . . . . 93

6.5.1 Eleição das unidades de lavra . . . . . . . . . . . . . . . . . . 94

6.5.2 Definição das dependências . . . . . . . . . . . . . . . . . . . . 94 
Anexo A - Rotina para o deslocamento esapacial para a adaptação do uso $\begin{array}{ll}\text { de co-krigagem } & 101\end{array}$

A.1 Exemplo de scrip para mudar coordenadas para a aplicação de co-krigagem 101

Anexo B - Visão geral da co-krigagem co-locada

B.1 Co-krigagem simples colocada $(\mathrm{CKSC}) \ldots \ldots \ldots$. . . . . . . . 104

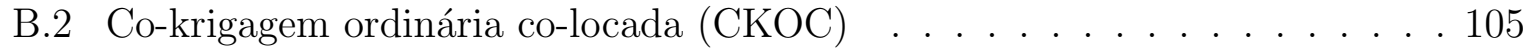

B.3 Modelo de Markov $1($ MM1) . . . . . . . . . . . . . . 106 


\section{Lista de Figuras}

2.1 Metodologia do doplo T. . . . . . . . . . . . . . . . . 15

2.2 Descrição da parte horizontal e vertical da $T$ superior . . . . . . . . . . . . 16

2.3 Sistema de rastreamento de informação IDEFO. . . . . . . . . . . . . . . . . 17

2.4 taxas de produção . . . . . . . . . . . . . . . . . . . . . . . . . . . . . . 19

2.5 Seção transversal de uma cava, mostrando três fases e suas ubicações depois do segundo e quinto anos. . . . . . . . . . . . . . . . . . . . . . 22

2.6 Avanços operacionais ("Pushback") por blocos. . . . . . . . . . . . . 23

2.7 Diagrama das atividades no planejamento da Mina de Cajati. . . . . . . 25

2.8 Diagrama do planejamento de curto prazo do grupo Codelco - Chile. . . . . 26

2.9 Perímetros operacionais dos blocos . . . . . . . . . . . . . . 27

2.10 Perímetros sobrepondo. . . . . . . . . . . . . . . . . . 28

2.11 Blocos operacionais seqüenciados em um período de curto prazo. . . . . . . 28

2.12 A questão do controle de teores. . . . . . . . . . . . . . . . . . 30

3.1 Três exemplos de extração do incremento exemplificadas em testemunhos de sondagem. . . . . . . . . . . . . . . . . . . . 34

3.2 Perfuratriz para sondagens com saca testemunhos . . . . . . . . . . . 35

3.3 Perfuratriz para desmonte com coletor de pó compartilhado, Perfuratriz Atlas Copco ROC D7, Mina Cajati . . . . . . . . . . . . . . . . . 37

3.4 Metodologia de amostragem do pó da perfuratriz na Mina de Cajati . . . . 37

3.5 Diferentes tamanhos do suporte amostral. . . . . . . . . . . . . . . . 38

3.6 Histograma com tamanho de blocos 10 X 10 m (barras verticais), blocos

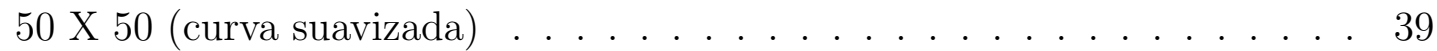

4.1 Desagrupamento por método da poligonal . . . . . . . . . . . . . . . . . 42 
4.2 Método de desagrupamento por células móveis . . . . . . . . . . . . . . . 43

4.3 Principais aplicações da geoestatística na avaliação de uma jazida. . . . . . . 44

4.4 Graus de continuidade da mineralização mostrados pelo comportamento do variograma na origem . . . . . . . . . . . . . . . . . . . . . 46

4.5 Desenho de um variograma experimental, os passos, tolerância angular, a largura máxima e tolerância de passo . . . . . . . . . . . . . . . . . . . 47

4.6 Anisotropia . . . . . . . . . . . . . . . . . . . . . . 48

4.7 Anisotropia geométrica. . . . . . . . . . . . . . . . . . . . . . 48

4.8 exemplo de contornos dos variogramas direcionais . . . . . . . . . . . . . . . 49

4.9 Desenho do processo de correção anisotrópica: . . . . . . . . . . . . . . . . 49

4.10 Modelos de variogramas mais comuns na natureza . . . . . . . . . . . . 51

4.11 Variogramas que se diferenciam pela escala . . . . . . . . . . . . . . . 52

4.12 Variogramas que se diferenciam pela escala . . . . . . . . . . . . . . 53

4.13 Influência da variância da krigagem ordinária . . . . . . . . . . . . . 56

4.14 Situação hipotética de Co-krigagem colocada. . . . . . . . . . . . . . . 62

4.15 Filtro imaginário do modelo de Marckov $2 \ldots \ldots$. . . . . . . . . 63

4.16 Contribuição relativa dos dados secundários . . . . . . . . . . . . . . 65

5.1 Mapeamento da aplicação da proposta deste trabalho . . . . . . . . . . . 68

5.2 Localização do complexo mineiro. . . . . . . . . . . . . . . . . . . 69

5.3 Complexo Alcalino de Jacupiranga . . . . . . . . . . . . . . . . . . 70

5.4 Litologias do complexo de Cajati. . . . . . . . . . . . . . . . . . 70

5.5 Fluxograma do processo de beneficiamento da apatíta. . . . . . . . . . . 72

5.6 Furos de sondagens e amostras de pó-de-perfuratriz com os furos de sondagem no plano. . . . . . . . . . . . . . . . . . . . . . . . . . 73

6.1 Histograma dos comprimentos dos furos de desmonte . . . . . . . . . . . 74

6.2 Histograma do $P_{2} O_{5}$ proveniente do pó do desmonte . . . . . . . . . . . . 75

6.3 Comparativos entre os níveis -30 a 10 . . . . . . . . . . . . . . . 75 
6.4 Comparativos entre os níveis 10 a 50 . . . . . . . . . . . . . . 75

6.5 Comparativos entre os níveis 50 a $100 \ldots \ldots$. . . . . . . . . . . 76

6.6 Comparativos entre os níveis -30 a 100 . . . . . . . . . . . . . . . . 76

6.7 Histograma da mudança de suporte amostral do modelo krigado . . . . . . 77

6.8 Variograma direcional na direção de 86 graus . . . . . . . . . . . . . . . . . 78

6.9 Validação cruzada e erro. . . . . . . . . . . . . . . . . . . . . 79

6.10 Histogramas do modelo krigado usando os furos de desmonte . . . . . . . . 79

6.11 Análise de deriva em X da estimativa usando o desmonte em fatias de $10 \mathrm{~m} .80$

6.12 Análise de deriva em $\mathrm{Z}$ da estimativa usando o desmonte em fatias de $10 \mathrm{~m} .80$

6.13 Avaliação pelo método de slope . . . . . . . . . . . . . . . . . . . . 81

6.14 Avaliação da variância de interpolação . . . . . . . . . . . . . . . . . . . . 81

6.15 Histograma do desagrupamento da variável $P_{2} O_{5}$ do sondagem . . . . . . 82

6.16 variogramas na vertical utilizando os furos de sondagens . . . . . . . . . 83

6.17 Validação cruzada e erro. . . . . . . . . . . . . . . . . . . 83

6.18 Estimativa do modelo por krigagem ordinária de $P_{2} O_{5}$ do sondagem . . . . 84

6.19 Análise de deriva da estimativa usando as sondagens na direção $X$ em fatias de $10 \mathrm{~m} \ldots \ldots \ldots \ldots \ldots$. . . . . . . . . . . . . . . 84

6.20 Análise de deriva da estimativa usando as sondagens na direção $Z$ em fatias de $10 \mathrm{~m} \ldots \ldots \ldots \ldots \ldots$. . . . . . . . . . . . . . . 84

6.21 Avaliação pelo método de slope do modelo gerado por sondagens . . . . . . 85

6.22 Avaliação da variância de interpolação modelo gerado por sondagens . . . . 85

6.23 adaptação para o deslocamento das amostras de desmonte . . . . . . . . 86

6.24 Adaptação para o deslocamento das amostras de sondagem . . . . . . . . . 86

6.25 Furos adaptados contendo as duas informações primárias e secundárias . 87

6.26 Coeficiente de correlação dos nós comuns do desmonte e sondagem . . . . . 87

6.27 Variograma cruzado ominidirecional . . . . . . . . . . . . . . . . . . 89

6.28 Correlogramas das variáveis primária e secundária . . . . . . . . . . . . . . 89 
6.29 Histograma da estimativa por co-krigagem no modelo MM2 . . . . . . . . . 90

6.30 Análise de deriva da estimativa por co-krigagem na direção $X$. . . . . . . 91

6.31 Análise de deriva da estimativa por co-krigagem na direção $Y$. . . . . . . 91

6.32 Análise de deriva da estimativa por co-krigagem na direção $Z$. . . . . . . 91

6.33 Avaliação pelo método de slope da estimativa modelo MM2 . . . . . . . . . 92

6.34 Avaliação da variância de interpolação da estimativa do modelo MM2 . 92

6.35 Dependências de fases operacionais da seqüência da programação . . . . . 94

6.36 Blocos operacionais na seqüência de operacionalição . . . . . . . . . . . . 95

6.37 Programação operacional comparativa com restrições e dependências . . 95 


\section{Lista de Tabelas}

2.1 Diferença entre planejamento de longo prazo e estratégica . . . . . . . . . 20

6.1 Resumo de estatísticas por níveis. . . . . . . . . . . . . . 77

6.2 Resumo total das estatísticas por níveis . . . . . . . . . . . . . . 77

6.3 Resumo estatístico das estimativas de $\mathrm{P}_{2} \mathrm{O}_{5}$ pela $\mathrm{KO}$ e $\mathrm{CCKO} \ldots$. . . . . 93 


\section{Lista de Abreviaturas}

REM Relação Estéril Minério

CVM Cadeia de Valor Mineral

ERP inter - relações supervisionadas do sistemas de gestão

IDEF0 Integration Definition Method Zero

VAL Valor atual líquido

TRI Taxa de retorno do investimento

MM2 Modelo de Markov 2

MPC Modelo de Curto Prazo

KO Krigagem Ordinária

CVM Cadeia de Valor Mineral 


\section{Convenções e Lista de Símbolos}

Os seguintes símbolos serão utilizados:

\begin{tabular}{|c|c|c|}
\hline símbolo & descrição & página \\
\hline$f$ & fator de redução da variância & 18 \\
\hline$R$ & tonelagem anual a se lavrar & 18 \\
\hline$n(h)$ & o número de pares para certa distância $h$ & 45 \\
\hline$Z_{i}(u)$ & primeiro par separado a uma distância $h$ & 45 \\
\hline$\gamma(h)$ & função variograma & 45 \\
\hline$K$ & a razão de anisotropia & 48 \\
\hline$C_{0}$ & variância aleatória & 50 \\
\hline$C$ & variância espacial & 50 \\
\hline$S^{2}$ & variância de interpolação & 55 \\
\hline$\lambda_{i}$ & $\begin{array}{l}\text { os ponderadores obtidos da resolução de um sistema linear da } \\
\text { krigagem }\end{array}$ & 55 \\
\hline$Z^{*}\left(x_{0}\right)$ & o estimador lineal obtido da combinação linear da krigagem & 55 \\
\hline$Z\left(x_{i}\right)$ & o dado disponível & 55 \\
\hline$\rho$ & coeficiente de correlação linear & 57 \\
\hline$m_{x}, m_{y}$ & as médias da correlação entre a primeira e segunda variável & 57 \\
\hline$\sigma_{x}, \sigma_{y}$ & desvios padrão da correlação entre a primeira e segunda variável & 57 \\
\hline$m_{x}, \sigma_{x}$ & a média e desvio padrão da variável $x$ & 58 \\
\hline$\sigma_{y}, m_{y}$ & a média e desvio padrão da variável $y$ & 58 \\
\hline$m_{i}$ e $m_{j}$ & as médias das variáveis $Z_{i}$ e $Z_{j}$ respectivamente & 58 \\
\hline$\sigma_{x}$ & a média e desvio padrão da variável $x$ & 58 \\
\hline$\gamma_{i j}(h)$ & a função variograma cruzado & 59 \\
\hline$\lambda_{\alpha 1}(u)$ & os pesos dos dados primários $Z_{1}\left(u_{\alpha 1}\right)$ & 60 \\
\hline$Z_{C K O}^{*}(u)$ & o dado primário estimado em $u$ & 60 \\
\hline$Z_{C K O}^{*}(u)$ & o dado primário estimado em $u$ & 60 \\
\hline$Z_{1}, Z_{2}$ & as variáveis primárias e secundárias locadas em $\alpha 1$ e $\alpha 2$ & 60 \\
\hline$\lambda_{\alpha 1}$ & o peso para a variável primária & 60 \\
\hline
\end{tabular}




\begin{tabular}{lll}
\hline símbolo & descrição & página \\
\hline$\lambda_{\alpha 1}$ & o peso para a variável secundária & 60 \\
$m_{z 1}$, & as médias desagrupadas de $Z_{1}$ e $Z_{2}$ & 61 \\
$m_{z 2}$ & & \\
$Z_{C K O}^{*}(u)$ & dado primário estimado em u e $Z_{1}$ e $Z_{2}$ são as variáveis primárias & 60 \\
& e secundárias locadas em $\alpha 1$ e $\alpha 2$ respectivamente. & \\
$Z_{2}^{\prime}$ & dado secundário mais afastados que é filtarado & 61 \\
$Z_{2}(u)$ & dados secundários colocados que filtran a influencia de $Z_{2}^{\prime}$ & 61 \\
$Z_{C K C O 2}^{*}(u)$ dado primário estimado com a co-krigagem co-locada em $u$ & 62 \\
$\rho_{12}(h)$ & a multiplicação do correlograma cruzado & 64 \\
$\rho 12(0)$ & correlograma cruzado para $h=0$ & 64 \\
$\rho_{2}(h)$ & correlograma da variável primária & 64 \\
$N_{v}-1$ & variáveis restantes da co-krigagem & 65 \\
$Z_{v}^{*}$ & valor estimado & 80 \\
$Z_{v}$ & o valor real dos dados & 80 \\
\hline
\end{tabular}




\section{Introdução}

No contexto atual, a lavra de jazidas com baixos teores se tornou muito comum, exigindo um detalhamento mais minucioso nestas jazidas, principalmente por sua variabilidade característica de cada formação. A modelagem geológica torna-se um fator importante para que uma empresa de mineração seja competitiva, pois um melhor conhecimento dos atributos geológicos é parte essencial de um planejamento de lavra eficiente.

Como as atividades de mineração estão ligadas à existência de reservas minerais e sendo cada vez mais difícil se encontrar jazidas com altos teores, um dos gargalos freqüentes no planejamento é a diferença entre o que foi planejado e o executado. Em geral, essa situação está associada à própria complexidade da jazida e às limitações da amostragem realizada, ocorrendo problemas em atingir os níveis de flutuações toleráveis na alimentação da usina.

Por outro lado, os altos custos são uma limitante para o incremento do número de sondagens . Por este motivo, aparece a opção de poder incorporar informações de menor custo, que podem ser: informação das amostragens químicas disponíveis de diferentes bancadas, amostras por trincheiras, sondagens secundárias, amostras de canaletas, etc. Isto significa que, na falta de informações de sondagens primárias, as informações secundárias podem auxiliar na melhor estimativa dos blocos e, assim, na tomada de decisão no planejamento de curto prazo.

A modelagem geológica é baseada em furos de sondagens, sobre o qual são avaliados os recursos e realizado o planejamento de longo prazo com critérios de otimização de cava e maximização do benefício ou maximização dos recursos. Nem sempre o planejamento lavra representa o que ocorre nas áreas onde será executada a lavra, já que estas são normalmente estimadas utilizando-se as primeiras informações (sondagens) e não tem o nível de discretização obtido nas amostragens de detalhe na própria lavra.

Este trabalho, inclui desde o projeto de lavra até planejamento operacional, com revisão de conceitos geoestatísticos, de krigagem, de co-krigagem e a co-krigagem no 
modelo MM2 denominada modelo Markoviano. Esta última técnica foi desenvolvida para os casos em que há informação abundante de outra variável. No estudo de caso deste trabalho, a variável secundária é a informação do desmonte Z2(u) e a variável primária é os furos de sondagens Z1(u). O método consiste na definição estratégica de busca, onde a vizinhança da variável secundária é reduzida para um ponto. Esta característica, unida à correlação entre as duas variáveis, é parte essencial para a geração de um Modelo de Curto Prazo (MPC). Como meio comparativo dos diferentes métodos de estimativas utiliza-se o método de análise de deriva (método comparativo por fatias) e da delimitação das categorias das diferentes estimativas pelo método de "Slope", o qual está baseado numa regressão.

Foram estimados três modelos de blocos usando-se os diferentes tipos de informações dispôniveis: (i) sondagens; (ii) informações de desmonte; e (iii) sondagem e desmonte. A partir dos modelos (i) e (iii), são reavaliados ou atualizados planos de médio prazo e os resultados são usados como base para a programação da produção.

A metodologia foi aplicada a um estudo de caso realizado em uma mina do Brasil, na qual o modelo de longo prazo foi estimado a partir de um mapeamento em detalhe (escala 1:500) com informações de sondagem executadas com diferentes direções (não somente verticais) com o objetivo de delimitar as diferentes litologias. Esses furos foram feitos em diferentes épocas (campanhas), ao longo dos últimos 20 anos, cada uma com objetivos específicos. Portanto, apesar dos domínios geológicos serem considerados satisfatórios, os modelos operacionais de curto prazo resultam deficientes devido à insuficiente informação primária (sondagem) e ao método de avaliação utilizado. Neste contexto, realizou-se uma avaliação dos três modelos com o intuito de avaliar qual é o mais adequado.

Foram utilizadas ferramentas disponíveis no mercado como: Datamine, Operation Scheduler, Geoslib e Kriging Parck, enfocando-se a aderência no modelo de curto prazo e, o aprimoramento do planejamento de curto prazo. O banco de dados utilizado é constituído por uma litologia piloto (Carbonatito Calcítico Norte CBN), a qual está bem definida litologicamente, possui baixa densidade nos furos de sondagens e uma quantidade maior de informação das análises do pó da perfuratriz.

\subsection{Objetivos}

Esta dissertação tem como objetivo aprimorar a diferencia dos modelos de curto prazo, a partir da diminuição da incerteza por adição de informação dos furos de desmonte e os 
ajustes da informação geológica. Para conseguir esse objetivo são analisados conjuntos diferentes de taxas e ritmos referente ao planejamento de médio prazo.A programação de curto prazo respeita, como critério principal, o benefício e maximização do valor presente líquido (NPV). otimização.

Este trabalho apresenta os seguintes objetivos específicos:

1. Avaliar os dados geológicos com o intuito de incorporar diretamente tanto a informação de desmonte como a de sondagem em um banco de dados único e, assim, poder utilizar um método de interpolação para uma variável (por exemplo Krigagem Ordinária $(\mathrm{KO}))$.

2. Adequar as informações do desmonte para torná-las fonte de informação secundária, satisfazendo as condições de haver amostras comuns (desmonte - sondagens) em alguns pontos, e desta forma, realizar as co-estimativas pelo método MM2.

3. Analisar a aderência dos planos de lavra em função do melhor conhecimento dos modelos de blocos, validando as estimativas comparativamente, gerando-se planos de curto prazo em função dos objetivos de programação de produção e controle do minério, providenciando melhores alternativas para controle de minério.

4. Gerar programas operacionais que permitam, prever a produção em conteúdo de minério,

\subsection{Justificativa}

Pelo fato da mineração ser considerada uma atividade primária pela incertezas geológicas, e pelos altos riscos envolvidos no planejamento de lavra, a precisão local tornase uma necessidade. A limitante do planejamento de longo prazo é o pouco investimento em novas sondagens em razão aos altos custos envolvidos na amostragem. Esta situação faz com que não se tenha confiabilidade suficiente nos planos de curto prazo, especialmente, ao realizar a reconciliação entre o planejado e executado. Porém, por meio de um conhecimento melhor da precisão local através da utilização de um maior número de informações, a obtenção de um modelo de curto prazo justifica-se na medida em que se podem conseguir ganhos na melhoria da previsibilidade e na maior produtividade na cadeia toda até a obtenção do minério beneficiado. tornando-se assim um auxílio importante na tomada de decisão nos planos operacionais. 


\subsection{Organização da dissertação}

Os capítulos da disertação estão organizados de forma que, inicialmente, é revisada a consistência da proposta por meio de um levantamento bibliográfico. Em seguida formaliza-se a metodologia e desenvolve-se um estudo de caso com a finalidade de poder demonstrar a aplicabilidade da proposta

Os capítulos seguintes estão organizados da seguinte forma:

- O Capítulo 2 apresenta o tema de planejamento de lavra, começando das primeiras concepções do planejamento em sentido geral, uma revisão do planejamento estratégico e de longo prazo e parte de planejamento de curto prazo, revisando os objetivos dos planos com uma visão operacional (programação operacional), sua seqüência e a relevância do controle de teores.

- O Capítulo 3 trata de uma revisão sucinta da amostragem, salientado-se mais a parte de métodos e metodologias de amostragens, onde são apresentados os conceitos de população, os critérios de seqüências de amostragens, o método de amostragem com recuperação de testemunho (sondagem) e método de trituração com recuperação do pó. Além disso, mostra-se também a importância do suporte amostral nas estimativas decorrentes.

- O Capítulo 4 apresenta uma revisão dos métodos de desagrupamento para a análise estatística das médias ou outro atributos que não tenham uma distribuição regular e, em uma segunda arte, os conceitos básicos da geoestatística, os métodos de estimativa, a visão do quantificação do erro à estimativa e, as ferramentas para medir a variabilidade conjunta de duas variáveis através da incorporação de informações secundárias aos dados primários.

- O Capítulo 5 Formaliza a metodologia e sua aplicação

- O Capitulo 6 Discute os resultados do estudo de caso onde, com dados obtidos da Mina de Cajati, constróem-se os modelos de blocos tanto utilizando-se uma variável, como as duas variáveis pelo método de co-estimativa. Estes modelos são unicamente re-estimados no modelo de blocos saídos do planejamento de médio prazo em um período de dois anos. 


\section{Planejamento de Lavra}

\subsection{Conceitos iniciais}

Um dos pontos-chave para melhorar a desempenho de uma empresa de mineração é o tempo de resposta na operação em relação às necessidades do mercado (DE-TOMI; CARRASCO; FARIA, 2005). Assim, o dinamismo em que se desenvolve o negócio da mineração faz com que seja necessário que o planejamento forneça direções corretas e rápidas para a operação de lavra. A exatidão dos resultados da mina está relacionada ao controle de riscos da operação, e um dos principais riscos presentes na operação de mina é o risco geológico.

Diferentes autores, apresentam definições complementares do conceito de planejamento de lavra. O planejamento pode ser considerado.

1. Uma adaptação às inevitáveis mudanças nos ciclos;

2. A antecipação do possível futuro;

3. Um estilo de direção;

4. Uma atitude mental e trabalhista, mais que uma técnica;

5. Uma decisão ou escolha prévia;

6. Uma crença ou desejo de que algo aconteça;

7. Não confundir o desejo com a realidade.

Planejar uma empresa, de acordo com o dicionário da Real Academia da Espanha, é organizá-la conforme um plano determinado. Planejar significa, literalmente, fazer planos, e se estes estiverem documentados adequadamente, tornam-se projeto. O planejamento deve, portanto, ser uma ferramenta para a tomada de decisão. Neste sentido, segundo Plá et al. (2001) as etapas que se devem seguir são basicamente: 
1. Determinação dos objetivos de lavra a serem conseguidos;

2. Mapear os objetivos em sub-objetivos específicos em tempo e dimensão;

3. Desenvolver alternativas possíveis;

4. Comparação entre as diferentes alternativas;

5. Valorização das alternativas em tempo;

6. Valorização das alternativas em orçamentos;

7. Escolha provisional da alternativa mais conveniente;

8. Medição das conseqüências adversas dessa alternativa;

9. Tomada de decisão.

Entre as alternativas possíveis não se deve confundir o que queremos com aquilo que é, isto significa claramente não confundir o desejo com a realidade.

Planejamento, em linhas gerais do negócio de mineração, é baseado no foco da produção de bens minerais, surgindo o conceito do Duplo $T$ mostrado na Figura 2.1, que divide as operações entre o sistema Cadeia de Valor Mineral (CVM) e o sistema inter - relações supervisionadas do sistemas de gestão (ERP).

Esta metodologia de abordagem contem o $T$ de cima invertido e o $T$ de baixo (normal), ou seja, um duplo $T$, onde o componente horizontal da parte superior (Figura 2.2) se refere às etapas de produção desde o desmonte, passando pelo transporte, estocagem, usina, venda e logística de entrega. O componente vertical da parte superior representa a contribuição intelectual ao processo, onde são tomadas as decisões a respeito das diversas etapas seqüenciais de produção (DE-TOMI; CEOTTO, 2003). Na mineração o $T$ inferior encontra-se bem desenvolvido e muitas empresas oferecem soluções no mercado (sistemas integrados). A parte superior (CVM), corresponde às seqüências de manejo da informação dos recursos até um plano operacional compatível com o que acontece na realidade.

Observando-se a porção vertical da parte superior do diagrama da Figura 2.2, considerase um sistema integrado ou gerenciamento conjunto do levantamento geológico, modelagem geológica, modelagem de blocos, seqüenciamento da lavra, projeto operacional e planejamento operacional. Já a porção horizontal trabalha em função de softwares de rastreamento de informação que permitem um entendimento claro do que está acontecendo na cadeia toda. Cabe salientar que, para uma melhor comunicação entre esses 


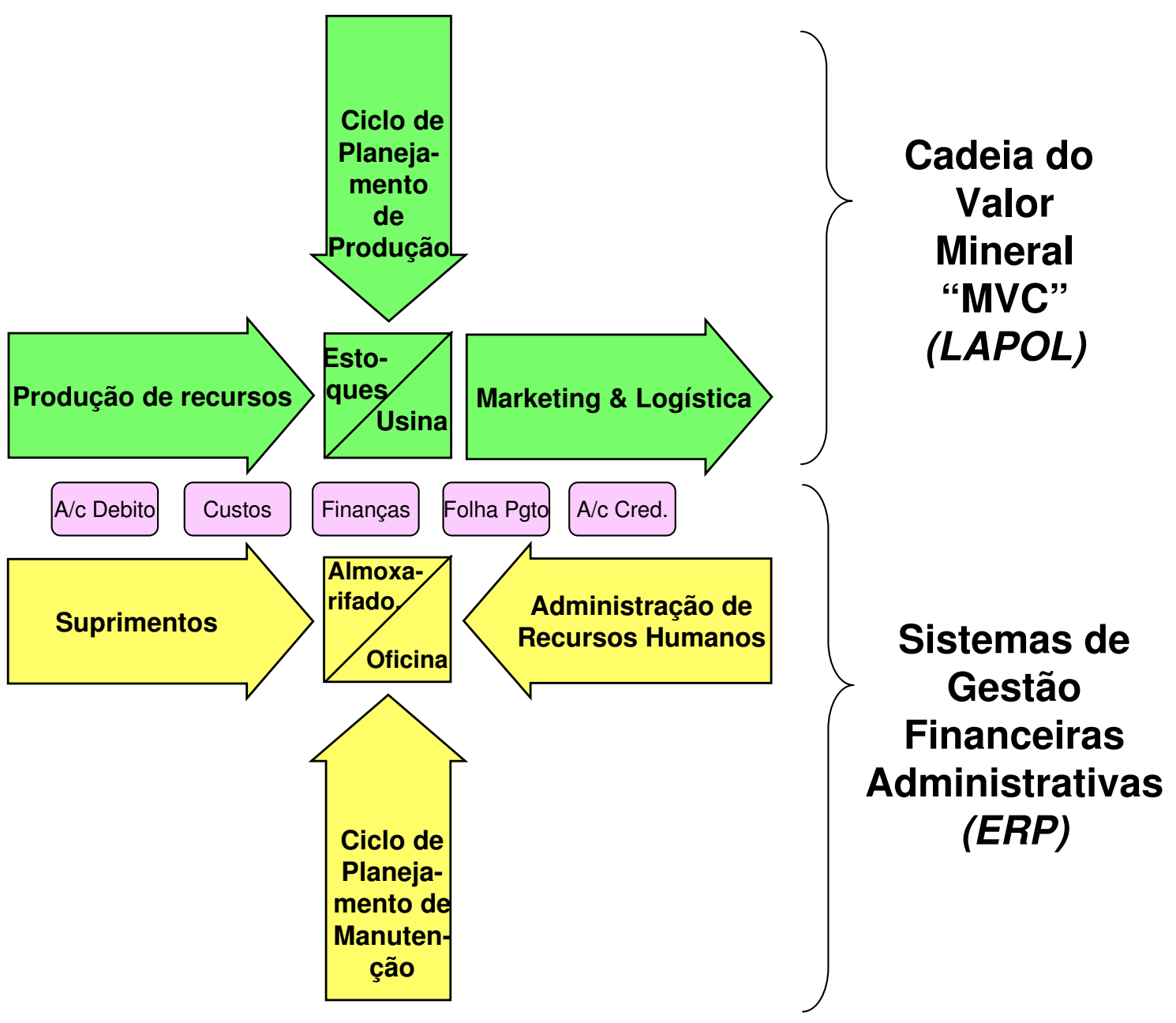

Figura 2.1: Metodologia do doplo $T$.

Fonte: De-Tomi e Ceotto (2003)

sistemas devem ser usados banco de dados auditáveis, que possam dar uma confiabilidade às informações da cadeia inteira CVM.

O rastreamento das informações de produção para a medição da aderência do planejamento tal como é detalhado na Figura 2.2 é essencial para o sucesso da operação, pois através de uma visualização destas atividades, será aprimorado do planejamento, cumprindo os contratos de venda, tanto em curto prazo como em longo prazo. A utilização de sistemas de rastreamento de informações na mineração permite que o desempenho do planejamento de lavra seja medido regularmente (DE-TOMI; CEOTTO, 2004).

O planejemento de lavra pode ser representado por meio do método Integration Definition Method Zero (IDEF0), desenvolvido para modelar as decisões, ações e atividades de uma organização ou sistema. 


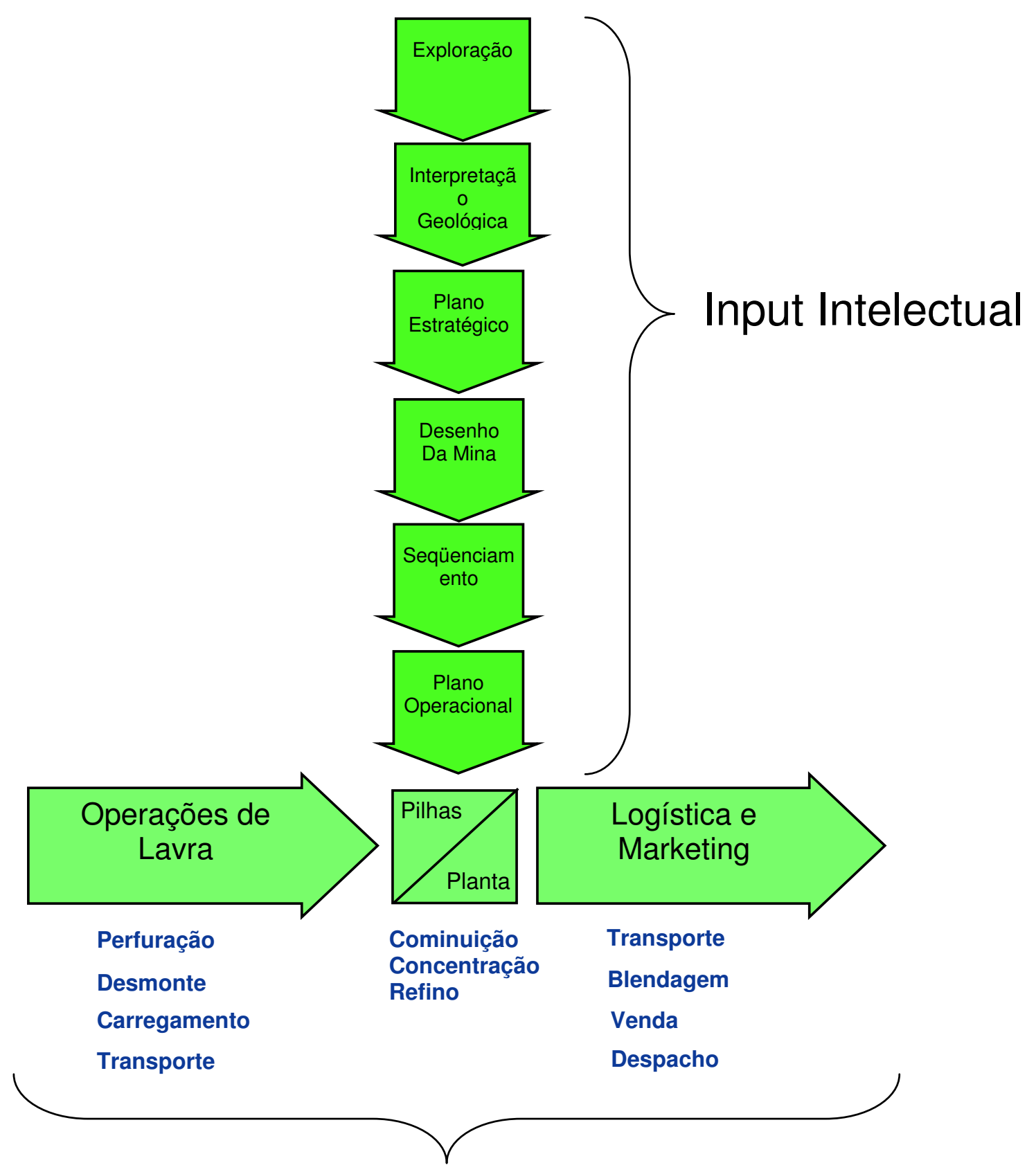

Operação

Figura 2.2: Descrição da parte horizontal e vertical da $T$ superior Fonte: De-Tomi e Ceotto (2003)

A Figura 2.3 representa um exemplo de como é rastreada uma atividade: a caixa representa a atividade (extração e concentração) a ser desenvolvida; a seta da esquerda representa a entrada ou alimentação (Minério) para a atividade; a seta da direita representa a saída do produto (Concentrado); a seta de baixo (Operação de lavra) representa o mecanismo que realizará a atividade em questão; e a seta de cima representa o controle 
necessário para a atividade a ser desenvolvida.

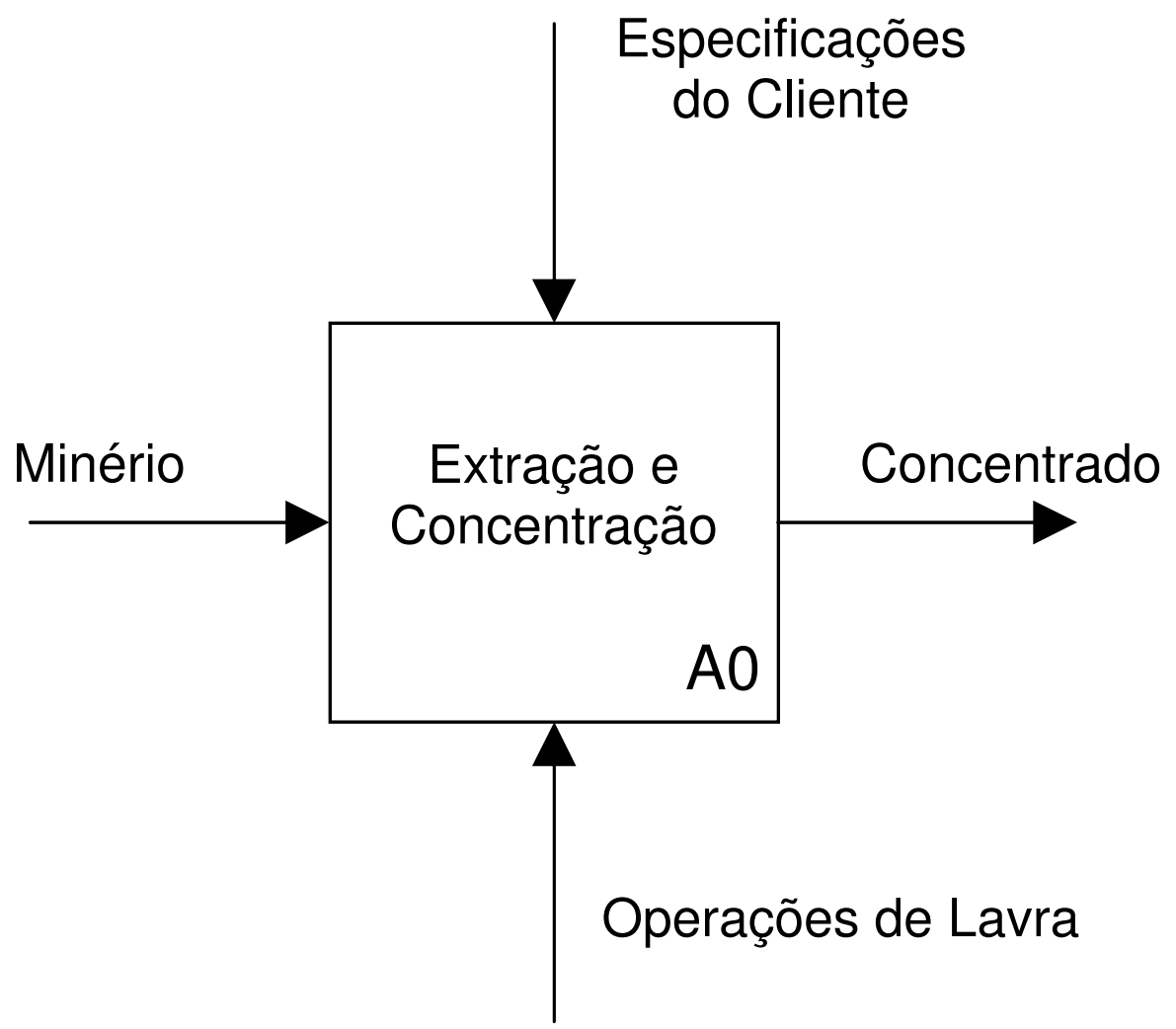

Figura 2.3: Sistema de rastreamento de informação IDEFO.

Fonte: De-Tomi e Ceotto (2004)

Entretanto, como a indústria mineral deve atender contratos com clientes, obedecendo à exigência dos prazos de entrega dos produtos e os índices de qualidade especificados, as quantidades e teores previstos devem ser considerados com a importância devida já nos dois primeiros estágios da contribuição intelectual da CVM (Interpretação e Geologia). Para atingir essas exigências, é importante ter um modelo geológico bem conhecido, onde a previsão de flutuações nos parâmetros de lavra associados a um atributo geológico seja minimizada; a previsão desta variabilidade é uma importante informação para o planejamento de lavra. À medida que se possa prever os riscos geológicos que possam intervir na lucratividade dos projetos de mineração, estará garantido o sucesso da operação.

O propósito do planejamento de lavra é prover subsídios para o engenheiro de minas decidir sobre a capacidade de lavrar determinadas unidades de lavra do depósito a partir de teores estimados (PERONI, 2002). Salienta-se, porém, que existem, a partir do primeiro momento em que são tomados os dados amostrais, incertezas a respeito do modelo geológico que deve ser considerado ao se projetar uma cava e desenvolver a lavra. Esta 
questão é bem importante na hora de tomar a decisão de lavrar determinadas áreas com alto risco, que podem influenciar em alcançar as metas de produção.

Assim, um plano de operação deve ser decomposto em períodos trimestrais e mensais. Desta forma, para a execução do planejamento, é necessário ter os seguintes programas:

1. Programação de reservas lavráveis: Um inventário detalhado das toneladas, com suas respectivas locações (nível do bloco) com o grau de certeza ou probabilidade de desvio, tanto das quantidades lavradas no ano anterior, como das previstas para o próximo programa de lavra e aquelas novas reservas achadas com as respectivas informações incluídas.

2. Programação de equipamentos e meios.

3. Programação de pessoal e infra-estrutura.

4. Programação de produção, orçamentos e cronograma de atividades.

\subsection{Parâmetros para o planejamento de lavra.}

O planejamento e desenho da lavra em mineração, basicamente, devem estabelecer os seguintes critérios iniciais para começar a trabalhar em um projeto de lavra de uma jazida nova ou em ampliação de uma mina existentem As reservas em função do beneficio:

A FUNÇÃO DE TAXAS DE PRODUÇÃO: está baseada nos estudos estatísticos realizados. A equação é denominada fórmula de Taylor:

$$
\operatorname{Taxas}(m t / \text { ano })=0,15 \cdot R^{0.75} \cdot(1+-0.2)
$$

Onde, $R$ é a tonelagem anual a se lavrar.

A Figura 2.4 apresenta a relação entre o taxas e reservas lavráveis.

VIDA UTIL: são os anos de lavra das reservas medidas e demonstradas ou os anos para o período considerado como plano.

Relação Estéril Minério (REM) = Relação máxima de $m^{3}$ de estéril por tonelada de minério, que por certo, é uma função da geometria da jazida e de parâmetros geométricos que determinam a segurança da operação.

TAXA DE PRODUÇÃO: é um dos parâmetros que mais influi mais claramente no estudo da viabilidade. A definição de taxa ou escala a ser lavrada depende da quantidade 


\section{FORMULA DE TEYLOR}

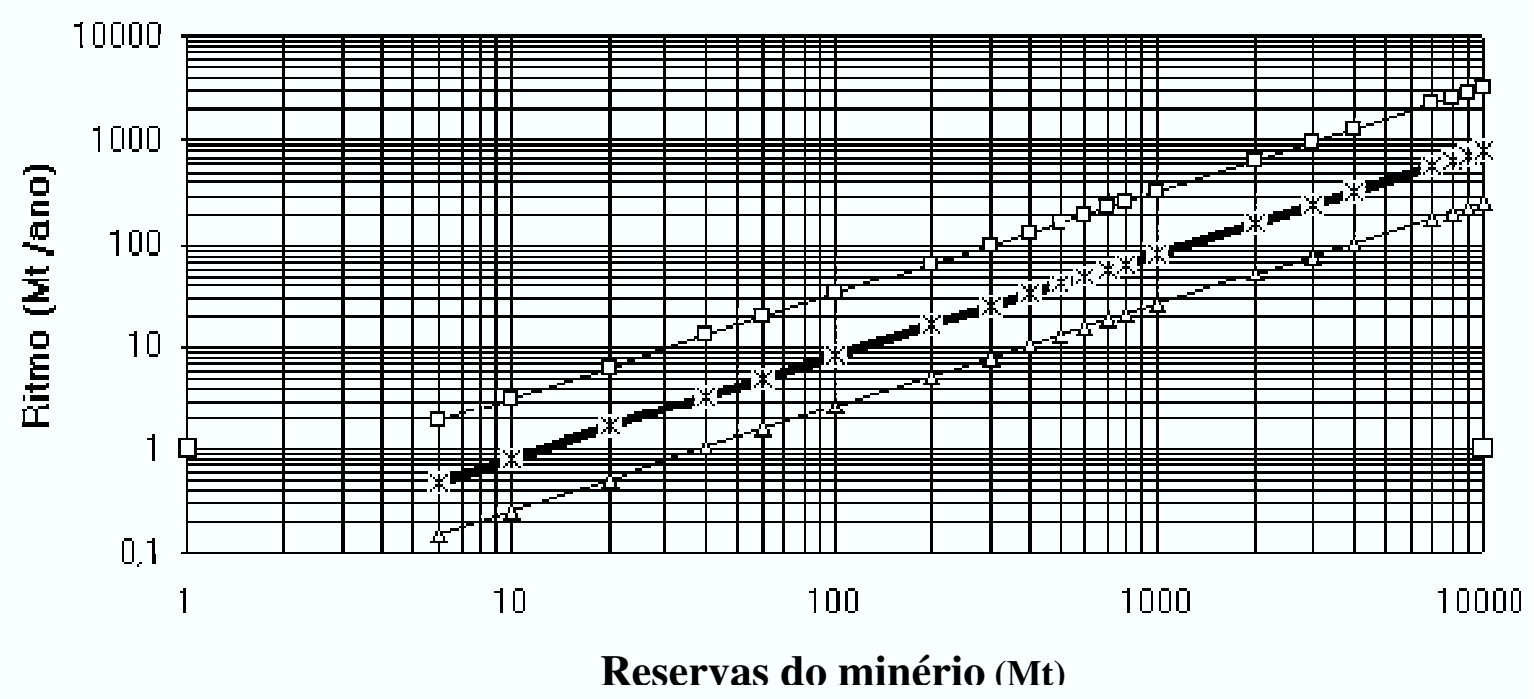

Figura 2.4: taxas de produção

Fonte: Plá et al. (2001)

de minério extraído ou produzido por ano. Esta taxa é influenciado pelo mercado, que indica a produção anual a ser vendida. Evidentemente, certos fatores técnicos condicionam, não somente a taxa mínima pela capacidade dos equipamentos, como também o incremento da produção que não pode ser gradual, especialmente no processo de concentração do minério, onde as unidades de britagem, moagem e beneficiamento têm capacidades limitadas que condicionam o nível ideal de produção.

O conceito de vida útil é o resultado da divisão das reservas comprobadas pela taxa de produção.

\subsubsection{Planejamento estratégico e de longo prazo}

É importante definir o critério inicial de avaliação de projetos de lavra. A questão estratégica que pode inviabilizar muitas vezes um projeto refere-se à correta valorização da jazida mineral, processo que passou a ser um critério exigido por parte de bancos de investidores, na apreciação do investimento a ser realizado. Em países como Austrália e Estados Unidos, a utilização de códigos de avaliação de jazidas, passou a ser exigida concomitantemente com a validação de profissionais especialmente em avaliação de reservas.

O planejamento estratégico corresponde à alta direção da empresa e age fundamentalmente sobre os produtos da empresa. Segundo Calder (2001), o objetivo do planejamento 


\begin{tabular}{|c|c|c|}
\hline CARACTERÍSTICA & ESTRATÉGIA & LONGO PRAZO \\
\hline Do problema ou objetivo & $\begin{array}{l}\text { Problemas novos, estru- } \\
\text { turais }\end{array}$ & $\begin{array}{l}\text { Problemas com alguma } \\
\text { estrutura }\end{array}$ \\
\hline $\begin{array}{l}\text { Importância da ex- } \\
\text { periência prévia }\end{array}$ & Pouca & Pouca a muito \\
\hline $\begin{array}{l}\text { Natureza da informação } \\
\text { base }\end{array}$ & Quantitativa & $\begin{array}{l}\text { Mais quantitativa e da- } \\
\text { dos conhecidos }\end{array}$ \\
\hline Perspectivas no tempo & Do futuro até hoje & De hoje para o futuro \\
\hline Horizonte & 15 a 20 anos & 3 a 5 anos \\
\hline Foco & $\begin{array}{l}\text { Alta direção (Poucas pes- } \\
\text { soas) }\end{array}$ & $\begin{array}{l}\text { Direção operativa (mui- } \\
\text { tas pessoas) }\end{array}$ \\
\hline Executores & $\begin{array}{l}\text { Alta direção (Poucas pes- } \\
\text { soas) }\end{array}$ & $\begin{array}{l}\text { Direção operativa (mui- } \\
\text { tas pessoas) }\end{array}$ \\
\hline Sistema & $\begin{array}{l}\text { Falta sistemática, mas } \\
\text { domina o conteúdo }\end{array}$ & $\begin{array}{l}\text { Forma com domínio de } \\
\text { procedimento }\end{array}$ \\
\hline Técnicas e ferramentas & $\begin{array}{l}\text { Poucos números, embora } \\
\text { utilizados }\end{array}$ & $\begin{array}{l}\text { Muitos números e muito } \\
\text { utilizado }\end{array}$ \\
\hline Utilizações principais & $\begin{array}{l}\text { Identifica as mudanças e } \\
\text { adequa e expande a em- } \\
\text { presa em função deles }\end{array}$ & $\begin{array}{l}\text { Coloca e coordena os re- } \\
\text { cursos integrais. Integra } \\
\text { as comunicações e cria } \\
\text { equipes }\end{array}$ \\
\hline
\end{tabular}

Tabela 2.1: Diferença entre planejamento de longo prazo e estratégica fonte: Plá et al. (2001).

estratégico na mineração é definir os planos de extração no curto e longo prazo, os quais permitem atingir os objetivos da empresa. Isto considera não só os grandes objetivos, como também os planos, a captação de recursos e os meios para conseguí-los. Uma decisão estratégica de curto prazo poderia ser, por exemplo, parar uma mina por falta de lucratividade em um determinado mercado e, em um determinado momento, voltar a lavrá-la quando as condições do mercado tivessem mudado.

O Planejamento de longo prazo é normalmente operacional, pois projeta as operações de lavra em um determinado período de tempo, desenvolvendo uma seqüência de extração do minério e estéril dentro da cava final. Existem três passos principais para a criação de um plano de lavra em uma mina a céu aberto:

1. Desenho do limite da cava;

2. Desenhos das fases de lavra dentro do limite final;

3. Seleção de equipamentos e determinação de taxas e seqüências de extração por bancada e por fase. 
Em suma, o planejamento estratégico está baseado na mudança das condições externas sobre as quais se desenvolve a empresa durante toda a vida da mina. Essas podem ser: o tempo, as condições econômicas, os custos operacionais, os custos de capital, taxas de interesse e os aspectos reguladores, enquanto, segundo Plá et al. (2001), o planejamento de longo prazo considera as atuais operações para o futuro, como um resultado da dimensão no tempo, possibilitando uma seqüência de lavra dentro do limite final da cava. As diferenças entre planejamento estratégico e de longo prazo são apresentada na Tabela 2.1:

\subsubsection{Considerações gerais de cava final e o fluxo de caixa}

Antes de definir considerações de desenho, é importante mencionar o conceito de análise de sensibilidade, definida como procedimentos que serve para conhecer a influência de uma mudança no valor de algum dos parâmetros ou variáveis (investimentos, custos de operação, vida, entre outros) sobre os diferentes índices que medem a rentabilidade do projeto Valor atual líquido (VAL), Taxa de retorno do investimento (TRI). Assim, esta análise identifica aquelas variáveis que têm uma influência maior nos resultados frente a distintos graus de erro da estimativa (BUSTILO; JIMENO, 1997), ajudando a decisão de realizar estudos mais profundos das variável crítica, com a visão de melhorar as estimativas, deduzir o grau de risco e buscar estratégias de atuação para poder melhorar a informação geológica.

A etapa seguinte, a de desenho da cava final, é um procedimento iterativo. Inicialmente é realizada uma otimização dos limites econômicos, baseada na maximização dos benefícios, executada sobre um modelo mineralizado constituído por blocos tridimensionais regular. Os algoritmos mais utilizados são: Método do cone flutuante (Método Heurístico) e método de Lech Grossmam (Método rigoroso).

Um sequenciamento pode ser desenhado, tendo em conta uma série de alternativas de transporte e taxas de produção. O requesito de equipamentos para cada uma das opções, pode ser estimado para realizar uma análise de fluxos de caixa para o processo global. As localizações dos limites econômicos da cava são intimamente dependentes dos aspectos relacionados com o fluxo de caixa, sendo necessário avaliar outros limites econômicos, de modo a determinar a sensibilidade do fluxo de caixa com os limites exatos da cava da Figura2.5.

A flexibilidade é o elemento estratégico chave no desenvolvimento de um plano de lavra. Este se pode conseguir desenvolvendo a mina de acordo a uma série de cavas expansivas no tempo. No caso das condições econômicas mudarem, é possível modificar o 


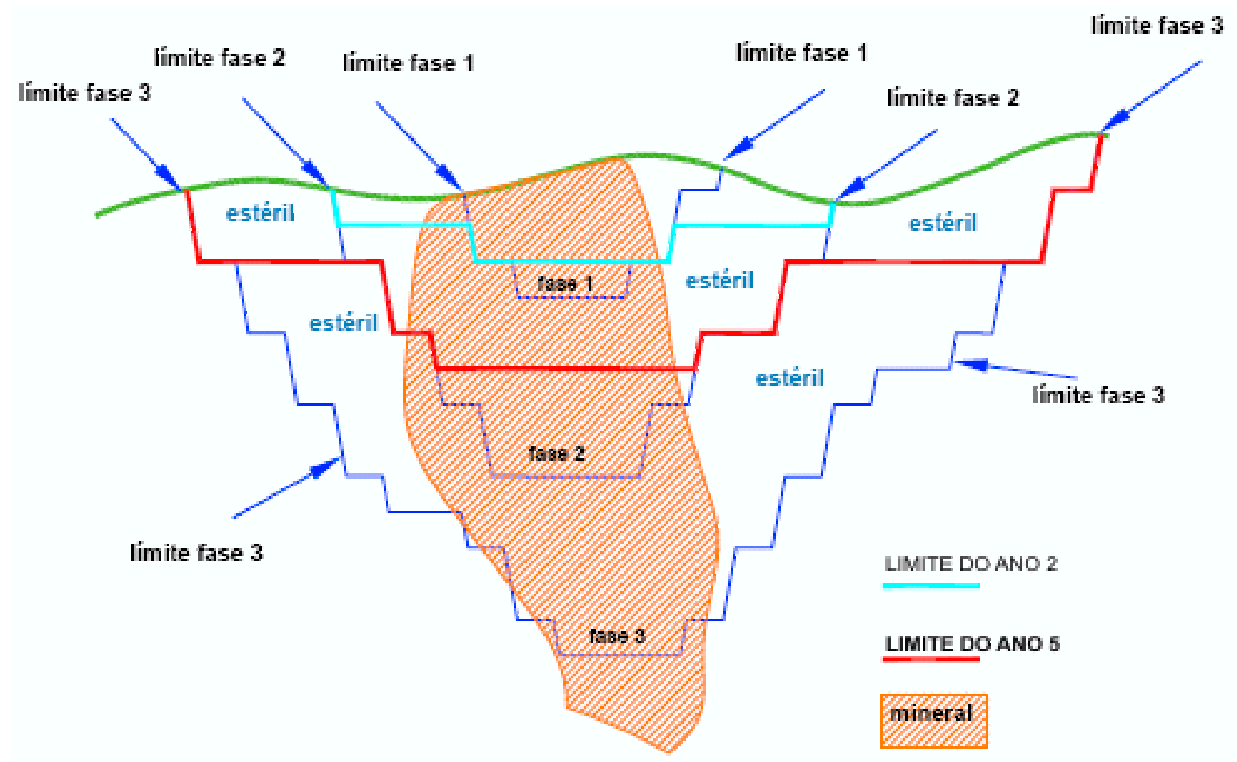

Figura 2.5: Seção transversal de uma cava, mostrando três fases e suas ubicações depois do segundo e quinto anos.

Fonte: Calder (2001)

desenho das futuras fases. Não existe restrição alguma a respeito do limite final da cava. Cada fase deve ser suficientemente extensa para permitir que as operações de lavra sejam eficientes (CALDER, 2001).

\subsubsection{Seqüenciamento de lavra no planejamento de longo prazo.}

O sequênciamento de lavra envolve o desenvolvimento de uma seqüência de extração do minério e estéril dentro do limite final da cava. O objetivo é definir uma seqüência que consiga atingir da melhor forma possível os objetivos de produção da empresa.

Segundo Faria (2004), os Objetivos do planejamento de lavra e abrangência na mina de Cajati, por exemplo, são os seguintes:

1. Oferecer aos clientes internos uma visão antecipada de toda a evolução do processo produtivo da mina (lavra);

2. Integrar a exploração geológica (pesquisa) até a lavra, oferecendo uma grande carga de informações referentes a custos e qualidade do minério a ser lavrado ao longo da vida da jazida.;

3. Oferecer à operação de lavra caminhos alternativos para a execução de sua tarefa, dando suporte e informações pertinentes; 
4. É vital uma postura pró-ativa de modo a auxiliar a operação de lavra. Participar ativamente de todos os projetos envolvidos na operação da mina, como por exemplo, novos investimentos, opções de transporte e layout da cava.

Na seqüência de extração da lavra, é elaborados o plano de exaustão, ou seja, os passos que se devem seguir ordenadamente para se chegar ao final da mina. Como diz o conhecido axioma mineiro, deve-se seguir sempre o seguinte caminho: "do teto ao muro, de cima para baixo e da maior qualidade à menor qualidade ".

Neste contexto, o planejamento de lavra é executado a partir de uma cava final otimizada em que todos os blocos possuem benefícios. Isto significa que os blocos lavrados dão lucro. Isto é feito, normalmente, dentro de espaços confinados ou avanços operacionais, denominados pushbacks. Cada um destes pushbacks atende uma determinada taxa de produção para a mina. No interior destes pushbacks são elaborados os planos anuais e trimestrais de lavra. A Figura 2.6 mostra o número de pushbacks a que cada bloco pertence.

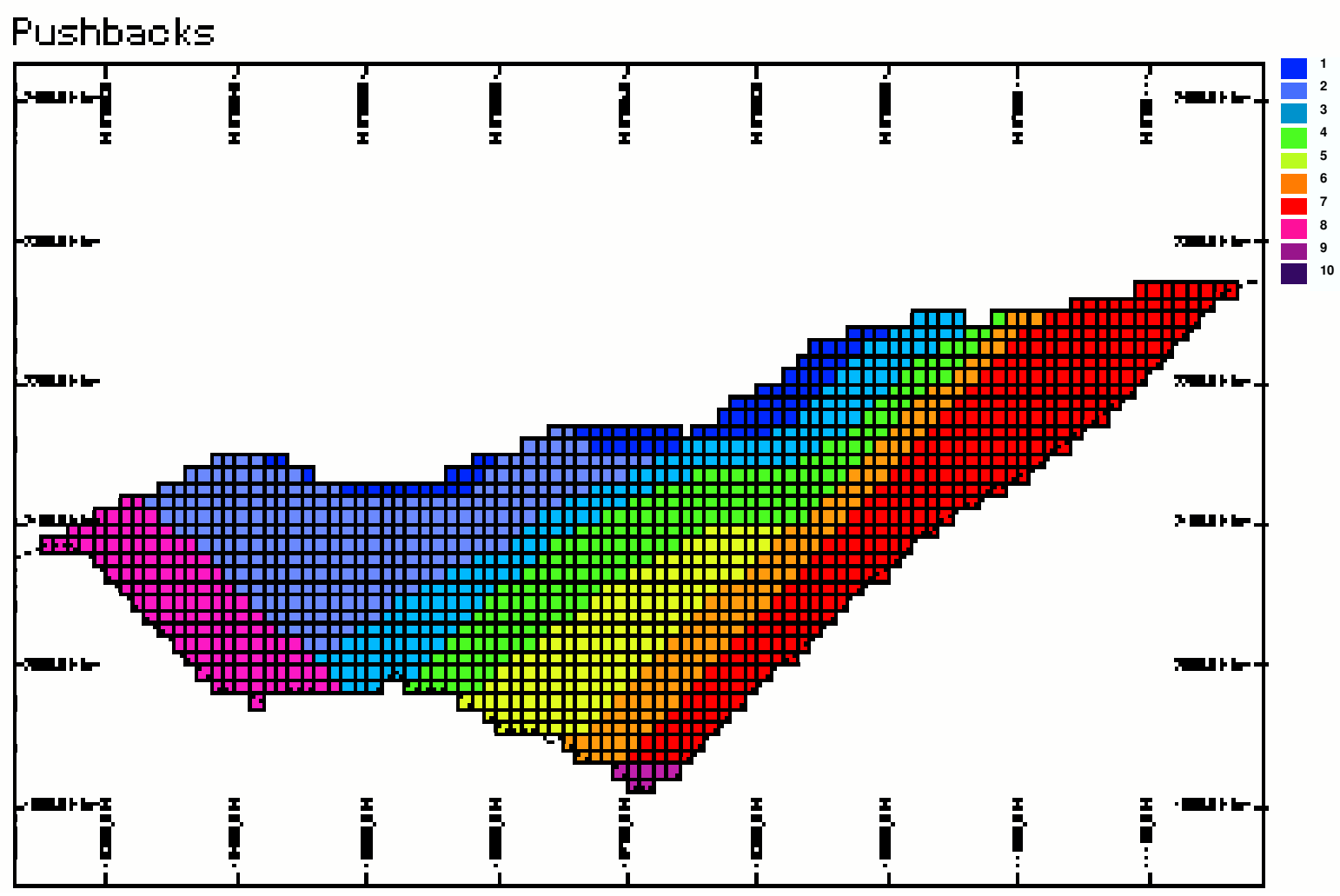

Figura 2.6: Avanços operacionais ("Pushback") por blocos.

Fonte: Datamine (2001) 


\subsection{Planejamento de curto prazo}

Após a conclusão do planejamento de longo prazo e garantido o controle de qualidade do material ao longo da vida da mina, segundo De-Faria (2003) a etapa seguinte é planejar com horizontes mensais e semanais.

Os procedimentos propostos nas rotinas de planejamento de curto prazo são os seguintes:

1. Identificação e separação dos blocos referentes ao período que se deseja trabalhar no curto prazo, o primeiro ano do planejamento de longo prazo.

2. Preparação e exportação do modelo de blocos para o programa de curto prazo, tendo-se em consideração a aderência do modelo;

3. Definição da produção desejada e as variáveis de controle. Por exemplo, uma produção mensal de 500.000 toneladas com um teor médio de 5,0 por cento de $\mathrm{P}_{2} \mathrm{O}_{5}$.

4. Definição de parâmetros operacionais, tais como número de frentes de lavra, disponibilidade de equipamentos, rendimento e produtividade destes;

5. Execução do planejamento de curto prazo.

Com o intuito de visualizar-se o processo de planejamento de curto prazo, apresentase a Figura 2.7, onde é representado como é executado o planejamento de lavra da Mina de Cajati, em que são utilizados softwares especializados com recursos computacionais (FARIA, 2004) $)^{1}$.

Para uma melhor visualização da abrangência do modelo de curto prazo, apresentase o diagrama de atividades da Figura 2.8 para a execução do planejamento de curto prazo, mostrando a contribuição das informações geológicas (análise do pó da perfuratriz e mapeamentos geológicos). Desta forma, gera-se um a atualização do programa de extração (programa de extração mensal ou semanal) e, assim, obtém-se um programa de alimentação da usina com um menor grau de incerteza.

De forma mais específica, o planejamento de lavra de curto prazo requer a consideração de muitas variáveis e suas complexas inter-relações, como por exemplo: as espessuras e variabilidade das camadas, características físicas e químicas dos materiais, condições da

\footnotetext{
${ }^{1}$ Esta bibliografia é acervo particular do membro do equipe de planejamento de lavra da mina de Cajati, Agenor de Faria Junior
} 


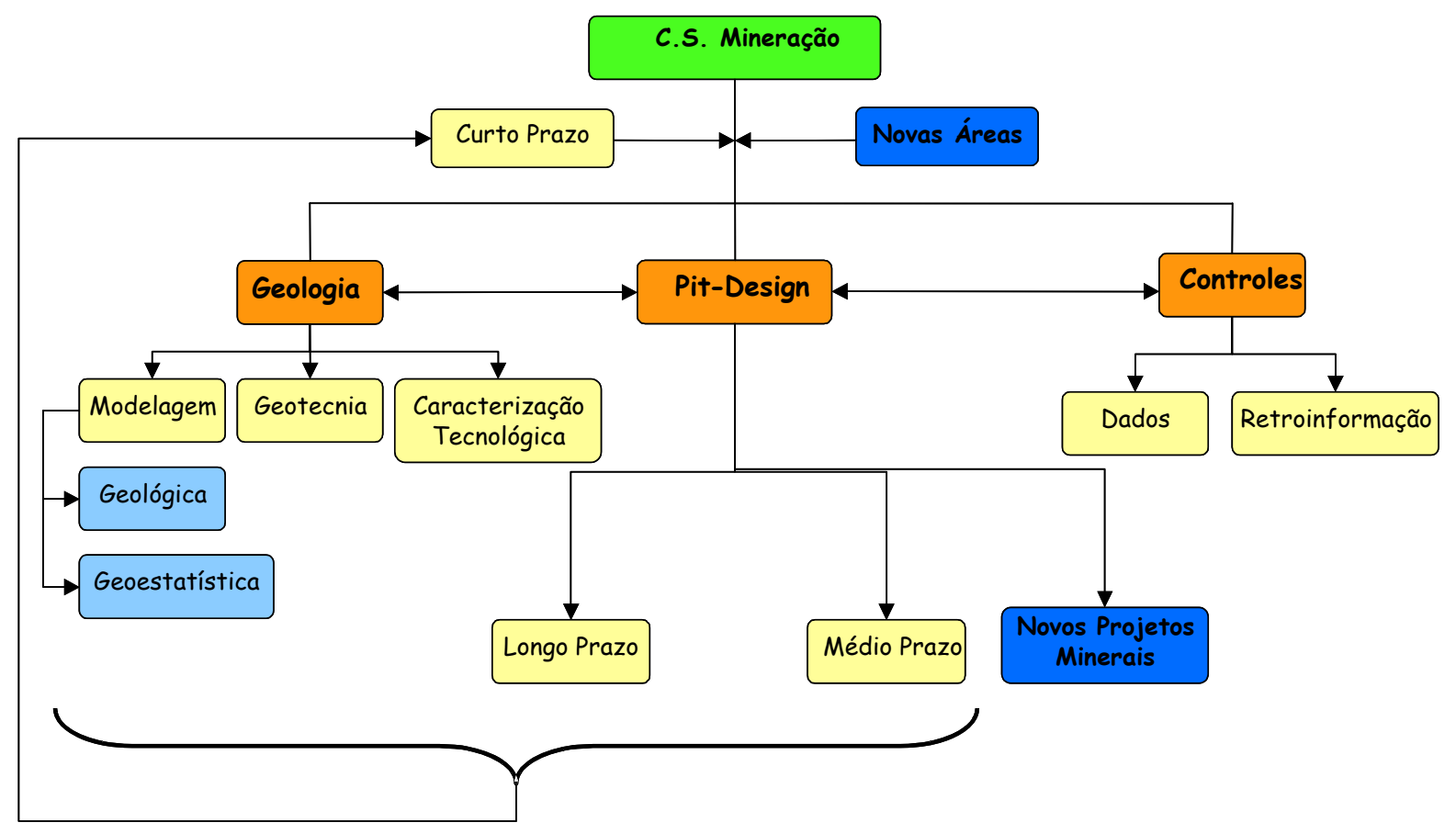

Figura 2.7: Diagrama das atividades no planejamento da Mina de Cajati. Fonte: Faria (2004)

superfície (vegetação, drenagens, construções, estradas), estruturas geológicas, seletividade da lavra, taxa de produção, localização de aqüíferos, geometria e continuidade do depósito, relações de estéril/minério, clima e restrições políticas da área do depósito, seleção de equipamentos e políticas ambientais cada vez mais rigorosas (SEWALD, 2000).

A cava final representa a envolvente maior que maximiza o benefício operacional da porção da jazida a ser lavrada. Como esta envolvente é uma função de todas as variáveis técnicas do projeto de lavra, o benefício é calculado, e as reservas variam constantemente com o melhor conhecimento da jazida. Esta situação tem resultado nas discussões da utilização para o planejamento de curto prazo, onde os resultados do longo prazo priorizam a maximização do lucro ou metal (CHAUSSON, 2005). Tais discussões levaram a esforços de realizar programações operacionais, de modo a determinar novas seqüências detalhadas, usando uma maior informação operacional.

Pelas múltiplas variáveis que influem no planejamento de curto prazo aparece a nova concepção de aprimoramento de técnicas de operacionalização de áreas, que estão relacionadas à fase de translação dos planos de longo prazo.a curto prazo (mensal ou semanal). 
PLANEJAMENTO DE CURTO PRAZO

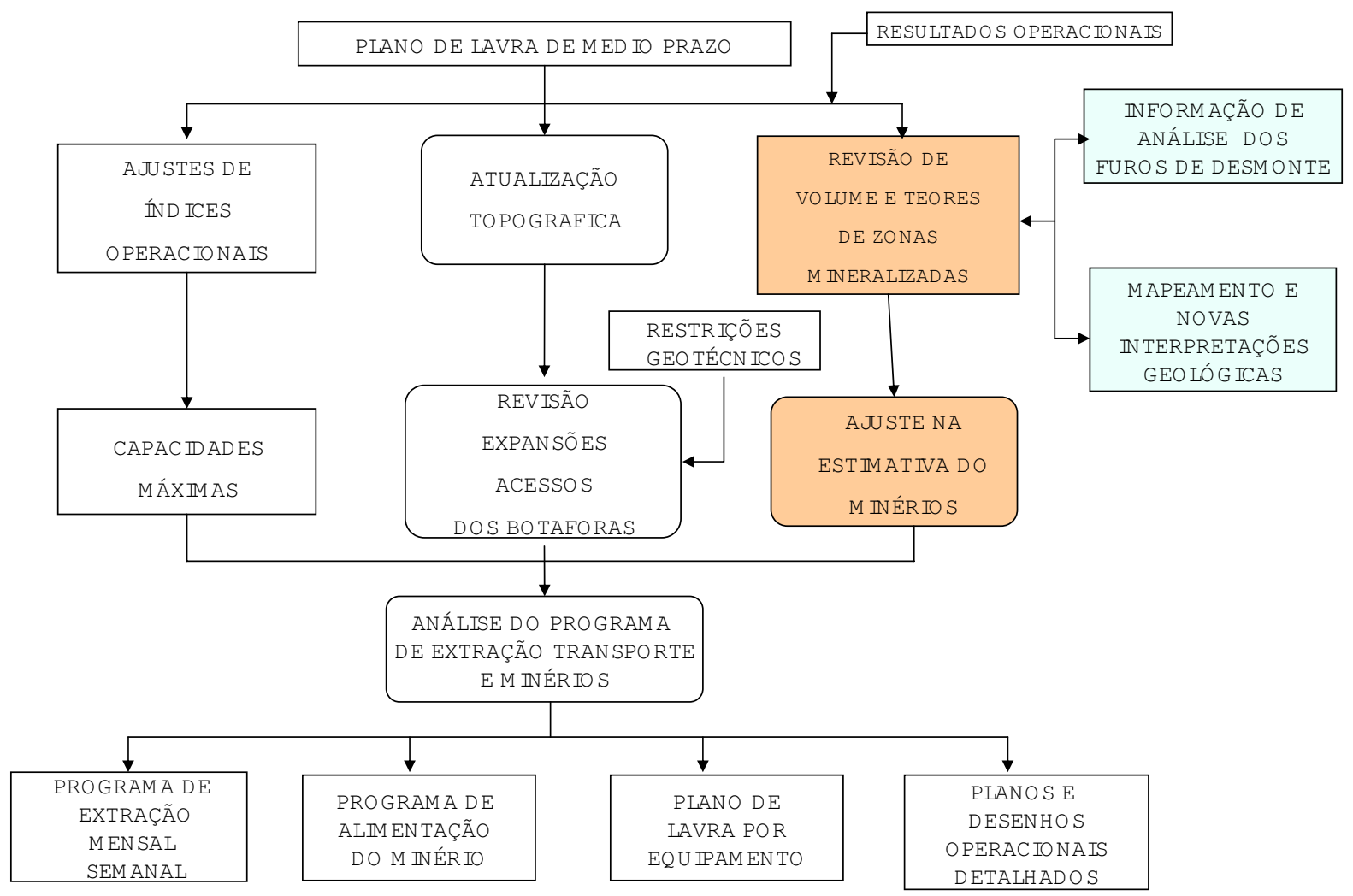

Figura 2.8: Diagrama do planejamento de curto prazo do grupo Codelco - Chile. Fonte: Codelco (2003)

\subsection{Planejamento de lavra operacional}

A função principal da programação operacional é gerar planos semanais, respeitando-se o critério de maior beneficio econômico dado no longo prazo e os objetivos de produção (operacionais). Neste contexto, essas programações, incorporando a experiência do planejador e os novos modelos de blocos, levam a uma melhor escolha de blocos por bancadas. Entretanto, as múltiplas fases que poderiam ser geradas numa cava onde existem múltiplos avances operacionais "pushback" podem ser programadas tão facilmente quanto uma unidade pequena.

\subsubsection{Objetivos dos planos operacionais}

Segundo Bustilo e Jimeno (1997), os objetivos dos planos operacionais são ajustar os conjuntos de taxas de produção, cotas de produção por equipamento, qualidade do 
minério, misturas de pilhas, transporte, entre outros. Estes objetivos são definidos pelo corpo técnico de acordo as necessidades da usina, os quais permitirão minimizar a diferença entre o planejado e o executado.

Uma seqüência operacional (OS) é um agrupamento de blocos contínuos de uma unidade de lavra (bancada - fase), que por objetivos operacionais devem ser lavrados de forma conjunta (MANUAL-OS, 2006) conforme mostrado na Figura 2.9.

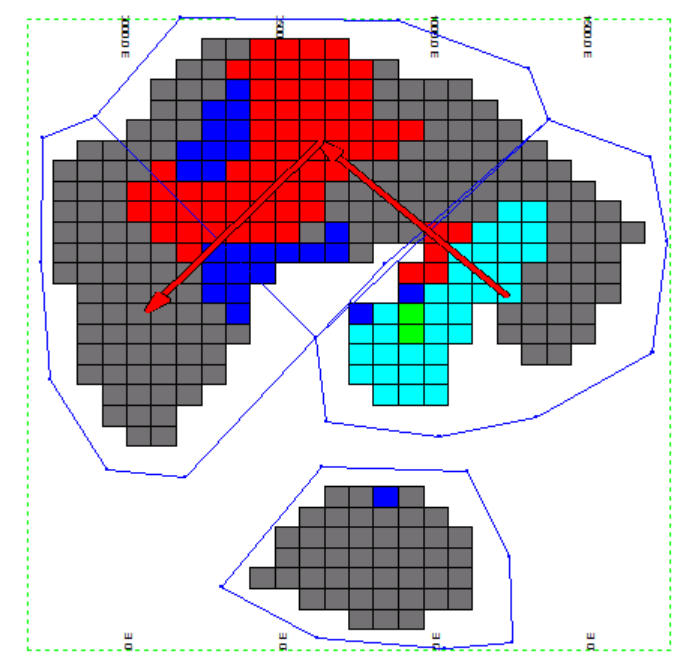

Figura 2.9: Perímetros operacionais dos blocos Fonte: Manual-OS (2006)

Um modelo de bloco pode pertencer somente a uma unidade de um tipo dado (estágio operacional ou bloco operacional). Se um bloco é encontrado no interior de dois ou mais perímetros operacionais do estágio, este estará incluído somente na unidade delimitada primeiramente (Figura 2.10).

No caso do perímetro do bloco inclui blocos de mais de um estágio operacional, o conjunto de blocos é ajustado como o estágio que tem a maior participação dentro do perímetro do bloco. Os blocos fora do estágio não são incluídos dentro do conjunto conforme à Figura 2.11.

O estágio operacional é a unidade lavrada para a programação operacional da mina. Somente o material incluído nessas unidades é programado, e todos os outros serão ignorados. 


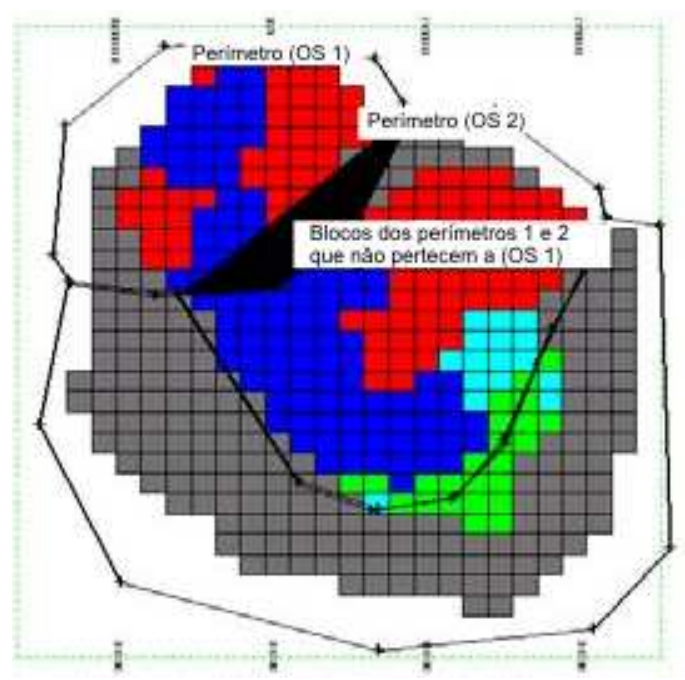

Figura 2.10: Perímetros sobrepondo. Fonte: Manual-OS (2006)

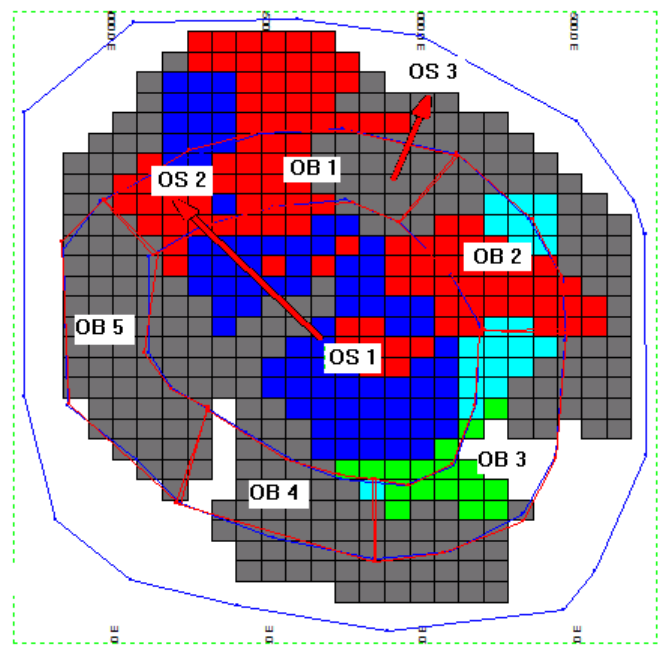

Figura 2.11: Blocos operacionais seqüenciados em um período de curto prazo. Fonte: Manual-OS (2006)

\subsection{Controle de teores na lavra}

Na etapa de preparação ou desenvolvimento da operação da lavra, aparece um dos problemas mais importantes da moderna mineração, e não só da mineração a céu aberto, mas de qualquer método de lavra, que é o controle da qualidade do minério a ser lavrado, garantindo que ele se mantenha homogêneo, já que as usinas de beneficiamento, cada vez mais, requerem uma constância na qualidade do minério que é processado.

Denomina-se controle de teores a quantidade de elementos vendáveis ou penalizáveis contidos num volume ou toneladas a lavrar na mina. Na realidade o controle de teor tem como intuito dar ênfase em confirmar os teores, ou seja, ter melhor controle da 
variabilidade. Atualmente, conseguir a quantidade de minério necessário com uma menor incerteza do seu conteúdo é um objetivo primordial, porque manter os volumes e ritmo da operação é relativamente fácil através dos equipamentos de grande capacidade e da disposição de uma frota suficiente que, desta forma, provê as toneladas horárias necessários para alimentar a usina, O garantir teor desse mineral seja o maior desafio do planejamento da moderna mineração, ou seja, garantir os teores do concentrado (CALDER, 2001)

\subsubsection{Controle da qualidade do teor}

Um controle importante é conseguir um rigoroso da qualidade de teor do produto que vem da mina antes de ser processado pela usina ou vendido, este teor deve incluir os necessários e corretos procedimentos de amostragem e de análises em laboratório. Assim, pelo fato da mineração de grande escala lidar com teores baixos e grandes tonelagens movimentadas, requer-se uma maior quantidade de amostras e, em muitos casos, até complexos sistemas de controle. O verdadeiro controle de qualidade dos teores na jazida nasce a partir da exploração efetuada pelos geólogos que, no processo de avaliação das reservas, devem marcar as pautas essenciais da distribuição espacial dos distintos elementos contidos nas rochas ou mineral a lavrar e devem indicar os dados essenciais a serem controlados pelo pessoal na lavra (PLÁ et al., 2001), que determine as variações estruturais e litológicas, as variações metalúrgicas e tipos de minério.

\subsubsection{Controle de teores nas frentes de lavra}

O controle de teores nasce da questão apresentada na Figura 2.12, onde, na maioria dos casos na mineração a céu aberto, o controle da qualidade do minério está baseado na amostragem nos próprios furos de produção ou de desmonte que, têm suficiente volume para conseguir a quantidade representativa nos bancos da mina por parte do pessoal de controle de teores. Após a coleta, envia-se amostras ao laboratório de análises químicas para que, depois de serem analisadas, sejam retornadas para a área de planejamento e de controle da mina e aí serem introduzidas no inventário informatizado com suas respectivas coordenadas e suas profundidade. Isto representa um incremento substancial de informação à malha de sondagem, o qual permite aplicar a ferramenta geoestatística para determinar e conhecer o teor médio da região que será lavrada com suficiente antecipação no planejamento de curto prazo.

É precisamente a variável tempo que costuma falhar neste processo, por isto é recomendável um suficiente adiantamento temporal na atualização da informação de longo 


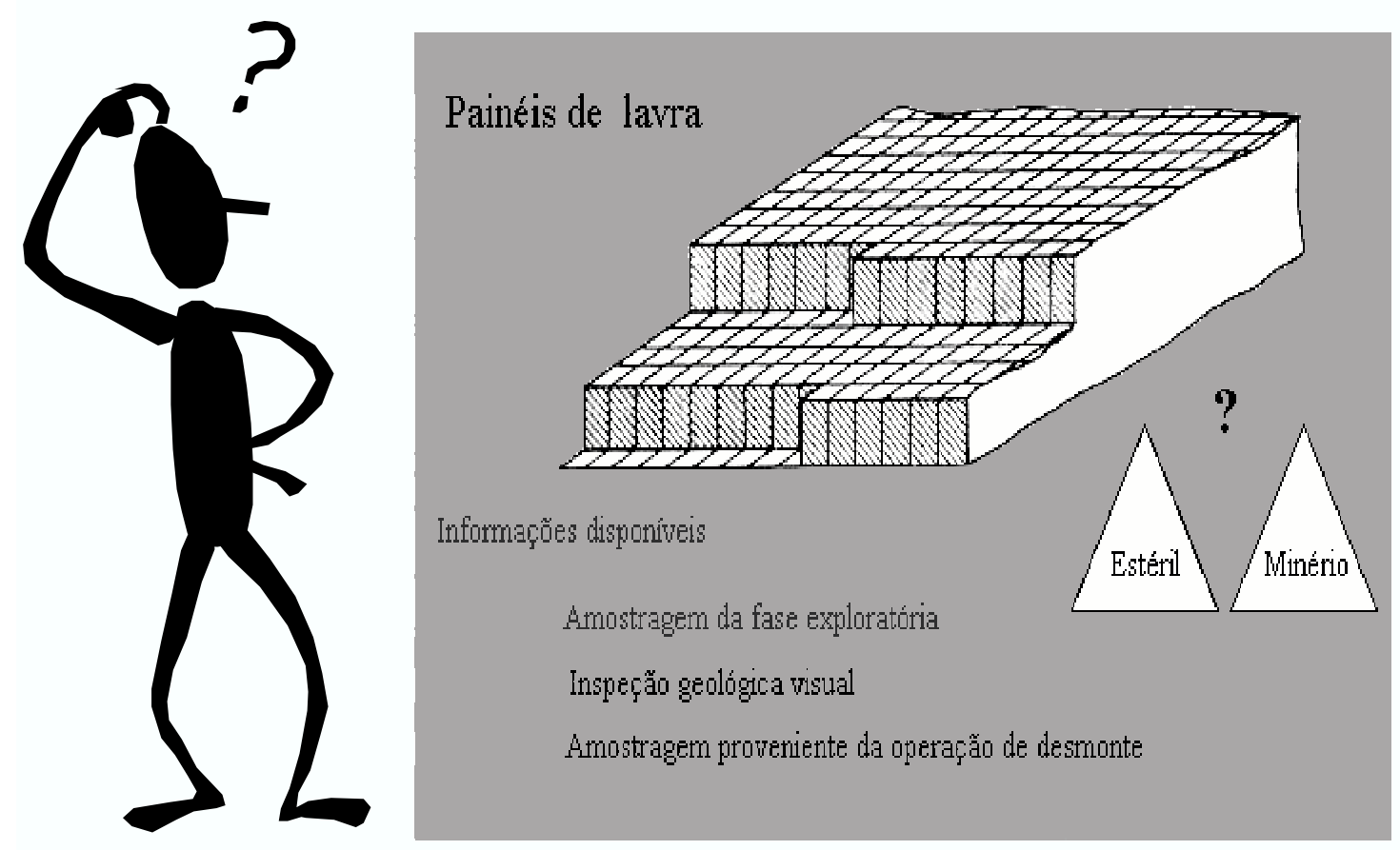

Figura 2.12: A questão do controle de teores.

Fonte: Costa (2003)

prazo. Por exemplo, seria ideal ter a informação da análise das amostras dos furos de desmonte com um adiantamento de um mês, ou seja, as perfurações para o desmonte teriam que se realizar com um mês de antecedência do fogo. Infelizmente esse procedimento é impraticável pelo dinamismo com o que são desenvolvidos as operações de lavra. Portanto, a rapidez na análise e processo da informação influirá no tempo de análise dos cenários das frentes de trabalho, realizando, muitas vezes, simulações com informações mais acuradas.

As condições estruturais da forma de fraturas do maciço, pode dar lugar a misturas entre minério e estéril, o que é conhecido como fator de diluição e pode influir na representatividade das amostras. O controle de teores tem como objetivo, além de melhorar o conhecimento das frentes de trabalho, aplicar técnicas e procedimentos para separar o estéril do minério, o qual é denominado como seletividade, fato que se deve incrementar ao máximo e, assim, reduzir a diluição do minério. Se a diluição é maior que o desejável, é necessário incrementar detalhes as amostras, por exemplo amostrar os furos de desmonte com intervalos de cada 5 metros de comprimento em uma bancada de 10 metros. No caso de que a jazida seja aleatória e complicada, pode-se chegar a ter uma malha de furos de sondagem inferior aos furos para desmonte, para o qual seria necessário uma malha especial diferente da utilizada para desmonte. 


\section{Amostragem}

Entre todos os estágios envolvidos no processo de avaliação de uma jazida, a amostragem tem uma importância significativa pelo fato de ser a primeira atividade que vai condicionar a viabilidade econômica da lavra. Esta tarefa apresenta uma série de características que a tornam um estágio com caráter crítico. Como é mencionado em (VAlle, 1990 apud BUSTILO; JIMENo, 1997) "Se as amostras não forem representativas da jazida, o restante da avaliação carecerá de interesse". Assim, o objetivo da amostragem é determinar a extensão da mineralização, os seus teores e sua distribuição espacial. Assim a importância da amostragem esta associado à base dos dados que juntamente com o modelo geológico são utilizados para fazer a avaliação por um método apropriado (YAMAMOTO, 2001). Uma amostragem inadequada pode provocar prejuízos para o futuro ou uma distorção de resultados com sérias conseqüências técnicas, mesmo que o método analítico utilizado seja o bastante preciso. Por outro lado, para um melhor entendimento da amostragem é necessário revisar, os conceitos de população e amostragens.

\subsection{Populações e domínios das amostragens}

No contexto geológico, população representa a massa total do material disponível na área em estudo. Essa população pode ser finita ou infinita, mas para propósitos práticos e computacionais, uma população, mesmo que seja finita, pode ser considerada infinita em virtude de sua amplitude. Por outro lado, as amostras constituem uma porção limitada desse universo populacional, e são usadas para estimar os parâmetros estatísticos da população. Na mineração, o número de amostras disponíveis sempre é limitado devido ao tempo e às restrições de recursos financeiros destinados às campanhas de sondagem.

O domínio de amostragem pode ser entendido como estruturas geológicas (físicas) que determinam tipos distintos de populações, e é uma extensão do conceito de população ou universo. Na mineração, os domínios mais freqüentes aparecem nas mais variadas condições geológicas, como, por exemplo: tipos diferentes de rocha, diferentes zonas de 
mineralização, diferentes episódios de mineralização, diferentes condições de oxidação ou redução, entre outras (PILGER, 2000)

A representatividade de uma amostra de uma determinada população é definida pela homogeneidade da matéria prima. Essa homogeneidade pode ser mostrada, basicamente, de duas formas:

- Na textura da mineralização, pois um minério de material grosso, com igual teor, é mais homogêneo que um fino .

- Na composição mineralógica, quando a homogeneidade é menor com igual teor ou naqueles minérios que possuem uma porcentagem mais elevada na fase de interesse econômico.

Um dos métodos mais utilizados para a amostragem representativa do minério é o de sondagens, as quais podem ser executadas por métodos percussivos, roto-percussivos e rotativos. Obviamente, a escolha do método de amostragem dependerá do tipo de depósito mineral, da profundidade do corpo do minério e, sobretudo, do tipo de amostra que o método em estudo necessita.

Na primeira etapa do programa de sondagem em um projeto não há, normalmente, informação suficiente para delimitar a continuidade da mineralização potencial. Uma vez que o projeto tem a possibilidade de ser viável, a malha de perfuração é adensada, obtendose um número maior de amostras que representam melhor a população. Se adicionadas com os dados obtidos na fase de exploração, essas amostras irão gerar um maior grau de representatividade na estimativa.

\subsubsection{Amostragem georeferenciadas e estratégia de amostragem}

Estratégia de amostragem é um conjunto padronizado de objetivos e condições que contribuem para um correto projeto de amostragem, uma adequada coleta de amostras e uma localização espacial apropiada. Plano ou protocolo de amostragem é um conjunto único de condições e operações específicas para um determinado local sob determinadas características visando um objetivo específico. Enquanto uma estratégia de amostragem pode ser generalizada para várias situações, um protocolo de amostragem se refere às necessidades específicas de uma situação particular, que pode ser condicionada pela própria característica da jazida. 
Segundo Meyers (1996), o plano ou protocolo de amostragem é apenas um dos componentes de uma estratégia de amostragem, incluindo as seguintes etapas:

1. seleção de uma dimensão de observação;

2. caracterização das heterogeneidades;

3. desenvolvimento de um plano de amostragem;

4. execução correta do plano de amostragem;

5. caracterização da variabilidade espacial;

6. otimização dentro de restrições dos Objetivos da Qualidade; dos Dados (OQD).

\subsubsection{Representatividade das amostras}

O principal objetivo de uma campanha de sondagem é produzir amostras representativas, que sejam acuradas e precisas. A representatividade expressa o quanto uma amostra, representa uma determinada característica de uma população. É importante lembrar as definições que distinguem esses dois conceitos: precisão e acuracidade. Precisão diz respeito ao "espalhamento" em torno do valor médio do atributo, e acuracidade é definida como sendo uma situação na qual a média dos erros desse atributo se aproxima de zero.

A Figura 3.1 é um exemplo que apresenta o resultado da delimitação incorreta da forma e do volume da amostra. Esse tipo de erro é dependente do dispositivo ou da ferramenta de amostragem que determinam o tamanho e os limites geométricos da amostra. A extração do incremento é considerada adequada se a regra do centro de gravidade é respeitada, isto é, se todas as partículas com seus centros de gravidade dentro dos limites incremento forem consideradas. O fragmento só é considerado se o seu centro de gravidade estiver dentro do dispositivo de amostragem

\subsection{Amostragem na sondagem}

A execução das sondagens na mineração tem se tornado um trabalho cada vez mais freqüente pelos benefícios próprios do método, pelo fato de que uma adequada amostragem neste método mostra-se como básico, tanto na etapa de exploração como nas campanhas de amostragens que acompanham as operações de lavra. A Figura 3.2 apresenta um exemplo de como são executadas perfurações na mesma bancada em uma mina em atividade com o objetivo de melhorar o conhecimento nas zonas de alta variabilidade. 


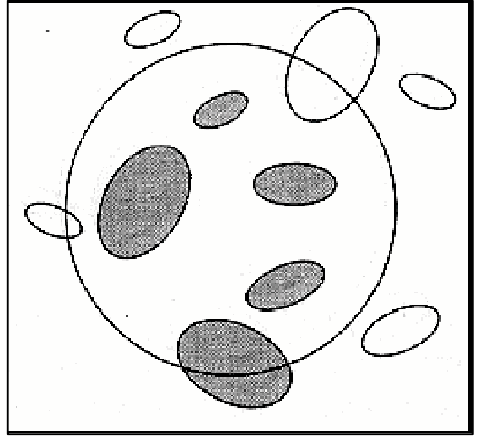

vista superior ortogonal ao do eixo onde são considerados todos os fragmentos

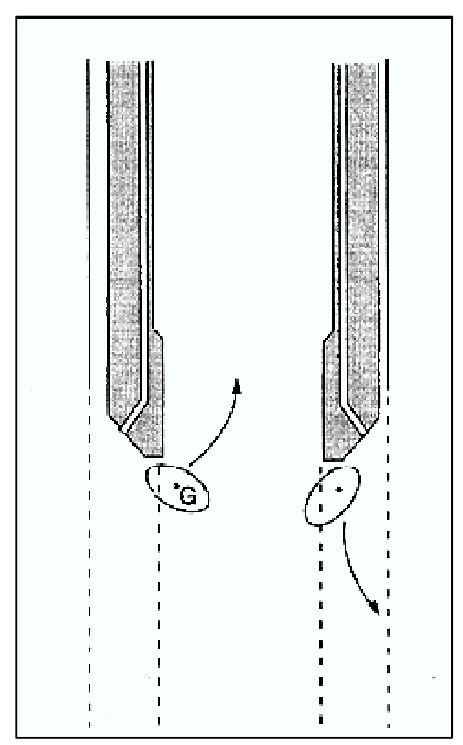

Figura 3.1: Três exemplos de extração do incremento exemplificadas em testemunhos de sondagem.

Fonte: Pilger (2000).

A amostragem por sondagem constitui na atualidade o método que fornece a maior fonte de amostras na mineração. Assim, o tratamento errôneo nessas amostras pode gerar erros que, uma vez acumulados, impossibilitarão a avaliação da jazida. Desta forma, a amostragem por sondagem é uma atividade vital para o sucesso da operação. Segundo Bustilo e Jimeno (1997), a sondagem com recuperação do testemunho apresenta, em relação a outros métodos de amostragem, uma série de vantagens. entre elas:

1. Obtenção de amostras contínuas completas do material mineralizado, em alguns casos, a presença de baixos índices de recuperação poder minimizar esta vantagem; neste sentido, recuperações inferiores a 75 por cento podem acarretar erros na etapa de avaliação do depósito;

2. Os riscos de contaminação são inferiores aos de outros métodos amostragem.

3. Na recuperação, consegue-se um volume constante pela unidade de comprimento, fator este que dificilmente é conseguido por outros métodos;

4. Baixa probabilidade de distorção de propriedades texturais e geotécnicas das rochas, pois teoricamente, o material é recuperado da mesma forma que encontrado em profundidade.

À medida que vão sendo retiradas da sonda, as amostras são colocadas em caixas apropriadas, geralmente de madeira ou plásticas. Neste momento deve-se ter especial 


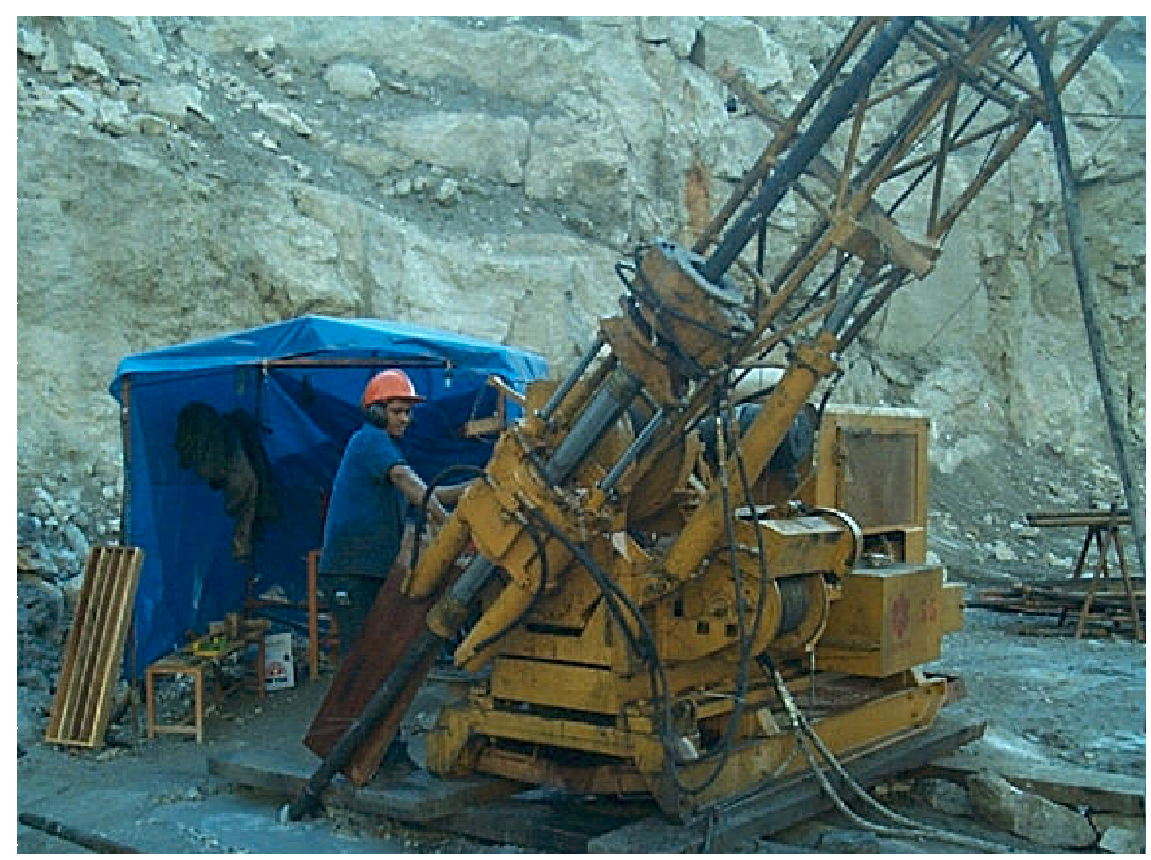

Figura 3.2: Perfuratriz para sondagens com saca testemunhos Fonte:BUNGE - Base de dados da área de planejamento da mina de Cajati.

cuidado de modo a colocá-las segundo as profundidades e orientações corretas já que erros como a inversão de sentido do trecho são muito freqüentes.

O testemunho, uma vez limpo e acondicionado, é dividido axialmente em duas partes, uma das partes é utilizada para a análises de teores e conteúdos, e a outra é guardada na caixa correspondente para análises posteriores e comprovação. Após este processo, definem-se os intervalos de amostragem, ou seja, a quantidade de amostra das partes devididas que se deve pegar para cada análise, não existindo regras para esta amostragem. Os fatores que vão condicionar o tamanho da amostra são:

1. Mudanças rápidas (repentinas) nos teores da mineralização (o teor deve ser o mais homogêneo para cada intervalo);

2. Mudanças nas camadas de interesse (por exemplo calcopirita, bornita, foscorita etc.);

3. Mudanças nas camadas dos minerais que possam condicionar o método de beneficiamento (sulfuros a ácidos e silicatos);

4. Mudanças litológicas das rochas encaixantes;

5. Mudança na textura da mineralização (massiva a disseminada); 
6. Potência da mineralização (se houvesse finos entre as camadas, devem ser amostrados em intervalos menores como se tratasse de um único e potente camada mineralizado);

7. Se os valores das amostras forem ser utilizados para uma posterior regularização composite, as amostras deverão ser realizadas com procedimentos para que o método seja ajustado (geralmente por bancadas);

8. No caso presença de valores erráticos que condicionem o valor da amostra notavelmente. Significa que, quanto maior seja o tamanho do testemunho tomado, menor será a influência desses valores erráticos;

Uma questão a considerar na escolha do tamanho da amostra é o método que posteriormente será utilizado na estimativa de reservas, em particular no caso do método geoestatístico, nos quais é imprescindível que o comprimento do testemunho seja o mais homogêneo possível nas diferentes amostras (ANNELS, 1991 apud BUSTILO; JIMENO, 1997). Assim, se as amostras são tomadas com valor estandar de $1 \mathrm{~m}$, os tamanhos que se tomam como amostras estarão compreendidos entre $0,5 \mathrm{~m}$ e $1,5 \mathrm{~m}$, como foi referido.

\subsection{Amostragem nos furos para desmonte}

Essa amostragem é constituída pelo pó proveniente da trituração do material nos furos de desmonte e é feita, por exemplo, por uma broca tricônica. Nestes casos, não se dispõe de um fluxo contínuo de material, mas sim de um conjunto de fragmentos pequenos que tornam viáveis numerosas amostras.

Este tipo de amostragem é feito não somente na etapa de exploração ou avaliação, mas também na própria fase da lavra, com o objetivo principal de controlar teores, delimitando áreas de minério e de estéril.

De acordo com os dados obtidos na etapa da estimativa inicial da avaliação (por sondagens), geralmente não se considera uma consistência suficiente na precisão local e, para ter neles toda a confiança necessária, é preciso uma informação adicional denominada secundária. Essa informação é amostrando no pó gerado a partir dos furos para o desmonte, conforme se vê na Figura 3.3.

Segundo Bustilo e Jimeno (1997), o pó de desmonte cumpre suficientemente as condições necessárias para serem utilizados, pois são suficientemente representativos do conjunto. A obtenção ocorre de acordo com a potência ou altura das bancadas e seu manuseio e 


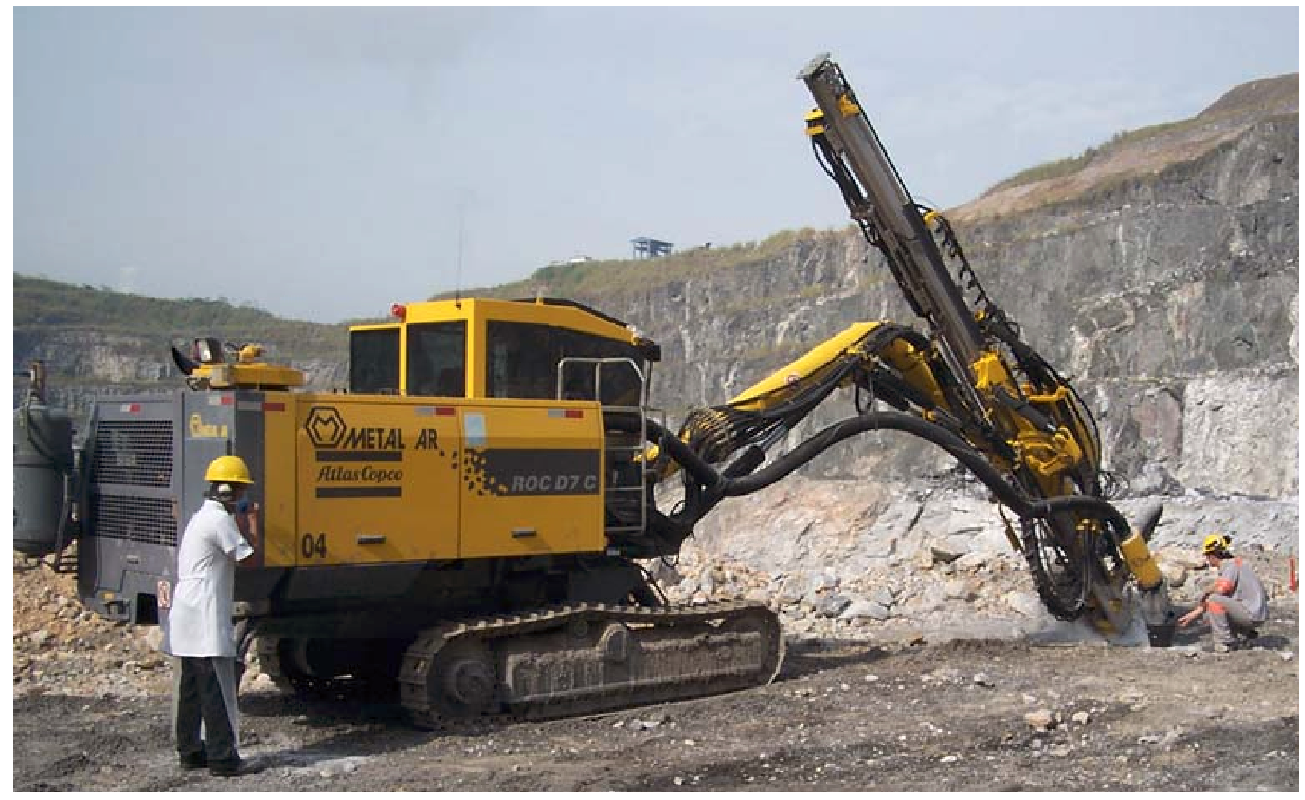

Figura 3.3: Perfuratriz para desmonte com coletor de pó compartilhado, Perfuratriz Atlas Copco ROC D7, Mina Cajati

Fonte: BUNGE - Base de dados da área de planejamento da mina de Cajati).

tratamento é simple, como é representado nas Figuras 3.4a, 3.4b, 3.4c, 3.4d, 3.4e, e a sua amostragem é sistemática.

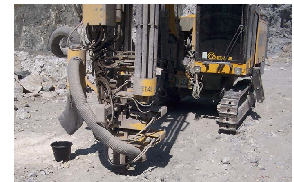

(a)

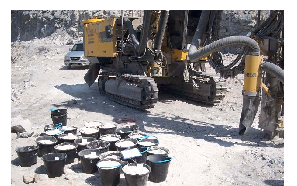

(b)

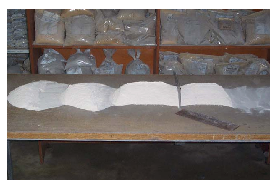

(c)

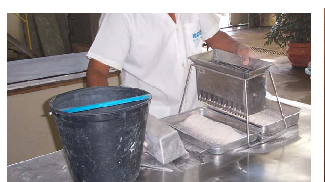

(d)

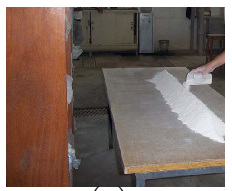

(e)

Figura 3.4: Metodologia de amostragem do pó da perfuratriz na Mina de Cajati (a)coleta pela perfuratriz,(b) amostragem, (c) condicionamento,(d) quarteamento e (e)disposição Fonte: BUNGE - Base de dados da área de planejamento da mina de Cajati).

\subsection{Suporte amostral}

Uma parte importante na avaliação de jazida é a análise do suporte amostral, ou seja, o tamanho das amostras, pois unidades amostrais de tamanhos diferentes podem gerar parâmetros estatísticos diferentes, particularmente com respeito às sua variância. Os limites de tolerância normalmente, consideram a variabilidade própria da jazida. Portanto, fica claro que o tamanho físico da unidade amostral é muito importante no entendimento dos diversos atributos geológicos. Esse conceito de tamanho físico da amostra é denominado suporte amostral como mostrado na Figura 3.5. 


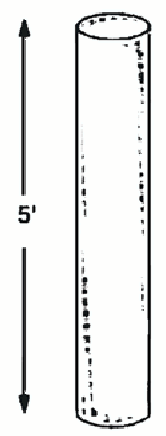

(a)

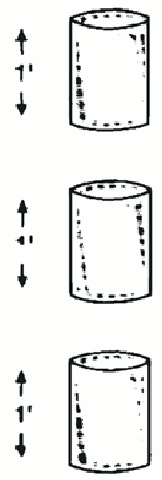

(b)

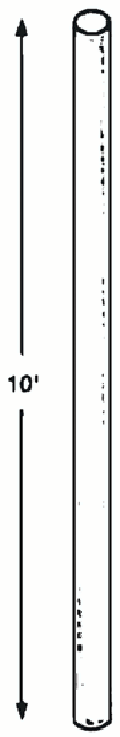

(c)

Figura 3.5: Diferentes tamanhos do suporte amostral.

Fonte: Meyers (1996)

No caso da mineração, freqüentemente os blocos são estimados a partir de amostras pontuais. Entretanto devido à diferença de volume entre as unidades amostrais e os blocos, é importante salientar que existe uma discrepância em estimar o valor de um bloco em função de amostras pontuais. Essa influência é conseqüência de que as estimativas levam incorporada a variância do suporte amostral como é mostrado na Figura 3.6. Podese observar uma menor dispersão da distribuição quando o suporte amostral é maior, refletindo-se sobre os valores extremos e na diminuição da variância e o desvio padrão da distribuição; a média, porém não é alterada.

Em uma situação ideal, uma amostra deveria ter o mesmo suporte que o bloco a ser estimado, o que na maioria das vezes é impossivel, pois as condições econômicas da amostragem restringem as campanhas de sondagem. Desta forma, devido a essas restrições operacionais, é necessário fazer uma composição matemática, corrigindo a variância da distribuição, com a finalidade de formar unidades amostrais iguais. Esse processo de composição, denominado correção de suporte amostral, afeta a estatística básica da população assim como as avaliações geoestatísticas decorrentes. Como critério de análise, o suporte e variância são a relação de aumento/diminuição da variância com o aumento/diminuição do suporte, conforme mostrado na Figura 3.6: 


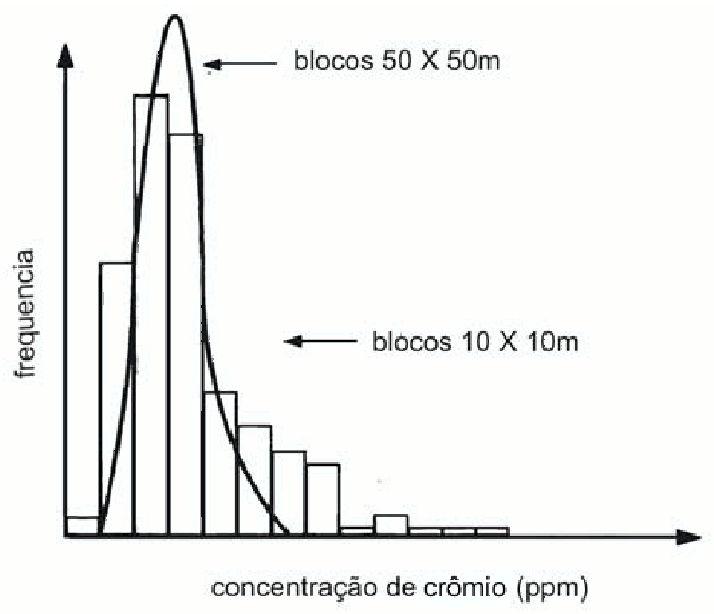

Figura 3.6: Histograma com tamanho de blocos 10 X $10 \mathrm{~m}$ (barras verticais), blocos 50 X 50 (curva suavizada)

Fonte: modificado: Meyers (1996)

\subsubsection{Métodos de correção do suporte amostral}

Para que ocorra a correção de suporte, a fim de ajustar a distribuição amostral decorrente de uma mudança do suporte, é abordado o método de correção afim; por a matemática simple e facilidade de aplicação:

Os principais são:

1. correção afim;

2. correção lognormal indireta

Ambos os métodos compartilham as seguintes características (ISSAKS; SRIVASTAVA, 1989).

- i. a média da distribuição é conservada; uma boa característica, visto que a média é melhor conhecida do que a variância;

- ii. propõem um fator de redução da variância $f$;

onde o espalhamento da distribuição é reduzido por meio desse fator, permitindo uma comparação visual entre distribuições amostrais e de blocos.

No processo de mudança de suporte, outro fenômeno pode ocorrer juntamente com a redução da variância, o qual é denominado simetrização. Como o método de correção 
reduz a variância com o aumento de assimetria da distribuição que, por certo, está relacionada com a homogeneidade da distribuição, o aumento da simetria em relação à diminuição da variância ocorre mais rapidamente em populações homogêneas. Esses dados que estão mais homogeneamente distribuídos espacialmente influem na taxa de redução da variância, ocorrendo mais lentamente em distribuições contínuas do que em distribuições erráticas. Assim, para distribuições menos contínuas, o efeito da mudança de suporte sobre o espalhamento da distribuição é maior. Portanto, Segundo Meyers (1996), o grau de continuidade espacial evidenciado pelo variograma pode ser usado como indicativo sobre o impacto do suporte amostral com respeito à redução da variância e à simetria da distribuição. Uma das maiores vantagens do método de correção afim é a sua simplicidade matemática apresentada abaixo:

$$
X^{\prime}=\sqrt{f(x-m)+m}
$$

onde: $f$ é o fator de redução da variância, $x$ e $x^{\prime}$ são os decis ou percentis originais e após a transformação, respectivamente e $m$ é a média da distribuição original. Uma das caraterísticas deste método é que ele reduz a variância da distribuição por meio da compressão da distribuição em torno da média, mantendo a forma da distribuição original.

O método de correção afim tem a propriedade de atribuir valores muito maiores para os menores valores da distribuição amostral e vice-versa (PILGER, 2000), podendo provocar classificações equivocadas em situações onde o teor de corte (TC) for muito baixo em relação à média. Essa característica pode ser muito indesejada em alguns casos, como por exemplo quando se trata de dados de concentração de contaminantes (engenharia ambiental). Como regra geral, o método de correção afim se mostra apropriado quando o fator de redução da variância for inferior a 30 . 


\section{Análise Geoestatística}

\subsection{Estimativa da incerteza no planejamento de curto prazo}

O termo geoestatística surgiu da combinação do caráter aleatório que apresentam as variáveis a serem estudadas (teor da jazida) com o caráter geológico. Esses métodos foram desenvolvidos por Matheeron na Escola de Minas de Paris no começo dos anos 60. A análise geoestatística é considerada uma etapa fundamental na avaliação de reservas, onde os depósitos que possuem zonas ricas e pobres, por serem controlados por fenômenos geológicos característicos próprios da sua formação (variabilidade natural do depósito), podem ser representados por meio do variograma. Este é a base da geoestatística que permite realizar as estimativas precisas, bem como avaliar o erro cometido nessas estimativas.

O termo de variável regionalizada introduzido por Matheerom foi criado para enfatizar as feições particulares das variáveis geológicas (MATHEERON; ARMSTRONG, 1987), apesar de, nos anos 40, as primeiras concepções aleatórias terem sido aplicadas em topografia nas discussões de Mahalanobis e Nair (VALENTE, 1989), segundo os quais a variável regionalizada é descrita como uma função numérica com uma distribuição espacial que varia de um lugar para outro com uma continuidade aparente.

Um conceito básico na teoria das variáveis regionalizadas é a chamada hipótese intrínseca, o qual designa que uma função descreve o comportamento da variável regionalizada dentro de um espaço ou área pre-determinada. Esta função é uma característica intrínseca da regionalização, e é representada pelo variograma. Vale dizer que a geoestatística assume que a distribuição das diferenças entre dois pontos é a mesma para toda área ou para o depósito todo e que ela depende somente da distância e orientação entre os pontos amostrais. Essa é a conceituação geoestatística da hipótese intrínseca, que pode ser reconhecida em qualquer fenômeno que apresente a correlação num espaço, ou seja, o variograma é o mesmo em qualquer lugar dentro da área de onde fosse amostrado. 


\subsubsection{Métodos de desagrupamento}

Em raríssimos casos, quando é praticável executar um esquema regular de amostragem, cada amostra recebe o mesmo peso das demais, gerando a melhor estimativa da população possível. Na maioria dos casos em que há amostragem em zonas preferenciais, procura-se um grupo ótimo de pesos que gere os parâmetros estatísticos da população e seja o mais representativo possível.

Os principais métodos de desagrupamento são:

1. Método da poligonal.- Neste método, os pesos atribuídos às amostras são diretamente proporcionais à área do polígono de (VARINI; RIPLEY, 1981 Apud SCHNEIDER, 2002) ao seu redor. Em zonas clusterizadas, as áreas dos polígonos tendem a ser pequenas (Figura 4.1), recebendo, por conseguinte, pesos menores.
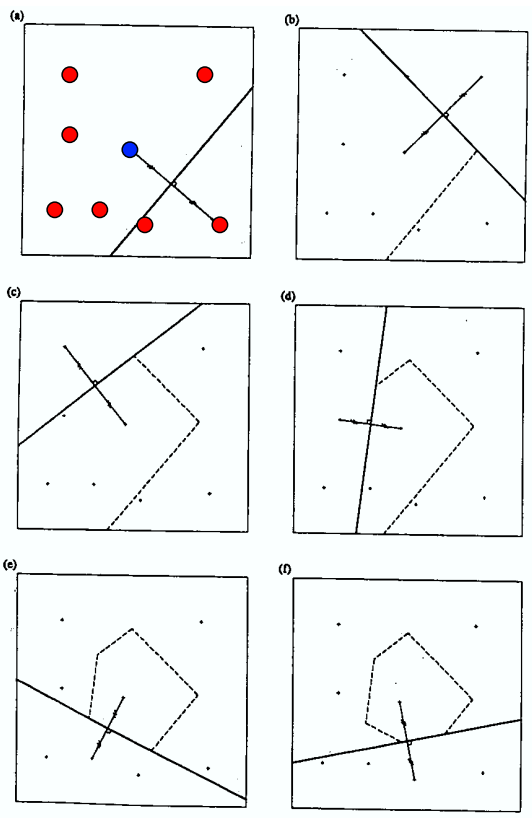

(a)

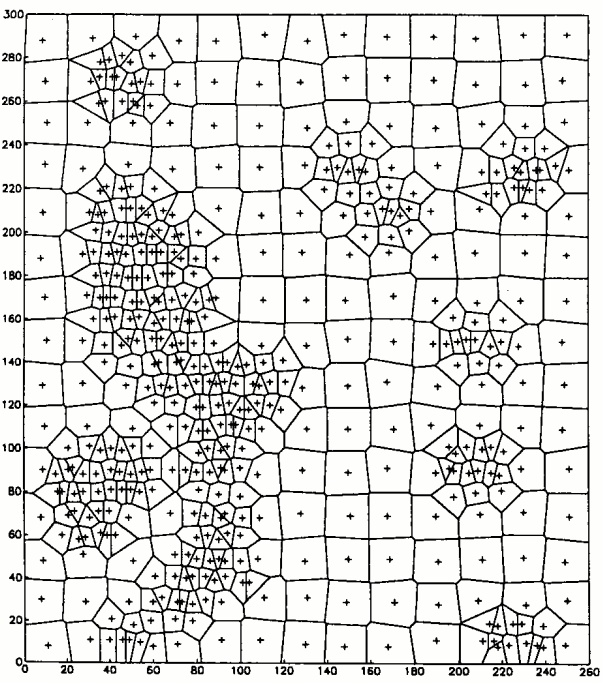

(b)

Figura 4.1: Desagrupamento por método da poligonal (a)representa a forma como é construída a delimitação do alcance das amostras. (b)delimitação do alcance das amostras. Fonte: Schneider (2002).

2. Método do Grid.- Quando não há condições de se descartar os dados agrupados, não é mais possível utilizar-se a metodologia anterior. Intuitivamente, dados em áreas densamente amostradas receberão menor peso do que dados em áreas pobremente amostradas. 
3. Método da Célula Móvel.- Este método é referido em Deutsch, Clayton e Journel (1998) e baseia-se na divisão regular da área total em regiões chamadas de células, como mostrado na Figura 4.2. Cada dado recebe um peso inversamente proporcional ao número de dados que caem dentro de uma mesma célula. Os dados agrupados recebem, geralmente, baixos pesos, em decorrência do elevado número deles que caem dentro de uma mesma célula.

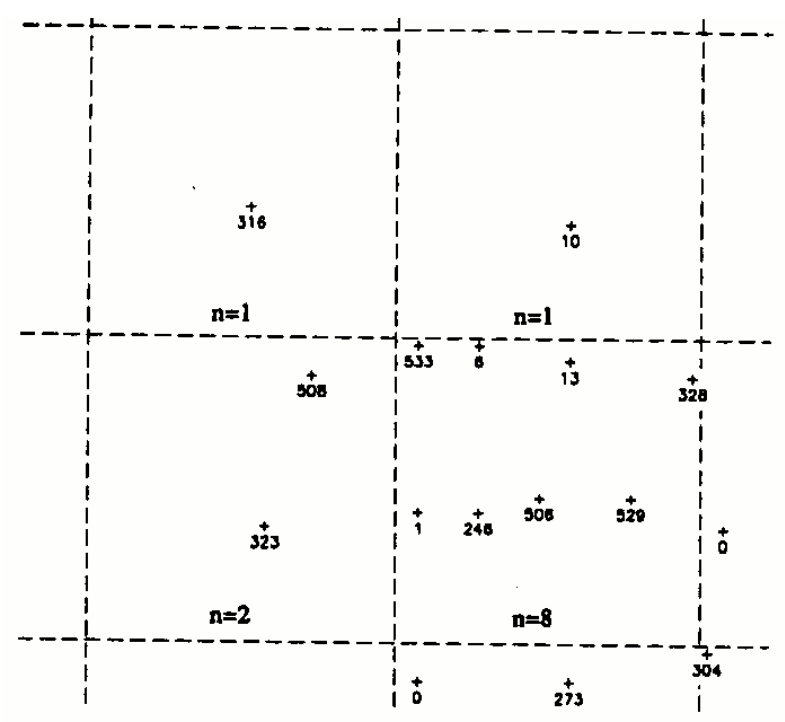

Figura 4.2: Método de desagrupamento por células móveis

Fonte: Issaks e Srivastava (1989).

\subsubsection{Correlação espacial}

O variograma é um produto final depois de um entendimento completo da correlação das amostras, pois ele é gerado como último produto da análise geoestatística e tem como principal característica descrever quantitativamente a variação de um fenômeno regionalizado. Desta forma, segundo Valente (1989), a dificuldade inicial da técnica geoestatística é principalmente a pesquisa de um variograma único para todo o espaço que se pretende tratar ou a divisão do espaço em zonas homogêneas no sentido de estacionaridade. Isso ocorre pois a estacionariedade usada na teoria de variável regionalizada é a estacionariedade de segunda ordem das diferenças entre a variável $Z(x)$ e a variável $Z(x+h)$, onde $(Z(x) ; X \in D)$ é um processo estocástico de valores reais definido sobre o domínio $\mathrm{D}$ em R, R2 ou R3 (IPT, 1989 apud YAмамото, 2001).

A Figura 4.3 descreve a idéia básica da aplicação de técnicas na avaliação geoestatística de uma jazida a partir dos dados obtidos na análise de sondagem. Após esta aplicação, 
faz-se um estudo do tipo de distribuição apresentado e realiza-se o cálculo dos variogramas horizontais. A estes, ajusta-se um variograma teórico, o qual permite, através de técnicas de krigagem, realizar uma estimativa em um modelo pontual ou de blocos (krigagem de blocos). As variáveis geralmente envolvidas para esta estimativa são, normalmente, o teor e/ou potência.

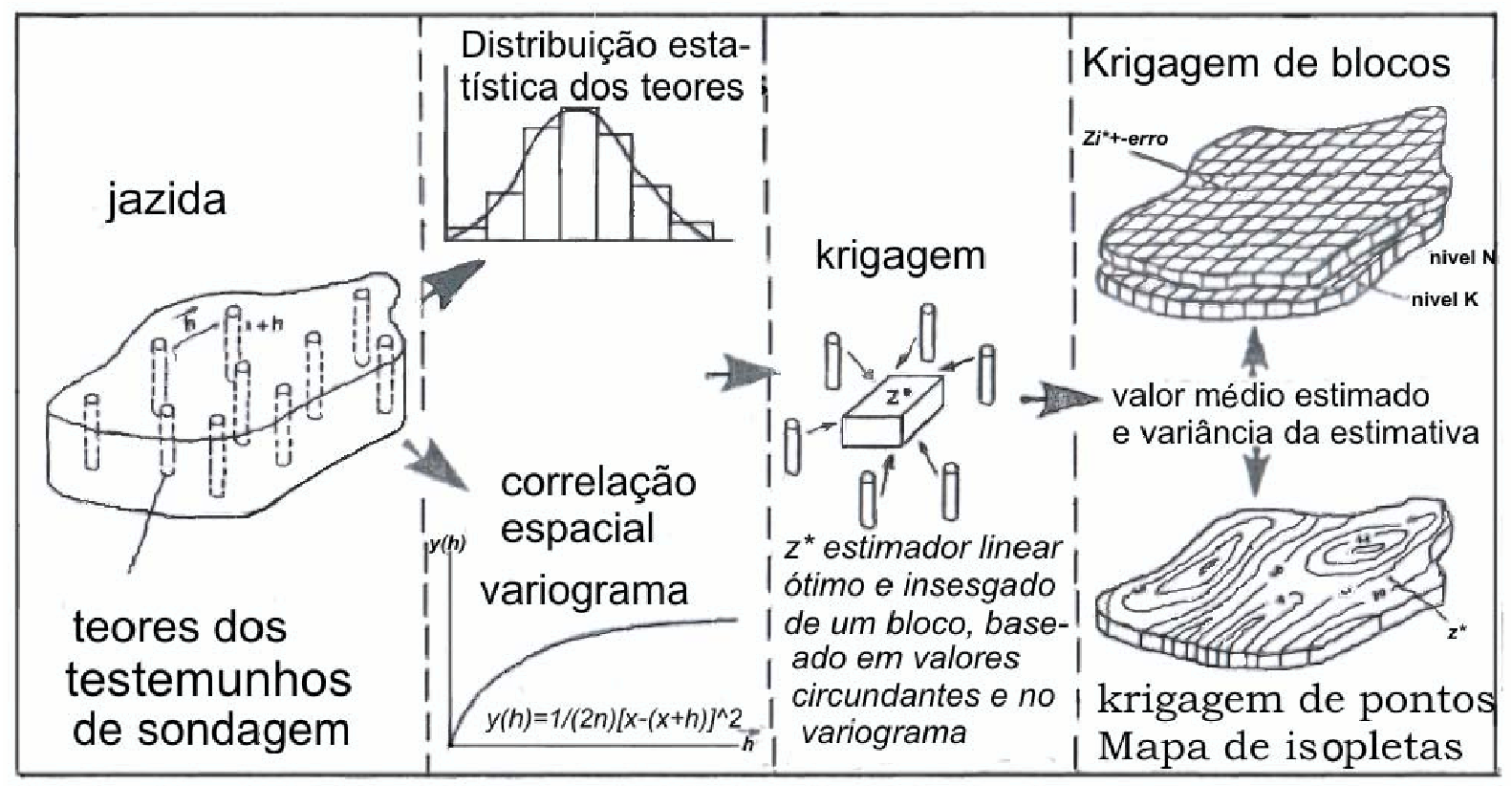

Figura 4.3: Principais aplicações da geoestatística na avaliação de uma jazida. Fonte: Instituto Tecnológico Geológico da España, (1991) apud Bustilo e Jimeno (1997)

Além destas aplicações apresentadas na Figura 4.3, a análise dos variogramas pode ser utilizada para determinar os seguintes aspectos (ANNELS, 1991 apud BUSTILO; JIMENO, 1997):

1. Tamanho ótimo da amostra;

2. Um esquema de amostragem;

3. Uma densidade de amostragem recomendada;

4. A área de influência de cada amostra, que pode ser calculada pelo métodos: elípticos, esferoidal ou elipsoidal;

5. Segundo a natureza da mineralização, a informação que oferece pode indicar a uniformidade da mineralização ou grau de concentração na etapa da precipitação da mineralização. 
A krigagem é feita após a conclusão do estudo geoestatístico, o qual poderá inclusive indicar a não aplicação desse método se o comportamento da variável regionalizada for totalmente aleatório. Este fenômeno é medido pela ferramenta básica da geoestatística que é o variograma, o qual mede as diferenças quadráticas de pares de valores separados de uma certa distância h em uma determinada direção. Krige e Schel foram os primeiros a utilizar esses conceitos em mineração, onde os variogramas experimentais, baseados na hipótese intrínseca (propriedade de estacionaridade geoestatística), descrevem a continuidade espacial das amostras de um fenômeno. Na Equação 4.1, $n(h)$ é o número de pares para certa distância h (lag) em uma determinada direção e $Z_{i}(u)$ e $Z_{i}(u+h)$ são os pares separados a uma distância h. A definição formal do variograma é:

$$
\gamma(h)=\frac{1}{2 n} \sum_{i=1}^{n(h)}\left[Z_{i}(u+h)-Z_{i}(u)\right]^{2}
$$

Esta função variograma $\gamma(h)$ é calculada para várias distancias $h$ (lags), formando assim, o gráfico do variogramas experimental para uma certa direção. Sobre o variograma experimental, pode se ajustar o variograma pelas regras básicas apresentadas em (ISSAKS; SRIVASTAVA, 1989), segundo o qual é utilizado normalmente o variograma experimental ominidirecional para o ajuste inicial do modelo. Desta forma, baseando-se nesse modelo, são ajustados os modelos dos variogramas direcionais. A consistência dos pontos deste modelo de variograma depende exclusivamente do número de pares de amostras, principalmente nos primeiros passos do variograma experimental. Esta continuidade em pequenas distâncias, a princípio, devem apresentar baixa variância espacial e podem ser descritos quatro tipos básicos de comportamento conforme na Figura 4.4.

Entretanto, em Journel e Huijbregts (1978) sugerem a utilização de pelo menos, 30 a 50 pares de amostras para cada ponto que conforma o variograma experimental que, por certo, deve-se observar, principalmente os primeiros número de pares próximo à origem do variograma. Nesse sentido, deve-se cuidar para que no momento de se fazer o ajuste do modelo do variograma, os pontos que definirão o efeito pepita nugget, se houver, deverão conter o maior número de pares de pontos possíveis, procurando honrá-los, e devem-se descartar aqueles contendo um número muito inferior ao locado imediatamente após.

Deste modo, para o cálculo do variograma experimental devem ser entendidos alguns parâmetros (Figura 4.5):

- Passo: é a distância que separa duas amostras, e deve ser um reflexo da malha de amostragens ou da densidade de amostragens; 
(A)

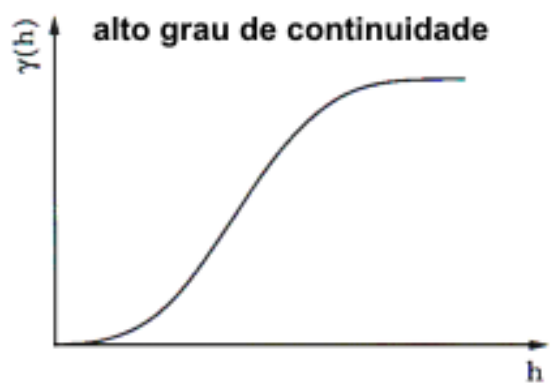

(C)

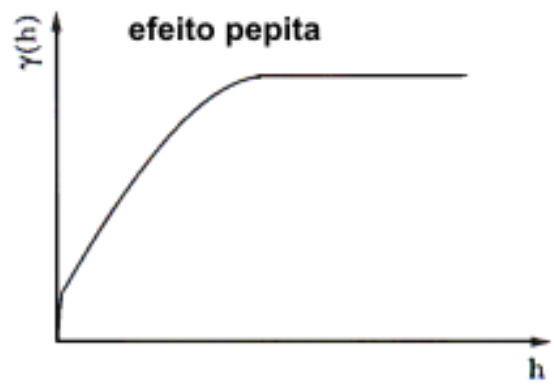

(B)

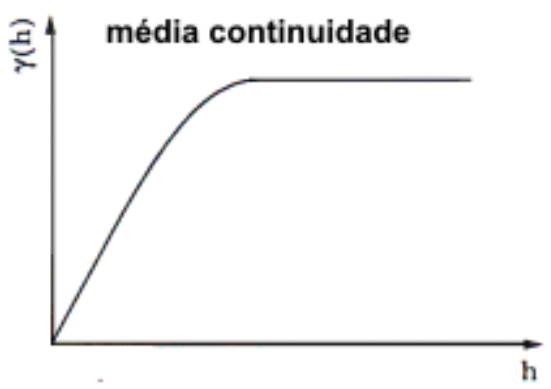

(D)

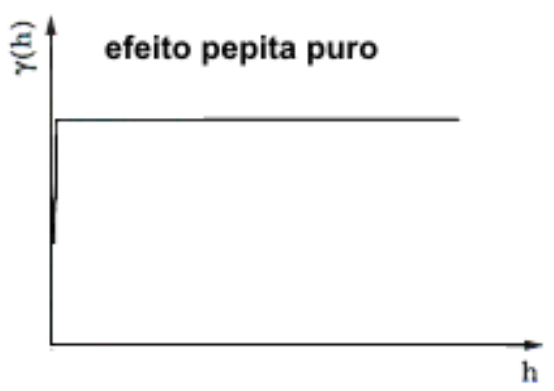

Figura 4.4: Graus de continuidade da mineralização mostrados pelo comportamento do variograma na origem

alto grau de continuidade (A); média continuidade (B); efeito pepita (C) e efeito pepita puro (D). Fonte: Bubenicek; Haas, (1969) apud Yamamoto (2001)

- Tolerância do Passo: é uma tolerância dada que acrescenta ou subtrai uma certa distância do passo, com a finalidade de localizar melhor os pares a serem encontrados, sobretudo em malhas de amostragens irregulares;

- Direção: é o ângulo que determina o variograma ao longo de uma direção que é definida pelos estudos de direções preferenciais (anisotropia);

- Tolerância angular: é o ângulo atribuído à direção que permite serem utilizados pontos que estejam fora da linha definida pela direção preferencial;

- Largura máxima: é uma distância a partir da qual o ângulo é delimitado na abrangência de amostras, pois a distância entre a direção e a linha formada pelo ângulo de tolerância que tende a crescer indefinidamente quando a distância do passo está sendo incrementada. Enquanto a distância da largura não é alcançada a busca de amostras forma um triângulo (2D) ou um cone (3D), e quando alcançada, esta assume a forma de um retângulo (2D) ou de um cilindro (3D).

- Número de passos: é o número máximo de vezes que o passo receberá o incremento 
da distância. A Figura 4.5 aproxima os parâmetros para o cálculo do variograma experimental.

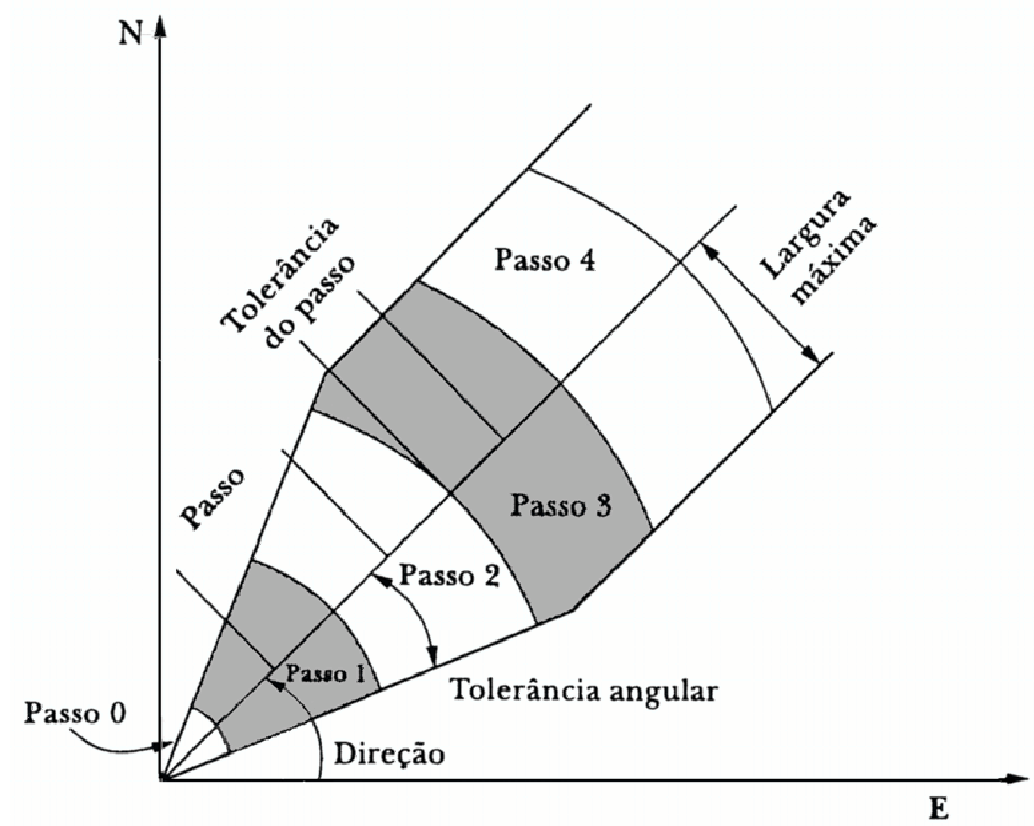

Figura 4.5: Desenho de um variograma experimental, os passos, tolerância angular, a largura máxima e tolerância de passo

Fonte: Yamamoto (2001)

\subsection{Anisotropia.}

A anisotropia direcional aparece quando se obtêm diferentes variogramas ao longo de diferentes direções da jazida. Isto significa que, no lugar de uma área de busca isotrópica (circular ou esferoidal), tem-se uma zona elíptica ou elipsoidal. Assim, a Figura 4.6 mostra a anisotropia geométrica. A anisotropia pode ser geométrica (Figura 4.6A), quando a amplitude varia e não o patamar; zonal (Figura 4.6B), quando a amplitude permanece constante e o patamar varia com a direção e mista (Figura 4.6C), na qual variam tanto a amplitude quanto o patamar.

Assim, uma ilustração do modo de busca de direções preferenciais é mostrada na Figura 4.7, onde são vistas nove direções, cada uma delas com um variograma direcional. Também se constata a distância de um elipsóide, verificando-se o alcance do variograma nas diferentes direções e, portanto, delimitando-se a direção de maior continuidade numa forma elíptica (maior e menor eixos de uma anisotropia geométrica) 
(A)

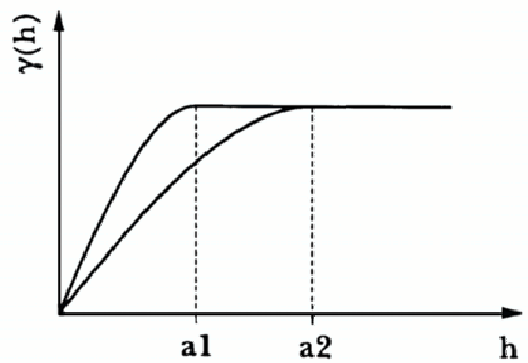

(B)

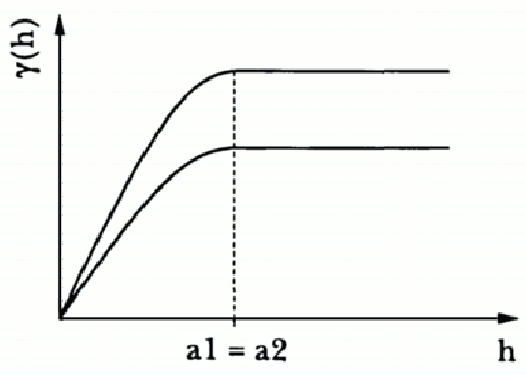

(C)

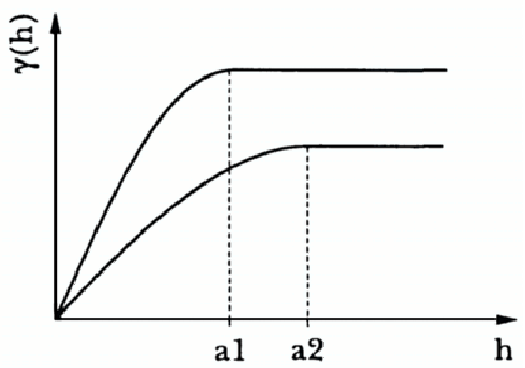

Figura 4.6: Anisotropia

Fonte: Yamamoto (2001).

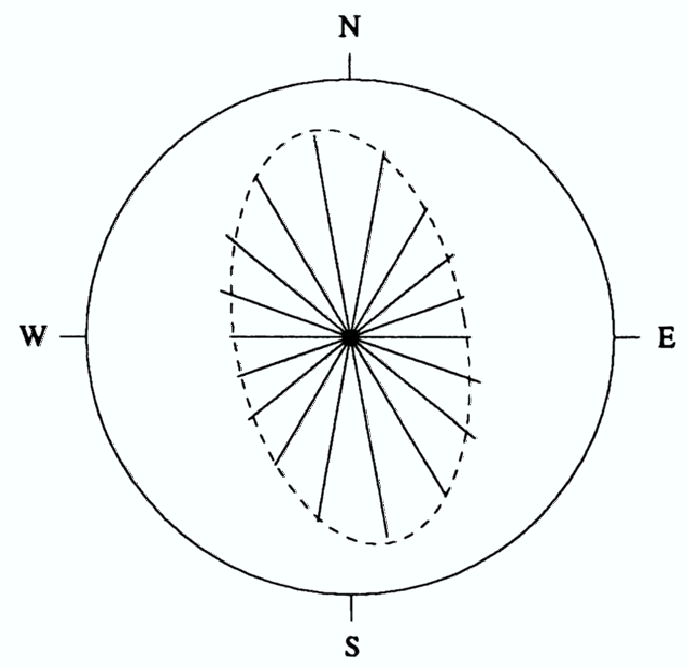

Figura 4.7: Anisotropia geométrica.

Fonte: Issaks e Srivastava (1989)

Segundo Issaks e Srivastava (1989) uma maneira rápida de se obter informações sobre possíveis direções de anisotropia de um fenômeno geológico é por meio do uso de mapas de contornos variográficos dos dados conforme a Figura 4.8.

No caso em que a variável de interesse apresenta anisotropia geométrica, esta correção se dá nas equações de krigagem, aplicando-se o ângulo do eixo de anisotropia e a razão de anisotropia à equação do cálculo da distância corrigida. A razão de anisotropia (K) é dada pela razão entre a maior amplitude pela menor ( $K>1$ sempre). Esta correção se faz pelo cálculo da distância corrigida (equação 4.2) e é vista nas Figuras 4.9a e 4.9b.

$$
h=\sqrt{\left[\left(x_{1}-x_{2}\right) \cos \theta+\left(y_{1}-y_{2}\right) \operatorname{sen} \theta\right]^{2}+K^{2}\left[\left(y_{1}-y_{2}\right) \cos \theta-\left(x_{1}-x_{2}\right) \operatorname{sen} \theta\right]^{2}}
$$




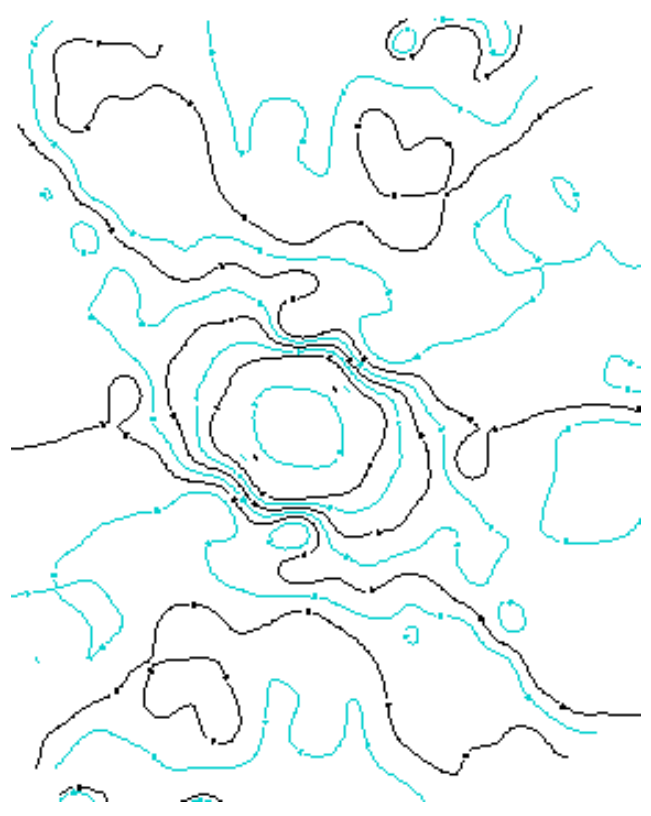

Figura 4.8: exemplo de contornos

dos variogramas direcionais

Fonte: Gerado no programa

Datamine

Se considerarmos uma elipse, o qual é realizado projetando pontos por fora da elipse, de tal modo que os pontos que estavam sobre uma elipse são projetados sobre um círculo na Figura 4.9A, sendo que os pontos se deslocam também proporcionalmente à elipse.

(A)

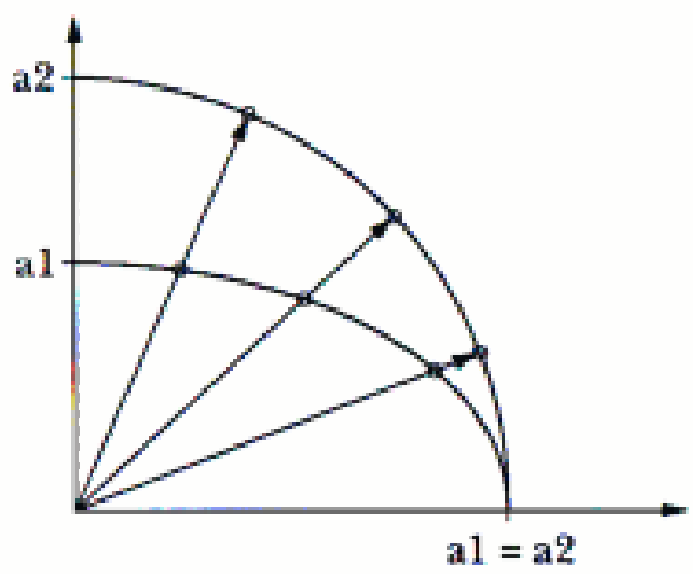

(B)

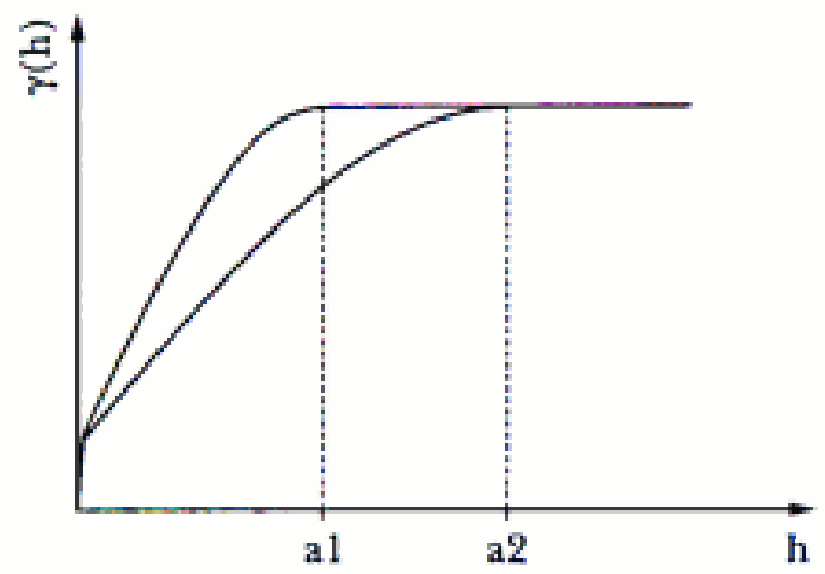

Figura 4.9: Desenho do processo de correção anisotrópica:

(A) projeção dos pontos sobre a elipse para o círculo circunscrito (B) variograma com anisotropia geométrica de amplitude iguais. Fonte: (YAMAMOTO, 2001). 


\subsection{Modelos teóricos do variograma}

Com o intuito de inferir a estrutura com a definição matemática conhecida de um depósito e o comportamento das variações de teores em áreas não amostradas a partir de um conjunto de pontos amostrados, deve-se ajustar um modelo teórico, pois o variograma servirá para calcular os valores de variância espacial que serão necessários para a organização de um sistema de krigagem. Embora o ajuste de um variograma teórico de um variograma experimental seja a forma mais comum de aproximação no esquema da continuidade espacial, não é a única nem necessariamente a melhor (BUSTILO; JIMENO, 1997). Existem numerosas situações na seleção de um modelo adequado baseado geralmente em aproximações qualitativas, pois a experiência de um conjunto de dados semelhantes pode constituir na hora do ajuste um guia melhor que o simples esquema mostrado por poucas amostras. Neste trabalho, utilizou-se como critério para o ajuste dos modelos o patamar estabelecido pela variância priori dos dados. Em alguns casos, porém, o ajuste pode ter sido feito abaixo da linha de variância. Este critério se justifica na medida em que apenas a parte inicial do variograma teria influência nas medidas de continuidades.

\subsubsection{Modelos de variogramas teóricos}

Representar um variograma por uma função matemática conhecida para resolver as equações de krigagem é uma condição fundamental na geoestatística. O variograma experimental não representa uma função matemática definida nem dispõe de pontos sob uma certa dispersão, principalmente nos passos mais longos. Entretanto, a modelagem do fenômeno regionalizado por um modelo teórico (ajuste de uma função matemática) em um variograma que descreva a variabilidade ou correlação existente nos dados é conhecida pelo ajuste de modelos teóricos em geoestatística, e isso geralmente é feito de maneira interativa, considerando os parâmetros obtidos do variograma experimental, ou seja: o modelo, o efeito pepita, o amplitude e patamar. Caso o ajuste não for satisfatório, novos parâmetros devem ser fornecidos até que o ajuste seja considerado satisfatório. O modelo mais comum na mineração é o esférico ou de Matheerom (Equação 4.3).

A Figura 4.10 representar os diferentes tipos de variogramas teóricos.

$$
\begin{gathered}
\gamma(h)=C_{0}+C\left[\frac{3}{2}\left(\frac{h}{a}\right)-\frac{1}{2}\left(\frac{h}{a}\right)^{3}\right] \operatorname{para}(h<a) \\
\gamma(h)=C_{0}+C \operatorname{para}(h \geq a)
\end{gathered}
$$


Onde $C_{0}$ é a variância aleatória, $C$ é a variância espacial

(A)

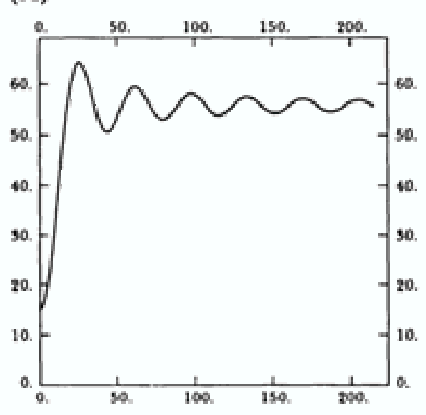

(D)

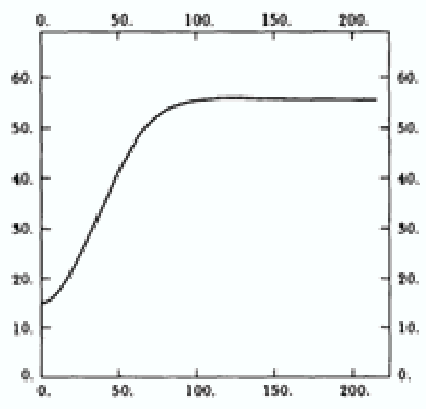

(G)

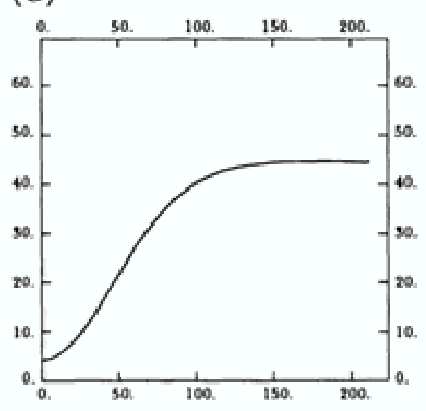

(J)

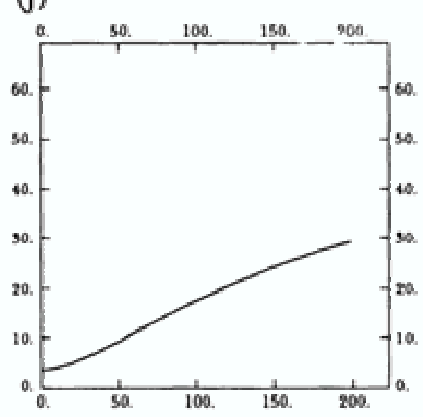

(B)

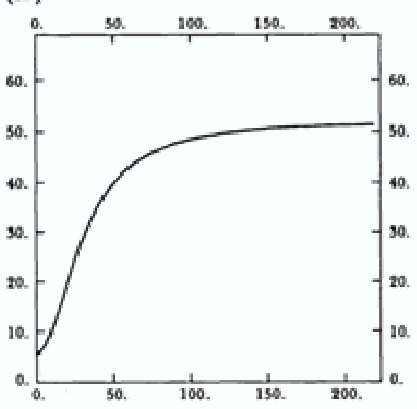

(E)

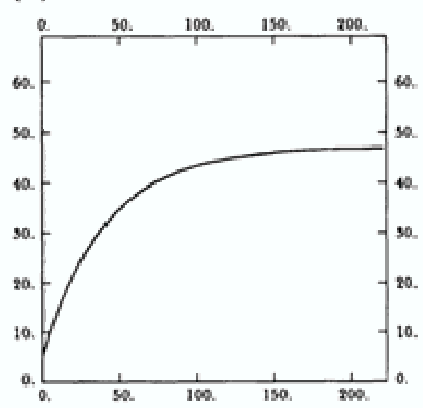

(H)

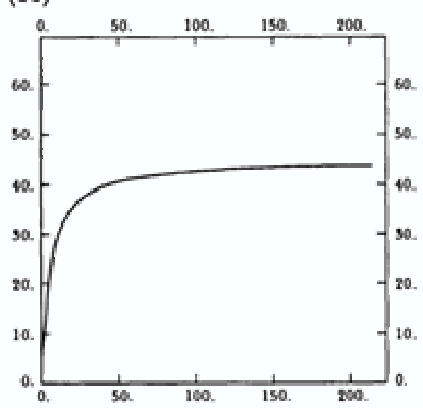

(L)

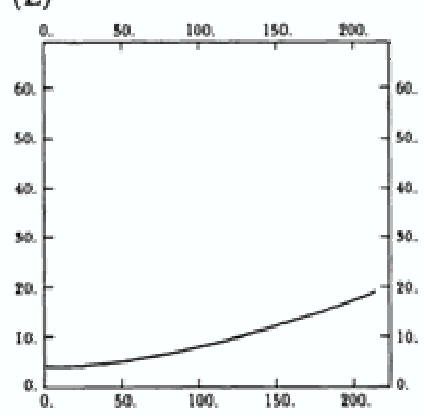

(I)

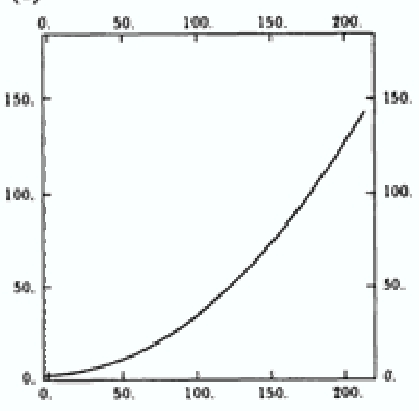

(C)

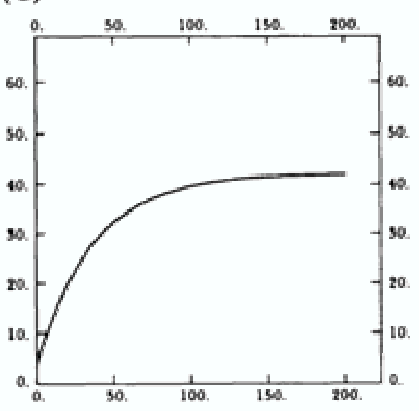

(F)

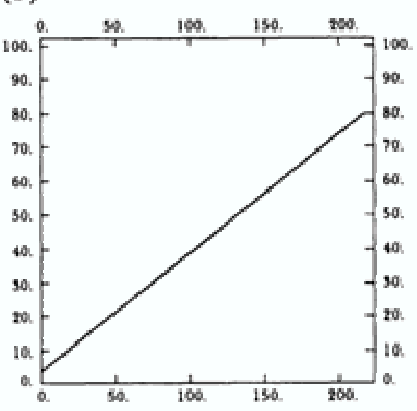

(M)

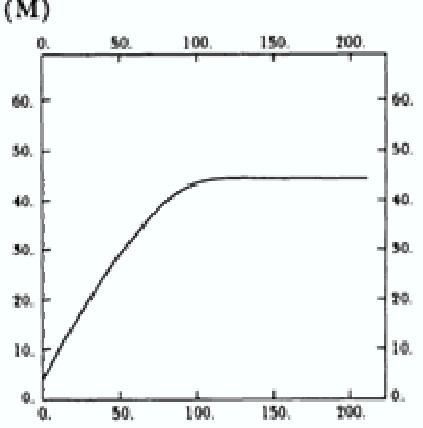

Figura 4.10: Modelos de variogramas mais comuns na natureza

Seno cardinal (A), Cauchy genérico (B), Exponencial (C), Cúbico (D), Linear (F), Gauss (G), Gamma (H), Potencial (I), KBessel (J), JBessel (L), Esférico (M)) Fonte: Rocha (1999) 


\subsection{Influência dos parâmetros do variograma na es- timativa por krigagem}

Segundo (BUSTILO; JIMENO, 1997) os seguintes parâmetros do variograma têm influencia na estimativa:

1. A escala

2. A forma

3. O efeito pepita

4. O alcance

1. Influência da Escala.- Esse parâmetro determina um ponto adequado de dois variogramas semelhantes na sua escala, ou seja, considera-se o valor $\gamma(h)$ quando se consegue atingir o patamar como mostrado na Figura 4.11. Geram-se dois valores iguais na estimativa, mas diferentes quanto às variâncias de krigagem. Este efeito pode ser comprovado acrescentando a proporção de escala, e incrementando-se, na mesma relação, a variância de krigagem.
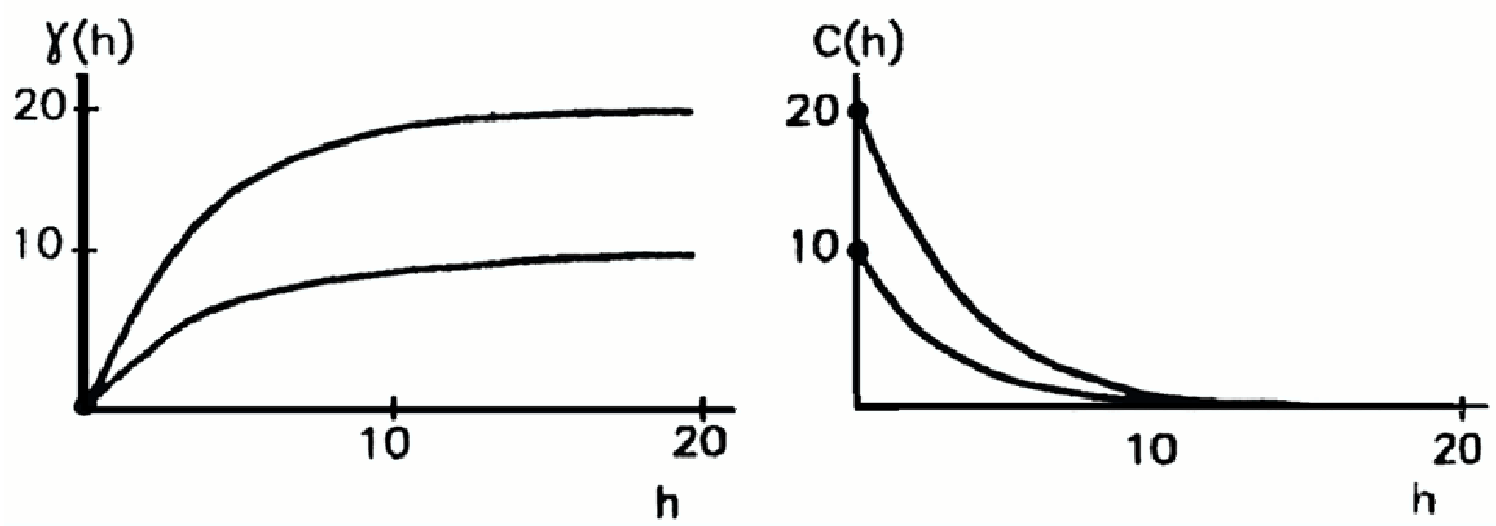

Figura 4.11: Variogramas que se diferenciam pela escala Fonte:Bustilo e Jimeno (1997)

2. Influência da forma.- Consideram-se, neste caso, os variogramas que apresentam o mesmo patamar, mas diferenciam-se na forma de atingí-o conforme mostrado na 
Figura 4.12 (o modelo gaussiano e o modelo exponencial). O segundo modelo exponencial gera fatores de ponderação maiores nos pontos mais próximos, enquanto os mais distantes recebem uma menor ponderação e, em alguns casos, inclusive, recebem valores negativos (BUSTILO; JIMENO, 1997). Isso ocorre porque os variogramas indicam um fenômeno muito contínuo. Assim, o processo de estimativa utiliza freqüentemente os pontos mais próximos.
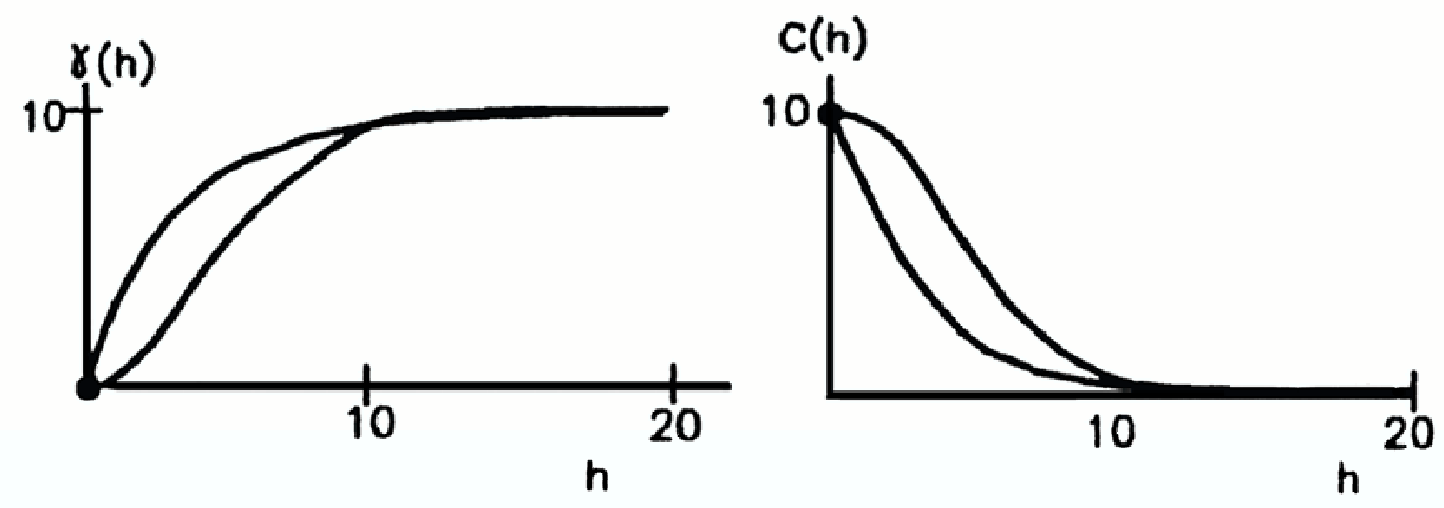

Figura 4.12: Variogramas que se diferenciam pela escala Fonte: Bustilo e Jimeno (1997)

3. Efeito pepita.- Neste tipo de comportamento apresenta-se uma descontinuidade na origem. Este comportamento normalmente reflete erros de amostragem, pois, por definição teórica, uma amostra é semelhante a si mesma, ou seja, todos os variogramas deveriam que começar na origem. O comportamento extremo deste fenômeno (Efeito pepita Puro), que demonstra um comportamento próximo ao da origem, o qual reflete a variação espacial de um fenômeno em transição, onde para um determinado valor de patamar a amplitude terá um valor infinitesimal.

4. Continuidade espacial.- O estudo de continuidade espacial envolve a medida de auto-correlação entre amostras em um determinado espaços separadas por uma distância h (lag) em uma certa distância. Segundo Yamamoto (2001) uma maneira prática de comparar os valores de amostras pode ser por meio de diagramas de dispersão, nos quais verifica-se o quanto a nuvem de pontos separa-se da bissetriz reta (1:1). Na análise de dispersão a nuvem de pontos aumentará com a distância h, pois os valores de amostras distantes tenderão a ser diferente e, portanto, os pontos nos diagramas de dispersão estarão distantes da bissetriz. 


\subsubsection{Validação do modelo ajustado}

Considera-se que um dos desafios na krigagem é a escolha do melhor modelo que se ajuste aos variogramas experimentais obtidos, pois os valores do efeito pepita, patamar e alcance no modelo, ajustam-se de forma manual e intuitiva. Baseado nesta questão, é válida a utilização da técnica de validação, que é uma re-estimativa dos pontos amostrados (ISSAKS; SRIVASTAVA, 1989). De acordo com essa técnica, o valor de um ponto amostrado é removido, sucessivamente, para logo ser estimado novamente, respeitando os modelos de anisotropia ajustados nos variogramas experimentais. Estes novos valores estimados são adicionados ao banco de dados somente para efeitos comparativos. Desta forma, pode também ser medido o erro de estimativa (diferença do valor real e o estimado). Esta medida deve ser zero ou próxima a zero, caracterizando um estimador não-tendencioso.

Esse processo interativo permite-nos definir quais parâmetros do variograma (efeito pepita, patamar e alcance) são os mais adequados para a modelagem.

\subsection{Krigagem}

Nas primeiras aplicações da geoestatística foi restringido o uso da krigagem ordinária pelo alto número de cálculos matemáticos necessarios. Isso porém, foi resolvido com a utilização da informática (processadores de alta velocidade), solucionando a estimativa de variáveis de interesse nos blocos de cubagem quando se trabalha com número de dados maiores.

A geoestatística utiliza a ferramenta da krigagem devido ao caráter não tendencioso e por calcular a melhor estimativa através da minimização da variância do erro. Segundo Issaks e Srivastava (1989), a estimativa de krigagem está associada ao melhor estimador linear não enviesado, do inglês BLUE (Best Linar Unbiased Estimation); linear, porque a estimativa é uma combinação linear das amostras vizinhas; não enviesado, porque a média do erro de estimativa é zero; e melhor, porque os fatores da ponderação determinam-se de forma que a variância da estimativa dos erros seja mínima, produzindo uma ótima estimativa. A estimativa de krigagem e a variância de estimativa são calculadas utilizandose o modelo de covariância (ou variograma) obtido no estudo de continuidade espacial. 


\subsubsection{Definição do erro de estimativa bloco a bloco}

Segundo Issaks e Srivastava (1989), enquanto as distribuições globais do erro são freqüentes, as distribuições locais não o são, Há certas aplicações para os quais a hipótese de normalidade para níveis locais é aceitável. Isto significa que dependendo do atributo a ser estimado, estes erros podem ser aceitáveis pela pouca variabilidade.

Por outro lado, a super-estimativa geralmente está relacionada ao espaçamento inadequado da malha de amostragem (ROCHA, 1999), sendo que a estimativa de krigagem ordinária atinge níveis aceitáveis de estimativa (minimiza o erro). Segundo o mesmo autor, para conseguir a melhor interpolação/estimativa possível dos atributos de uma variável de interesse, as características principais de uma avaliação de recursos dependem da distribuição espacial, e da qualidade e quantidade das amostras.

Assim, com o intuito de quantificar o erro da estimativa associada a um determinado atributo geológico de amostragem e respectivos padrões de amostragem (DAVIS, 1977), foram realizados trabalhos especificos usando a krigagem (DAVIS, 1997, p. 45-72); e (ISSAKS; SRIVASTAVA, 1989, p. 489-524). Por meio do parâmetro variância de krigagem (OK) foi demonstrado que a $K S$ (krigagem simples) incorpora somente as características geométricas dos padrões de amostragem utilizados (JOURNEL, 1986 apud BARROS, 2001), isto é, em uma distribuição espacial de pontos de amostragem, não são considerados valores e variabilidades locais (GOOVAERTS, 1997). Portanto, a estimativa por KO não é afetada pela variância das amostras locais, podendo haver valores de variâncias de krigagem iguais (com padrões de amostragem idênticos) para cenários completamente diferentes (em termos de variância dos dados locais), desde que o modelo de continuidade espacial seja o mesmo (Figura 4.13)

A interpretação na validação da krigagem em estudos especificos (JOURNEL; ROSSI, 1989) indica que a variância de krigagem mede apenas a configuração espacial dos dados. Assim, o certo é que este parâmetro de análise depende apenas do variograma e representa uma forma global de análise, e ela independe dos valores locais dos pontos. Yamamoto no ano 2001 propôs uma equação para o cálculo da variância de interpolação que é determinada como a média ponderada das diferenças ao quadrado entre os valores dos pontos de dados e a estimativa da variável (YAMAмOTO, 2001). A fórmula esta apresentada na Equação 4.5:

$$
S^{2}=\sum_{i=1}^{n} \lambda_{i}\left[Z\left(x_{i}\right)-Z^{*}\left(x_{0}\right)\right]^{2}
$$



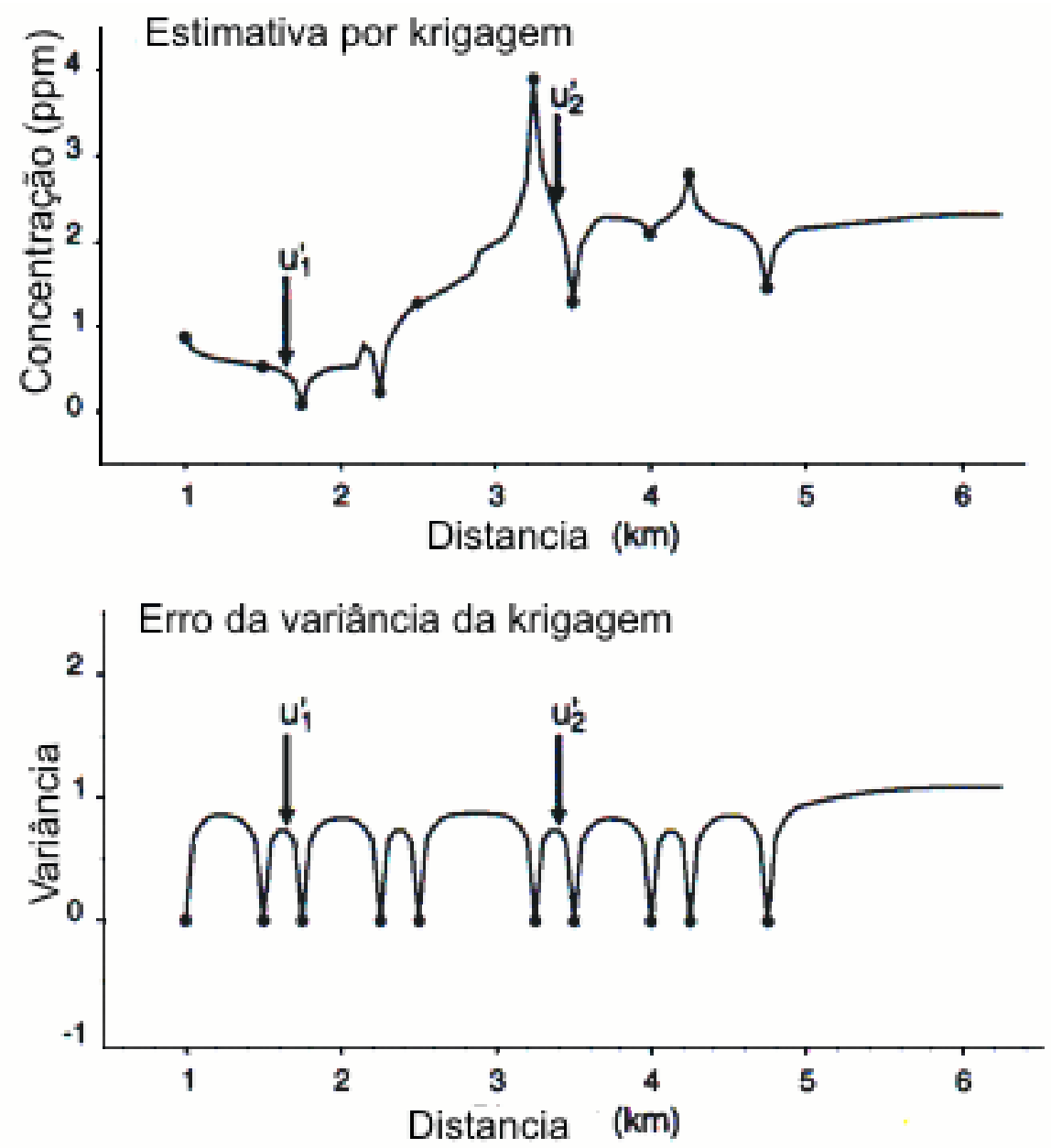

Figura 4.13: Influência da variância da krigagem ordinária (gráfico de cima) e suas variâncias (gráfico de baixo) com relação à proximidade dos dados amostrais. Fonte: Goovaerts (1997)

onde $Z^{*}\left(x_{0}\right)$ é o estimador linear obtido da combinação linear da krigagem, $Z\left(x_{i}\right)$ é o valor conhecido e $\left(\lambda_{i}, i=1, n\right)$ são os ponderadores obtidos da resolução do sistema linear da krigagem.

Segundo o mesmo autor, esta variância de interpolação apresenta as seguintes propriedades:

- Corresponde à propriedade de exatidão da krigagem ordinária. Isto significa que, se o ponto a ser estimado coincide com o ponto de dado original, então o peso desse ponto é igual a um, considerando-se que os outros pesos continuem sendo zero, portanto $s^{2}=0$;

- É proporcional aos pontos com dados conhecidos.

- Usa indiretamente a distância estrutural do variograma por meio do peso da kriga- 
gem ordinária $\lambda_{1}$, considerando que quanto mais influente for, maior é seu peso.

\subsection{Incorporação da informação secundária ao mo- delo existente}

Neste tópico é abordado um método geoestatístico capaz de reduzir a incerteza associada à estimativa por meio da incorporação de informações secundárias. Esta fonte de informações é obtida por meio da análise química do pó-de-perfuratriz. Considera-se informação secundária aquelas disponível em todos os locais contendo dados primários bem como nos pontos onde a variável primária será estimada (dado colocado). Deste modo, as informações secundárias podem ser divididas em dois tipos:

- atributo categórico (tipo de litologia)

- atributo contínuo (análises químicas, ou outro parâmetro quantitativo amostrado).

Se a informação secundária é densamente amostrada, mas não exaustivamente, é aceitável uma aproximação por interpolação para completá-la (OLIVEIRA, 2005), ou melhor ainda, através de simulação. Para os casos de informação secundária exaustivamente amostrada, o método apropriado que será apresentado é: a do co-krigagem colocada aplicando o Modelo de Markov 2 (MM2).

Para aplicação destes métodos, exige-se que a variável secundária esteja colocada em todos os nós da malha onde a variável primária irá ser estimada. Em casos de informações secundárias não seja exaustivamente amostrada deve ser empregado, o método de cokrigagem, o qual também será apresentado.

\subsection{Amálise da continuidade espacial de 2 variáveis}

\subsubsection{Coeficiente de correlação e covariância cruzada}

O coeficiente de correlação é o parâmetro estatístico mais amplamente utilizado para medir a relação entre duas variáveis de um mesmo conjunto isotópico. O coeficiente de correlação linear entre duas variáveis está definido pela Equação 4.6 (ISSAKS; SRIVASTAVA, 1989):

$$
\rho=\frac{\frac{1}{n} \sum_{i=1}^{n}\left(x_{i}-m_{x}\right)\left(y_{i}-m_{y}\right)}{\sigma_{x} \cdot \sigma_{y}}
$$


Onde $n$ é o número de dados, os índices $x_{1} \ldots x_{n}$ e $y_{1} \ldots . y_{n}$ referem-se aos dados das variáveis primária á secundária, e suas médias e desvios padrão são respectivamente $m_{x}$, $m_{y}$ e $\sigma_{x}, \sigma_{y}$. O numerador da Equação (4.6) é a covariância entre $x$ e $y$ para $h=0$. Em resumo, o coeficiente de correlação é a covariância padronizada pelo desvio padrão das duas variáveis, o que garante que o coeficiente de correlação esteja sempre no intervalo -1 $\mathrm{e}+1$.

Assim, desde que haja uma correlação entre duas variáveis pode ser obtida a equação que correlaciona as mesmas. A regressão linear é o método mais simples de equacionamento, pois assume que a dependência entre uma variável e a outra é descrita pela Equação da reta (ISSAKS; SRIVASTAVA, 1989):

$$
y=a x+b
$$

Onde as constantes $a$ e $b$ da equação acima são obtidas por:

$$
a=\rho \frac{\sigma_{y}}{\sigma_{x}} ; b=m_{y}-a m_{x}
$$

Onde $\rho$ é o coeficiente de correlação, e os índices $m_{x}$ e $\sigma_{x}$ são a média e desvio padrão da variável $x$ e $\sigma_{y} m_{y}$ média e desvio padrão da variável $y$.

Desta forma, com a covariância entre as duas variáveis $Z_{i}$ e $Z_{j}$ é possível conseguir uma covariancia conjunta como uma variância conjunta entre suas médias (GOOVAERTS, 1997):

$$
C_{i j}=\frac{1}{N(h)} \sum_{\alpha_{1}}^{n} Z_{i}\left(u_{\alpha}\right) \cdot Z_{j}\left(u_{\alpha}+h\right)-m_{i}(-h) \cdot m_{j}(+h)
$$

com:

$$
m_{i}(-h)=\frac{1}{N(h)} \sum_{\alpha=1}^{N(h)} Z_{i}\left(u_{\alpha}\right) ; m_{j}(+h)=\frac{1}{N(h)} \sum_{\alpha=1}^{N(h)} Z_{i}\left(u_{\alpha}+h\right)
$$

onde $N(h)$ é o número de pares separados pela distância $h$; e $m_{i}$ e $m_{j}$ são as médias das variáveis $Z_{i}$ e $Z_{j}$ respectivamente. 


\subsubsection{Variograma Cruzado}

Para conseguir a relação entre duas variáveis, é utilizado o variograma cruzado, o qual, para duas variáveis $Z_{i}(u)$ e $Z_{j}(u)$ é definido como a somatória das diferenças entre valores das duas variáveis afastadas por um vetor de separação $h$ entre si:

$$
\gamma_{i j}(h)=\frac{1}{2 N(h)} \sum_{\alpha=1}^{N(h)}\left[Z_{i}\left(u_{\alpha}\right)-Z_{i}\left(u_{\alpha}+h\right)\right] *\left[Z_{j}\left(u_{\alpha}\right)-Z_{j}\left(u_{\alpha}+h\right)\right]
$$

onde $\gamma_{i j}(h)$ é a função variograma cruzado, $\mathrm{N}(\mathrm{h})$ é o número de pares de dados $Z_{i}$ e $Z_{j}$ separados por um vetor $h$.

O variograma cruzado é simétrico, calculado a partir de incrementos, e não é modificado pela ordem das variáveis ou pela mudança no sentido de separação do vetor h.

Como o intuito da modelagem do variograma cruzado é a melhoria de estimativas de variáveis sub-amostradas (variáveis primárias) por métodos de co-estimativas (GOOVAERTS, 1997), o seu cálculo está limitado às amostras da variável primária. No seu cálculo, é necessário que as variáveis $Z_{i}$ e $Z_{j}$ sejam presentes em $u$ e $u+h$.

\subsection{Co-estimativas por co-krigagem}

A co-krigagem é um procedimento geoestatístico segundo o qual diversas variáveis regionalizadas podem ser estimadas em conjunto, com base na correlação espacial entre si. É uma extensão multivariada do método da krigagem quando para cada local amostrado obtém-se um vetor de valores em lugar de um único valor.

As informações secundárias não exaustivamente amostradas podem ser incorporadas pelo algoritmo de co-krigagem. Isto demostra, pois, que o método deve ser usado quando uma das variáveis apresenta-se sub-amostrada em relação às demais. Este método aplica a correlação espacial cruzada entre as variáveis primárias e secundárias, e é fundamental a verificação prévia da correlação existente entre as variáveis. Esta correlação, por sua vez, deve ser alta para que as estimativas sejam consistentes.

Partindo da premissa de que a variável primária é suplementada por dados secundários $(\mathrm{Nv})$ de um atributo contínuo em qualquer ponto diferente, o estimador linear de krigagem é estendido de maneira a incorporar os $\mathrm{Nv}$ dados adicionais. 


$$
Z_{1}^{*}-m_{1}(u)=\sum_{\alpha_{1}=1}^{n(u)} \lambda_{\alpha 1}(u)\left[Z_{1}\left(u_{\alpha 1}\right)-m_{1}\left(u_{\alpha 1}\right]+\sum_{j=2}^{N} \sum_{\alpha_{j}=1}^{n j(u)} \lambda_{\alpha j}(u)\left[Z_{j}\left(u_{\alpha i}\right)-m_{i}\left(u_{\alpha j}\right)\right]\right.
$$

onde $\lambda_{\alpha 1}(u)$ são os pesos dos dados primários $Z_{1}\left(u_{\alpha 1}\right)$ e $\lambda_{\alpha 1(u)} \operatorname{com} i>1$, e são os pesos dos dados secundários ou terciários. Somente os dados primários e secundários próximos ao ponto a ser estimado serão computados. A quantidade dos dados retidos e o tamanho da busca não precisam ser necessariamente os mesmos para todos os atributos. A co-krigagem pode ser de diferentes tipos, conforme o modelo de tendência $m_{i}(u)$ assumido:

- cokrigagem simples: considera tendência estacionária para toda a área.

- cokrigagem ordinária: limita ao domínio de estacionariedade da tendência em uma vizinhança local.

Dado que essa é uma combinação linear dos dados disponíveis, pode ser simplificada a estimativas por co-krigagem para uma variável primária, e uma secundária conforme a Equação 4.13:

$$
Z_{C K O}^{*}(u)=\sum_{\alpha 1=1}^{n 1(u)} \lambda_{\alpha 1}(u) Z_{1}\left(u_{\alpha 1}\right)+\sum_{\alpha 2=2}^{n 2(u)} \lambda_{\alpha 2}(u) Z_{2}\left(u_{\alpha 2}\right)
$$

onde $Z_{C K O}^{*}(u)$ é o dado primário estimado em $u$ e $Z_{1}$ e $Z_{2}$ são as variáveis primárias e secundárias locadas em $\alpha 1$ e $\alpha 2$ respectivamente, com os pesos $\lambda_{\alpha 1}$ para a variável primária e $\lambda_{\alpha 2}$ para a secundária.

Para esses casos, os pesos de co-krigagem ordinária das variáveis Z1(u) e Z2(u) são respectivamente (ISSAKS; SRIVASTAVA, 1989):

$$
\sum_{\alpha 1=1}^{n 1} \lambda_{\alpha 1}^{C K O}=1 \ldots . . . . . \sum_{\alpha 2=1}^{n 2} \lambda_{\alpha 2}^{C K O}=0
$$

De acordo as condições referidas acima, a estimativa do co-krigagem pode resultar em pesos negativos de co-krigagem para a variável secundária,onde há a possibilidade de estimativas negativas ou muito pequenas. Esta última situação tende a reduzir a influência da variável secundária (BOEZIO, 2004). Para resolver esse problema foi proposta uma única condição para os pesos, onde o somatório dos pesos da variável primária e secundária 
deve somar (ISSAKS; SRIVASTAVA, 1989) uma unidade:

$$
\sum_{\alpha 1=1}^{n 1} \lambda_{\alpha 1}^{C K O}+\sum_{\alpha 2=1}^{n 2} \lambda_{\alpha 2}^{C K O}=1
$$

Essa nova condição para os pesos infere uma modificação da Equação 4.13 onde as médias das duas variáveis são computadas:

$$
Z_{C K O}^{*}(u)=\sum_{\alpha 1=1}^{n 1(u)} \lambda_{\alpha 1}(u) Z_{1}\left(u_{\alpha 1}\right)+\sum_{\alpha 2=2}^{n 2(u)} \lambda_{\alpha 2}(u)\left[Z_{2}\left(u_{\alpha_{2}}-m_{z 2}+m_{z 1}\right]\right.
$$

onde $m_{z 1}$ e $m_{z 2}$ são as médias desagrupadas de $Z_{1}$ e $Z_{2}$ respectivamente.

Considera-se, portanto, que finalmente estas estimativas podem ser avaliadas em função e desvios padrão, que são relativamente mais baixos e homogêneos em setores com maior densidade de amostragem, aumentando bruscamente para a periferia, onde a malha corresponde somente à variável secundária (BARBOSA et al., 2002). Também a variância de co-krigagem é uma forma de avaliar a estimativa, pois a co-krigagem tem menor a variância de krigagem por considerar a covariância cruzada entre amostras da variável secundária e o local onde a variável primária é estimada. Como no caso da variância da krigagem, a variância de co-krigagem age como um indicador da qualidade da geometria das amostras, não avaliando assim a dispersão local dos dados.

\subsection{Estimativas por co-krigagem co-locada}

Quando a variável secundária està muito mais densamente amostrada, apresentando uma alta correlação entre elas. Este fato gera inestabilidade nos sistemas de co-krigagem pelo fato de que a covariância dos dados da variável secundária ser maior que a covariância das variáveis primária e secundária. Entretanto, os dados da variável secundária, próximos ao nó a estimar, filtram a influência dos dados mais distantes como é visto na Figura 4.14. Isto mostra a definição de uma estratégia de busca na qual a vizinhança de estimativa da variável secundária é arbitrariamente reduzida a apenas um ponto.

Para estes casos, a co-krigagem foi simplificada, retendo exclusivamente o dado secundário colocado no local $u$ onde irá ser estimada a variável primário. Este método é conhecida como co-krigagem colocada.

O sistema de cokrigagem co-locada para duas variáveis é uma combinação linear entre 


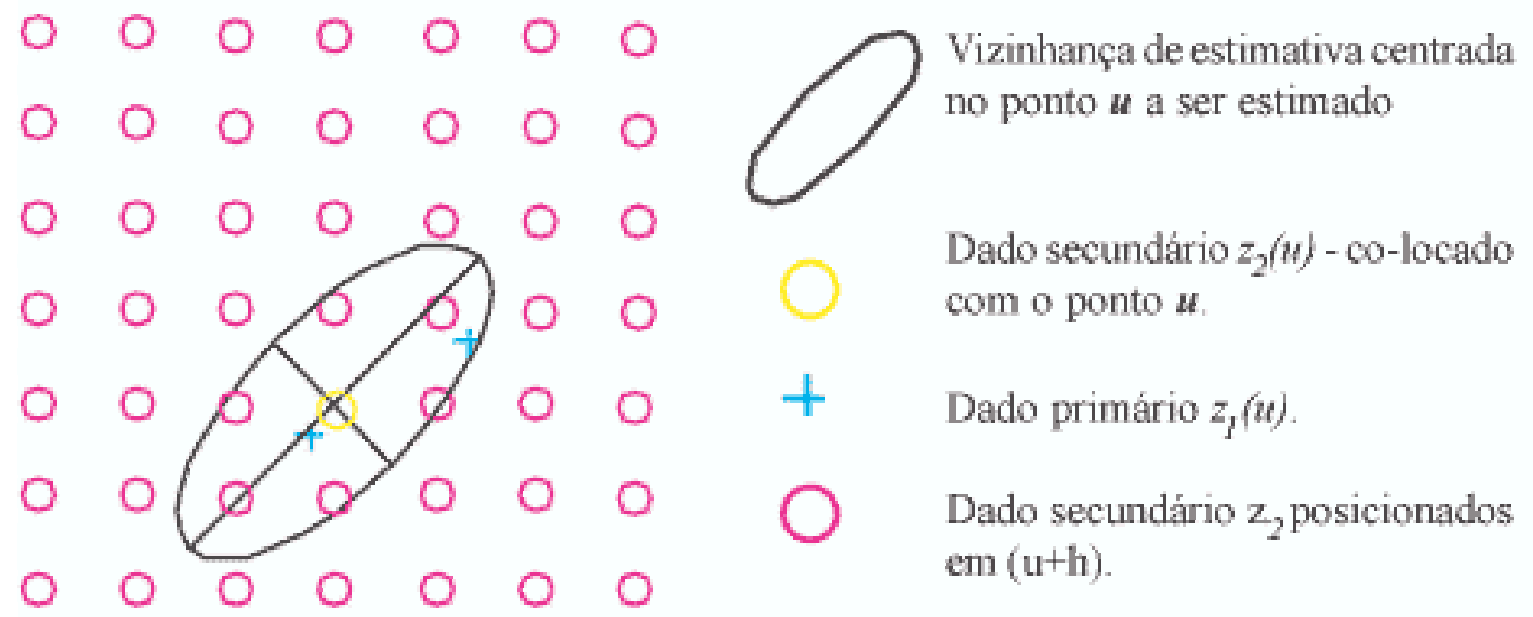

Figura 4.14: Situação hipotética de Co-krigagem colocada.

Situação hipotética, em que apenas o dado secundário co-locado (amarelo) é considerado na estimativa. Os outros dados secundários presentes no elipsóide de busca (vermelhos) não entram na resolução do sistema de Cokrigagem Co-Locada. Fonte: Remacre (2004)

os dados da variável primária e único valor estimado da variável secundária como mostrado na Equação 4.17:

$$
Z_{C K C O 2}^{*}(u)-m_{1}(u)=\sum_{\alpha 1=1}^{n(u)} \lambda_{\alpha 1}(u)\left[Z_{1}\left(u_{\alpha 1}\right)-m_{1}\left(u_{\alpha 1}\right)\right]+\sum_{i=2}^{N} \lambda_{i}(u)\left[Z_{i}(u)-m_{i}(u)\right]
$$

onde: $Z_{C K C O 2}^{*}(u)$ é o dado primário estimado em $u, \sum_{\alpha 1=1}^{n(u)} \lambda_{\alpha 1}(u)$ pesos de krigagem para a variável primária, $Z_{1}\left(u_{\alpha 2}\right)$ dado primário, $m_{1}\left(u_{\alpha 1}\right)$ média do dado primário, $\sum_{i=2}^{N} \lambda_{i}$ pesos de krigagem para a variável secundária colocada, $Z_{i}(u)$ dado secundário, $m_{i}(u)$ média do dado secundário.

Para que a informação secundária esteja disponível exclusivamente no nó onde a variável primária é estimada (co-krigagem co-locada estrita),além das informações disponíveis no nó $u$, também são utilizados os dados secundários colocados como os dados primários disponíveis nos locais $u_{\alpha 1}$ (RIVOIRARAD, 2001 Apud BoEzIO, 2004) .

\subsection{Modelo de Markov 2 (MM2)}

Segundo Shmaryan et. al. (1998) apud Remacre (2004), o modelo de Markov MM2 foi desenvolvido para os casos tem que a variável secundária $Z 2(u)$ é definida em um suporte 
muito maior que a variável primária $Z 1(u)$. Nesses casos, a co-variância $C_{2}(h)$ é muito mais continua que $C 1(h)$ e a co-variância cruzada experimental $C_{12}(h)$ tende a refletir a melhor continuidade de $C_{2}$. Há portanto a necessidade de uma equação para calcular a covariância da variável primária. Esta é expressa em função da variável secundária e de um resíduo independente com valor nulo. Essa é uma característica que normalmente ocorre na prática para tornar independentes as equações das variáveis estandarizadas $Z_{1}(u)$ e $Z_{2}(u)$, é necessário expressar as funções de co-variância como correlograma . Este pode ser escrito como a Equação: (JOURNEL, 1999):

$$
E\left[Z_{1}(u) \mid Z_{2}(u)=Z_{2}, Z_{2}(u)=Z_{2}^{\prime}\right]=E\left[Z_{1}(u) \mid Z_{2}(u)=Z_{2}\right]
$$

$\ldots \forall u, u^{\prime}, Z_{2} Z_{2}^{\prime}$.

Em outras palavras, os dados secundários colocados $Z_{2}(u)$ filtram a influência dos dados secundários mais afastados $Z_{2}\left(u^{\prime}\right)$ conforme mostrado na Figura 4.15, obrigando o sistema a computar somente o dado secundário colocado $Z_{2}(u)=Z_{2}$.

\section{Modelo Markoviano 2 - MM2}

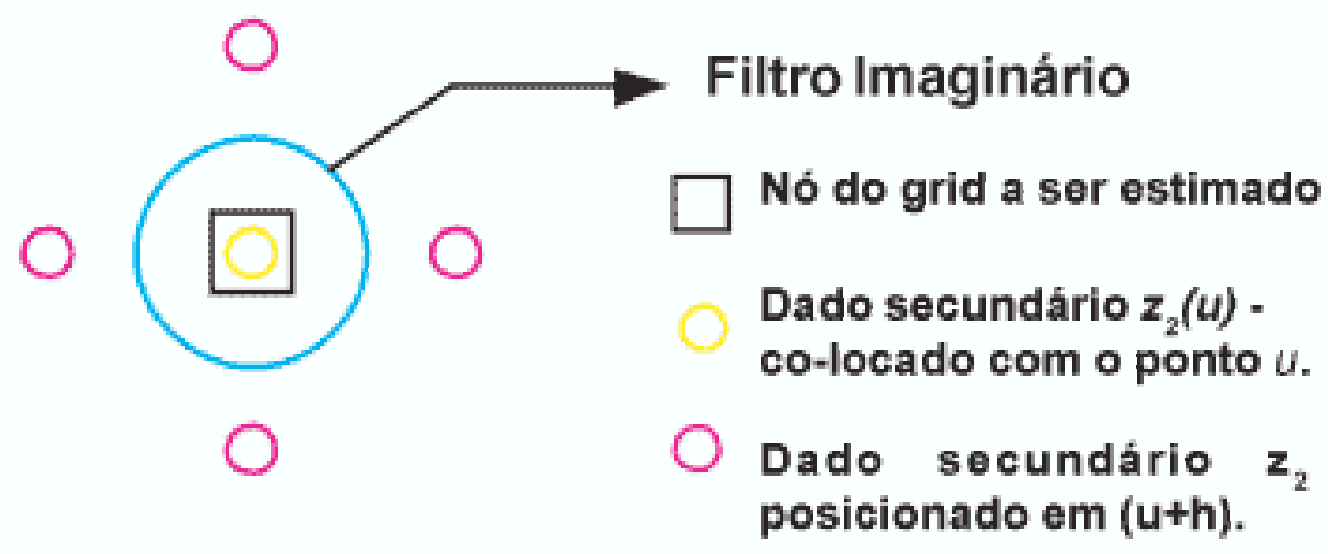

Figura 4.15: Filtro imaginário do modelo de Marckov 2

Fonte:(REMACRE, 2004)

O correlograma cruzado para MM2 pode ser aproximado pela seguinte Equação 4.19 (JOURNEL, 1999): 


$$
\rho_{12}(h)=\rho_{12}(0) \cdot \rho_{2}(h)
$$

onde o correlograma cruzado para $h=0 \rho_{12}(h)$ é igual à multiplicação do correlograma cruzado para $h=0 \rho_{12}(0)$ pelo correlograma da variável primária $\rho_{2}(h)$.

Por motivo da abundância amostral da variável secundária, o correlograma cruzado a partir dessa variável é mais adequado, pois seu ajuste com o maior número de dados é mais preciso, considerando a correlação entre as amostras. O MM2 exige que sejam respeitadas as condições de definição positiva.

$$
\rho_{1}(h)=\rho_{12}^{2}(0) \cdot \rho_{2}(h)+\rho_{12}^{2}(h) \cdot \rho_{R}(h)
$$

O correlograma de $Z_{1}(u)$ pode ser ajustado pela combinação linear do correlograma de $Z_{2}(u)$ mais um correlograma $\rho_{R}(u)$, onde os coeficientes são determindados pelo coeficiente de correlação entre $Z_{1}$ e $Z_{2}$.

Se o gráfico de dispersão entre as duas variáveis (primária e secundária) apresentar os pontos alinhados no entorno de uma reta de $45^{\circ}$, o MM2 é mais adequado.

Para este trabalho, o MM2 é preferido já que a sua hipótese constitutiva é mais adequada, assi como a inferência e modelagem do correlograma cruzado a partir dos dados secundários mais abundantes.

\subsection{Comparativo da krigagem simples a respeito a cokrigagem simples}

As estimativas por krigagem podem não ser ótimas quando analisadas globalmente devido à falta de informações de um atributo. Tipicamente, os valores baixos são superestimados, enquanto os valores altos são subestimados (efeitos de suavização). Outro inconveniente é que a suavização não é uniforme, mostrando-se menor próxima aos dados e aumentando com o afastamento. No entanto, na co-krigagem estes efeitos são melhorados já que as estimativas consideram dois atributos.

A co-krigagem é considerada mais eficaz pelos seguintes razões:

- Avariavel $\frac{N v(N v+1)}{2}$ e o variograma cruzado podem inferir ou juntar dois modelos; 
- O sistema de Co-krigagem, embora longo, pode ser resolvido Neste sentido, pode ser visto o benefício da adição de um modelo e dos esforços computacionais para a aplicação da co-krigagem.

- Essas vantagem podem ser vista na Figura 4.16.
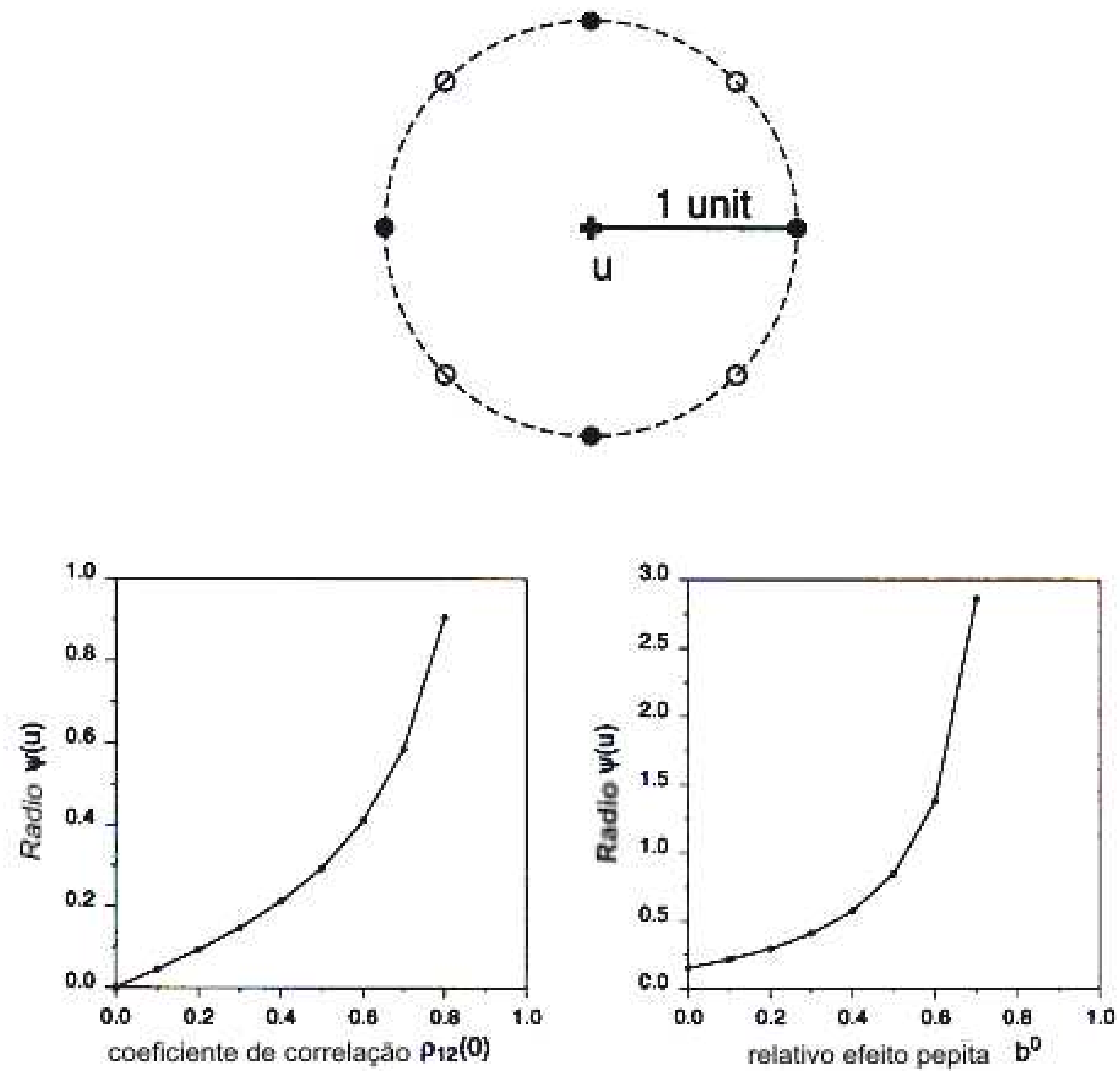

Figura 4.16: Contribuição relativa dos dados secundários (circulo aberto) versus os dados primários (pontos pretos) pela estimativa do cokrigagem de um primeiro atributo na locação $u$.Esta contribuição é medida pelo radio $\psi(u)$ Fonte:

Goovaerts (1997)

A Figura 4.16 mostra um caso isotópico, no qual todas as variáveis são amostradas nos mesmos locais, a co-krigagem apresenta a vantagem de preservar a coerência do estimador (GOOVAERTS, 1997). Isto significa que a estimativa da co-krigagem utilizando uma variável auxiliar $Z_{i} u$ é igual à soma das estimativas de co-krigagem das variáveis $Z_{i} u$, cada uma destas co-krigada em relação as $N_{v}-1$ variáveis restantes. 


\section{Metodologia}

\subsection{Metodologia proposta}

A metodologia proposta nesta dissertação considera diferentes procedimentos de estimativa, tomando como base a litologia CBN (Carbonatito calcítico norte), a qual contém o banco de dados de $P_{2} O_{5}$ das análises das sondagens e $P_{2} O_{5}$ das análises do pó da perfuratriz (desmonte). Essa informação é constituída por comprimentos de furos diferentes, a sondagem tem $5 \mathrm{~m}$ e o desmonte entre $0,5 \mathrm{~m}$ a $24 \mathrm{~m}$. As principais etapas da metodologia s ao:

- (i) Uma extensa compilação dos dados amostrados da área em estudo onde, a partir da análise de histogramas de sondagem e de desmonte, foi delimitada a relação entre os teores médios, como também a relação entre as duas variáveis de $P_{2} \mathrm{O}_{5}$ (sondagem e desmonte), por meio do deslocamento dos pontos sobre uma malha pré-definida.

- (ii) Caracterização da variável espacial e estimativa por krigagem ordinária da variável $\mathrm{P}_{2} \mathrm{O}_{5}$ individualmente, tanto de sondagem como de desmonte. No caso do desmonte realiza-se a correção da variância por meio do processo de mudança de suporte amostral.

- (iii) Um requisito indispensável para a aplicação da co-krigagem é que a variável secundária esteja colocada em todos os pontos. Para isto foi estimada por krigagem ordinária a variável de $P_{2} O_{5}$ (desmonte) em todos os pontos a serem estimados. Em seguida foi modelada a covariância do $\mathrm{P}_{2} \mathrm{O}_{5}$ por meio da hipótese do MM2.

- (iv) Baseado na abundância da variável secundária de $P_{2} O_{5}$ (desmonte), de mais fácil modelagem direta, procedeu-se à implantação da co-estimativa da variável $P_{2} O_{5}$ (sondagens), considerando que a variável de $\mathrm{P}_{2} \mathrm{O}_{5}$ (desmonte) foi adaptada como informação secundária por krigagem. Isso ocorre ao aplicar-se a co-estimativa no modelo pré-definido do planejamento de longo prazo. 
- (v) Os planos de curto prazo são criados por meio de um processo interativo, de acordo com os objetivos operacionais e combinações dos teores do minério. Isto com o intuito de atingir os requisitos da blendagem e maior controle na alimentação do minério à usina de beneficiamento. O critério de seleção de áreas é realizado respeitando as variáveis operacionais de mistura e áreas prioritárias para a lavra, condições geotécnicas já incluídas no planejamento de longo prazo e objetivos de produção e controle de minério.

\subsubsection{Mapeamento de atividades}

Assim como foi apresentado no capitulo 2, o sistema de mapeamento de informação (IDEFO) permite de uma forma gráfica representar uma seqüencia de atividades. Embora complexo, esse sistema pode ser subdividido em seqüências $\left(a_{0} \ldots . . a_{n}\right)$. Neste sentido, no diagrama da Figura5.1 são modeladas todas as atividades.

Conforme é mostrado neste diagrama, na entrada de dados (setas da esquerda), na saída dos dados (setas da direita), no sistema que realiza a atividade (setas de baixo), e nos controles necessários ou exigências de cada atividade (setas de cima), contribui no entendimento da seqüencia de atividades para atualizar do modelo de curto prazo (MPC) da atividade $\left(\mathrm{A}^{*} 3\right)$. Todo este mecanismo por atividade, desde o planejamento de longo prazo até a programação operacional, geram saídas finais de teores e volumes ajustados, ou seja, blocos de estéril e minério (porcentagem do minério). Assim também, na atividade $\left(A^{*} 4\right)$ é usada a ferramenta de programação operacional o que permite atingir os objetivos deste trabalho.

Por tanto, esta atualização será exexutada de forma dinâmica e focando atingir objetivos previstos na operação, tornando-se um procedimento automatizado e práticos. A programação operacional semanal considerará as informações operacionais como parte essencial para que os planos executáveis que reflitam melhor a informação do conteúdo do minério. 


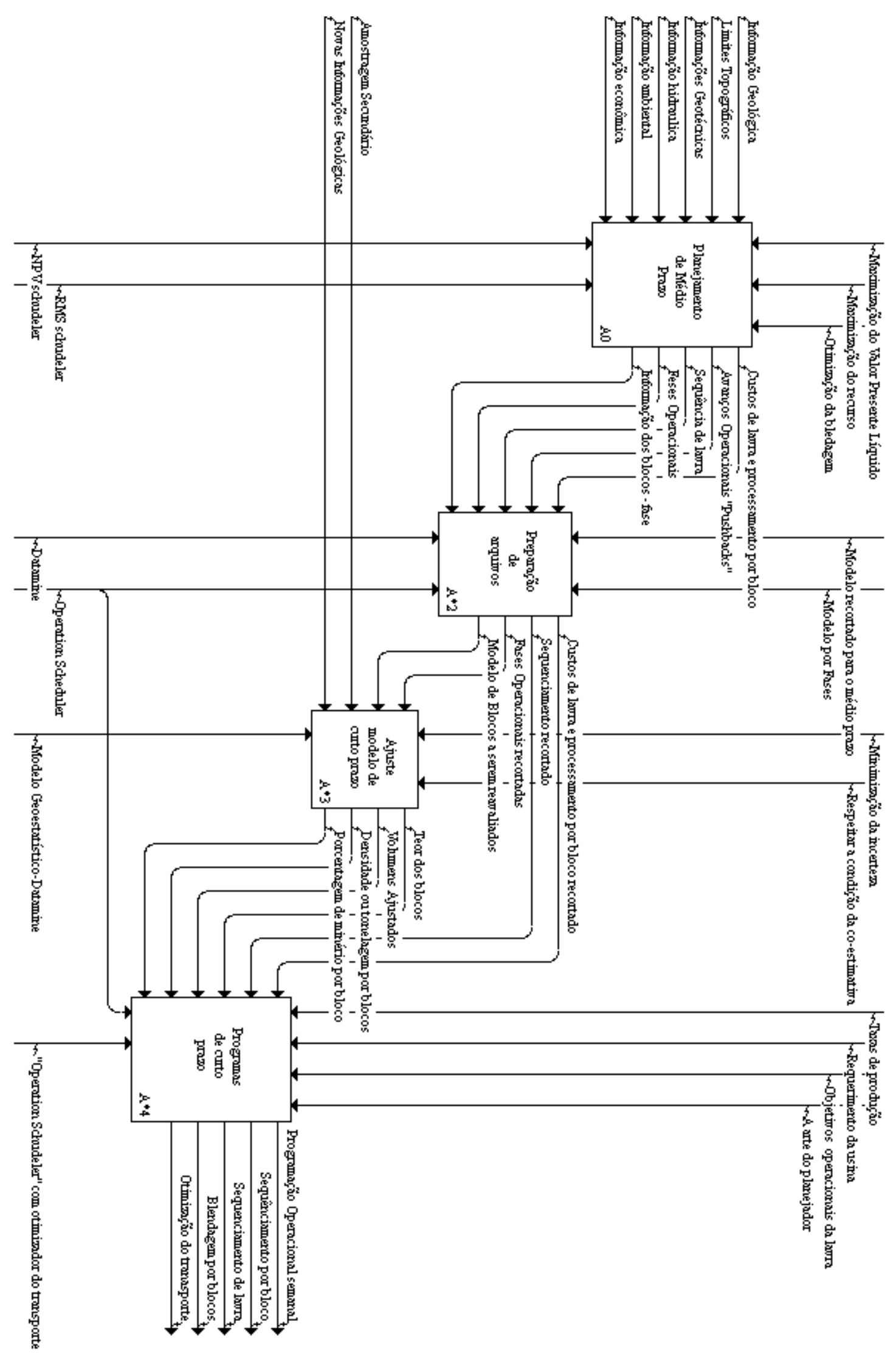

Figura 5.1: Mapeamento da aplicação da proposta deste trabalho (Planejamento Médio prazo Prazo - Planejamento de Curto Prazo). 


\subsection{Localização da mina em estudo}

O complexo mineiro de Cajati (Bunge Fertilizantes S.A.) está localizada no Vale do Ribeira, a Sudeste da Capital do Estado de São Paulo, a uma distância da cidade de São Paulo é de $229 \mathrm{~km}$ e o acesso ao monicipio de Cajati se dá pela $\mathrm{Km}$ 488,5 da rodovia Régis Bitencourt (BR-116)conforme mostrado Figura 5.2.
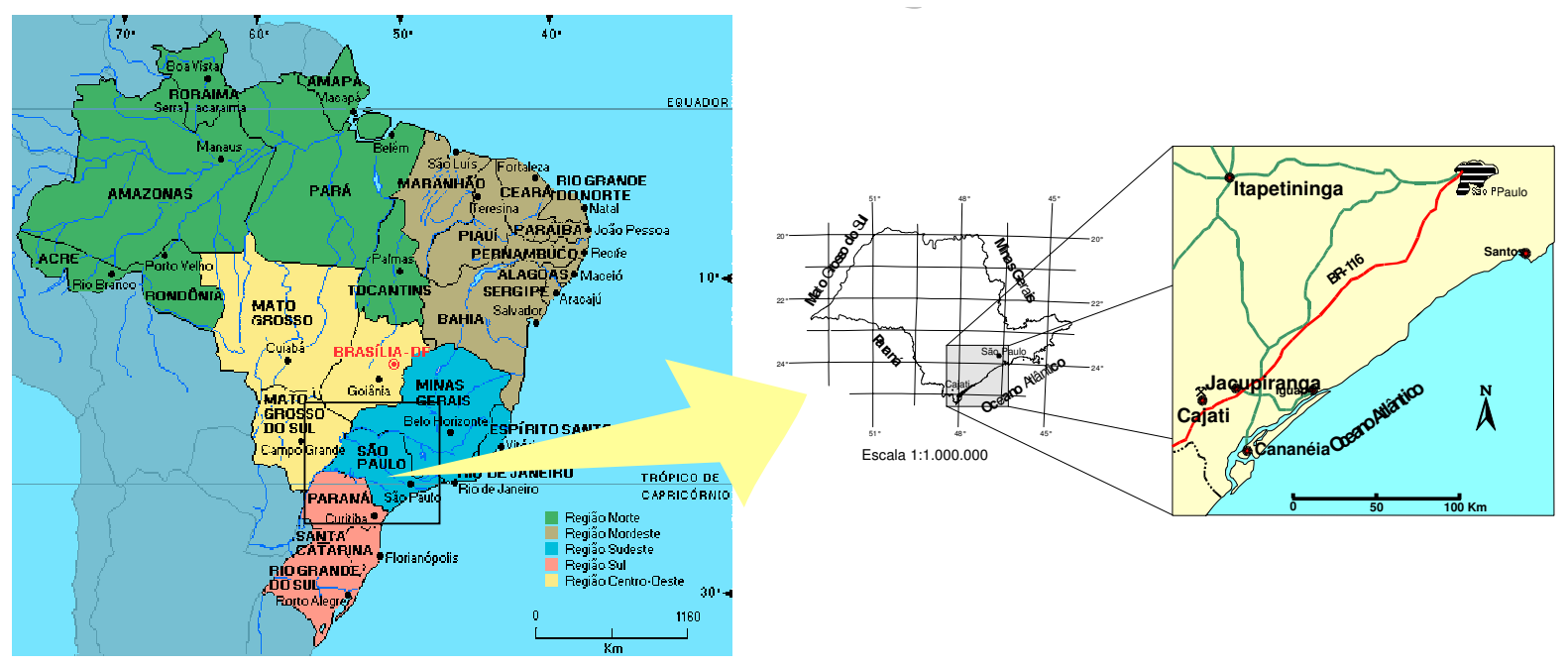

Figura 5.2: Localização do complexo mineiro.

\subsection{Geologia Regional e Local}

Esse lugar é constituída por rochas alcalinas, formado por uma formação denominado complexo Ultramáfico-Carbonatítico de Jacupiranga (BARROS, 2001). Este Complexo de exibe uma forma ovalada, com 10,5 x 6,7 km, orientada segundo NNW, encontrando-se encaixada em rochas pré-Cambrianas do Grupo Açungi, com granodioritos ao norte e mica e xistos ao centro e ao sul. O mapa geológico do complexo, segundo (GERMANn et al, 1987 apud BARros, 2001). Como pode ser observado na Figura 5.3.

A geologia local é constituída por rochas alcalinas englobadas sob a designação genérica de “complexo Ultramáfico-Carbonatítico de Jacupiranguito, sendo uma ocorrência clássica de rochas alcalinas. Caracterizado como um complexo não saturado que está próximo à Bacia do Paraná, formada em uma zona de intensa atividade magmática terciária e que inclui diversas ocorrências de material carbonatítico. A Figura 5.4 mostra definidas as diferentes litologias . 
(A)

(B)
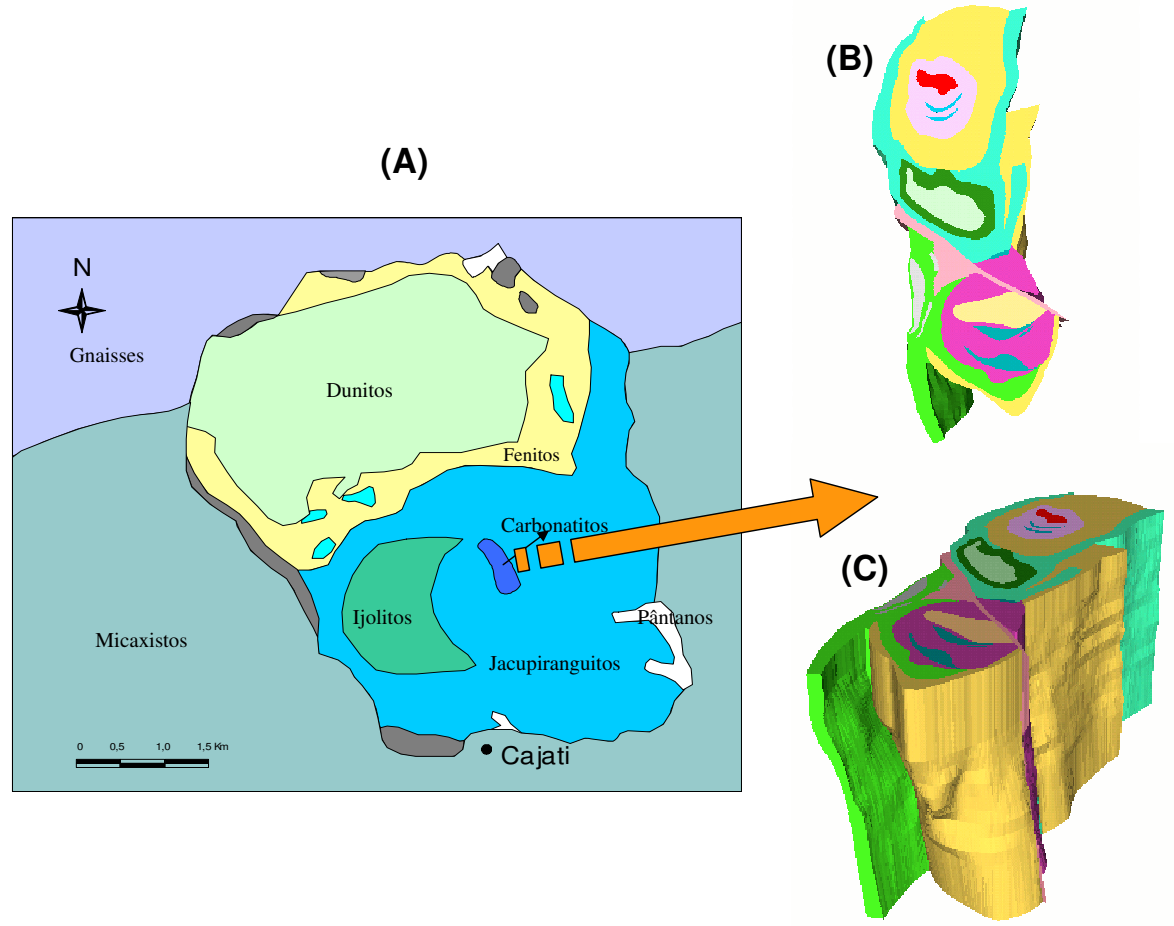

Figura 5.3: Complexo Alcalino de Jacupiranga

(A) Geologia regional, (B) Geologia local em 2D (B) Geologia local em 3D. Fonte: Saito; Bettencourt, et al, (2004) apud Faria (2004).

\begin{tabular}{|c|l|c|c|}
\hline & \multicolumn{1}{|c|}{ DESCRIÇÃO } & ABREV & COR \\
\hline $\mathbf{1}$ & Carbonatito Periférico Sul & CPS \\
\hline $\mathbf{2}$ & Carbonatito Calcítico Sul & CCS \\
\hline $\mathbf{3}$ & Caronatito Oxidado & COX \\
\hline $\mathbf{4}$ & Foscorito Sul & FCS \\
\hline $\mathbf{5}$ & Zona de Falha & ZFA \\
\hline $\mathbf{6}$ & Carbonatito Intermediário & CBI \\
\hline $\mathbf{7}$ & Carbonatito Foliado & CBF \\
\hline $\mathbf{8}$ & Carbonatito Branco & CBR & \\
\hline $\mathbf{9}$ & Carbonatito Norte & CBN & EST \\
\hline $\mathbf{1 0}$ & Foscorito Norte & FCN \\
\hline $\mathbf{1 1}$ & Carbonatito Dolomítico & DOL \\
\hline $\mathbf{1 2}$ & Xenólitos & Estéril & XEN \\
\hline $\mathbf{0}$ & & \\
\hline
\end{tabular}

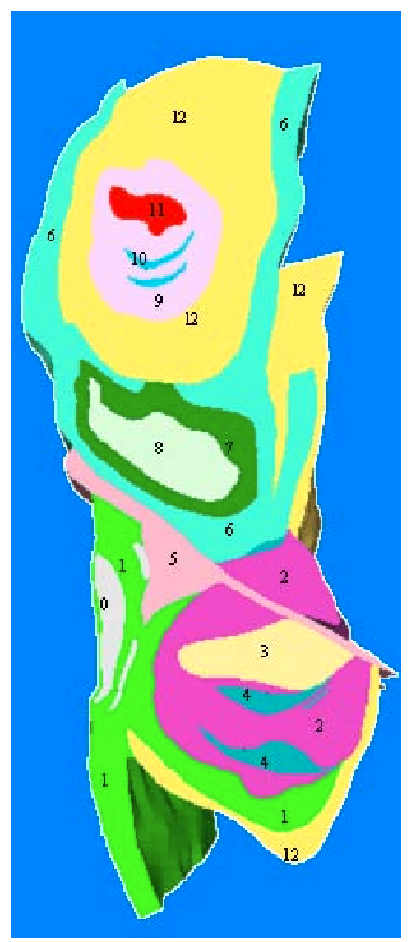

Figura 5.4: Litologias do complexo de Cajati.

Fonte: Banco de dados da área de planejamento 


\subsection{Histórico}

A produção da Mina de Cajati iniciou-se em 1943 com a lavra de minério residual com altos teores de $\mathrm{P}_{2} \mathrm{O}_{5}$, que consistia basicamente em apatita, magnetita e alguns argilominerais, todos eles provenientes da dissolução e lixiviação dos minerais carbonatados de rocha.

A base econômica da mina estava centrada na apatita como principal e praticamente único minério, a mina começou ter uma transformação na década de 60, com a perspectiva de esgotamento do material residual. Nos níveis inferiores deste matetial, se encontrava o que, até então, era considerado como protominério, constituído por "carbonatito são", com teores médios em torno de 5,5 por cento de $\mathrm{P}_{2} \mathrm{O}_{5}$.

A partir de 1969, o carbonatito são assumiu a condição de minério, através de alterações dos processos tecnológicos de beneficiamento, que permitiram a separação física dos minerais por meio do processo de flotação.

Em 1972, o estéril de calcário da usina de concentração de apatita, que possui um teor de $\mathrm{MgO}<4,50$ por cento, passou a ser aproveitado como matéria prima para a fabricação de cimento.

Com a crise na indústria de fertilizantes, no final da década dos anos 80, foram desenvolvidas aplicações industriais para os subprodutos, conseguindo-se mercados para os seguintes produtos:

- Ácido fosfórico refinado para a indústria farmacêutica e alimentícia, em 1987;

- Massa de revestimento, em 1989;

- Fosfato bicálcico para a alimentação de animais, em 1990;

- Calcário para corretivos de solos;

- Magnetita e areia de rochas para a construção civil.

\subsection{Fluxograma dos processos de beneficiamento}

O processo de recuperação do foscálcio (produto comercial) é representado pela Figura 5.5, no qual o único produto que é adquirido de provedores externos é o enxofre que, depois de um processo industrial fundição, forma o ácido sulfúrico. Este reagindo com o 
concentrado de apatita proveniente da usina, gera o ácido fosfórico do qual uma parte é vendida como produto e a outra parte, reagindo com o calcário forma o foscálcio, tanto em pó como a granel. Entre os outros produtos gerados de acordo com seu conteúdo de magnésio são:

- gesso (para diversos usos);

- cimento (cimento Cimpor);

- corretivo de solos (uso agrícola);

- agregados (para construção de rodovias).

\section{Fluxograma de Operações}

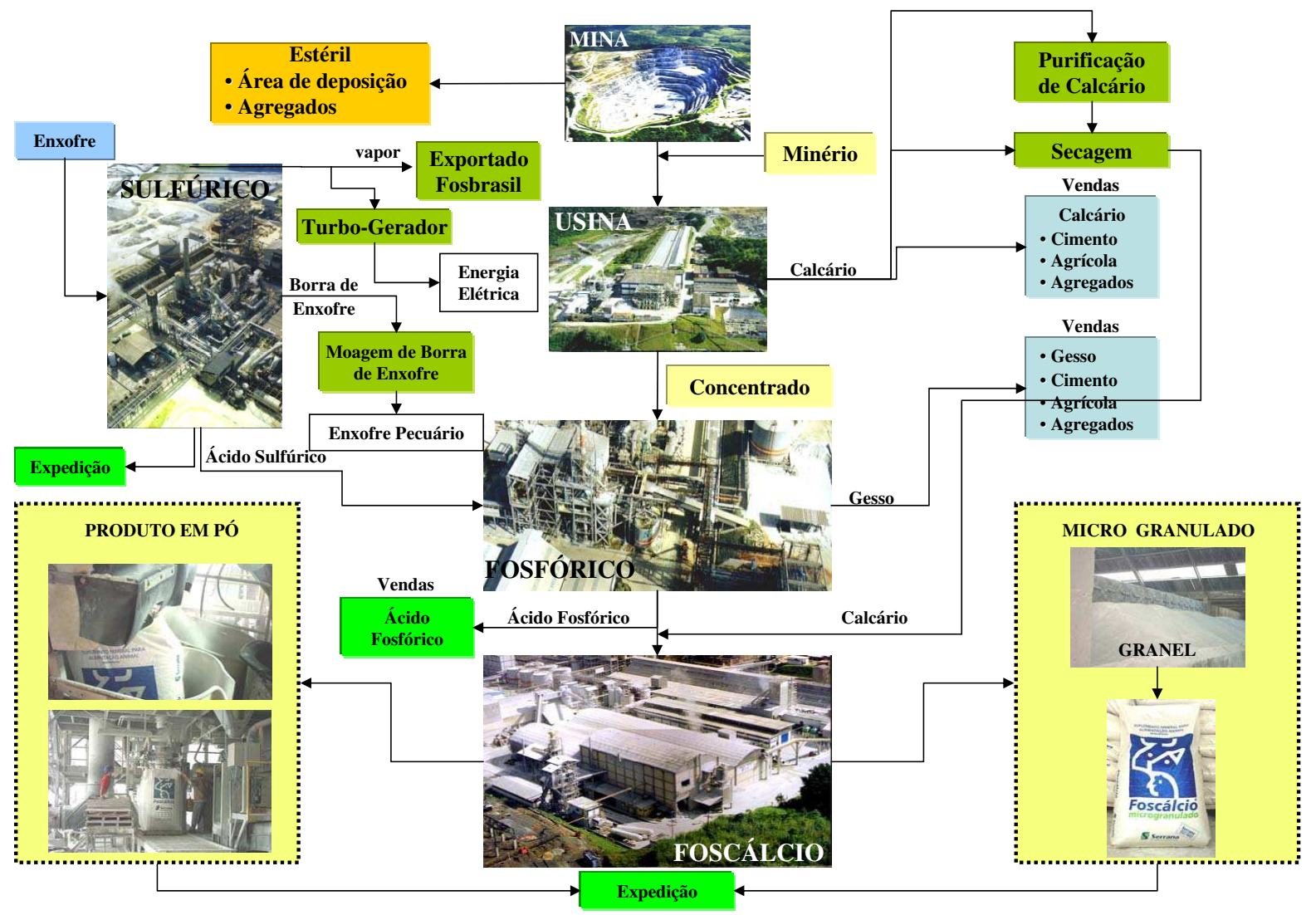

Figura 5.5: Fluxograma do processo de beneficiamento da apatíta. Fonte: Faria (2004) 


\subsection{Análise e estimativa da incerteza geológica}

Neste estudo a carência de informação de sondagens em alguns domínios geológicos faz com que não se tenha uma confiabilidade nos teores de óxidos de interesse, devido à impossibilidade de estimá-los com técnicas geoestatísticas. Estes setores foram estimados pelo método inverso do quadrado da distância e por este motivo observam-se as diferenças entre os teores in situ e os lavrados. Assim, analisa-se a forma de acrescentar a informação dos modelos secundários provenientes da análises químicas do pó dos furos de desmonte, já que estes representam, em alguns domínios, a única informação.

\subsubsection{Localização das amostras de teor de $\mathrm{P}_{2} \mathrm{O}_{5}$ do desmonte e sondagem}

Os mapas de localização das amostras são importantes para verificar a disposição espacial e revisar a ocorrência de zonas preferencialmente amostradas e a distribuição dos teores. A Figura 5.6 apresenta o mapa de localização no plano das sondagens quanto aos furos de desmonte.

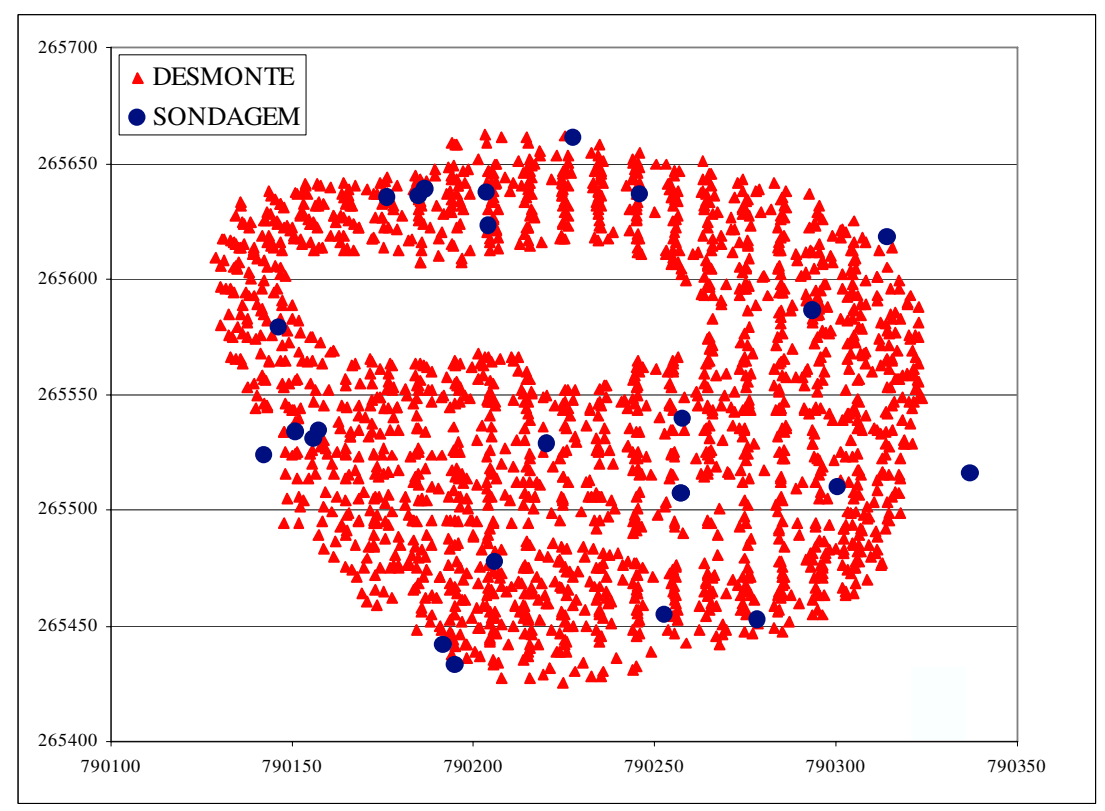

Figura 5.6: Furos de sondagens e amostras de pó-de-perfuratriz com os furos de sondagem no plano. 


\section{Resultados}

\subsection{Banco de dados da análise do pó do desmonte}

O banco de dados é composto por 1925 amostras, adquiridas pela amostragem do pó provenientes dos furos para desmonte com $7,5 \mathrm{~cm}$ de diâmetro. Das amostras contidas no banco de dados, 2 amostras foram descartadas por terem um comprimento menor de 2 metros e estarem incompletas nos campos de teores. A Figura 6.1 apresenta uma distribuição de freqüências, a qual dá uma idéia da variabilidade dos comprimentos das amostras de pó.

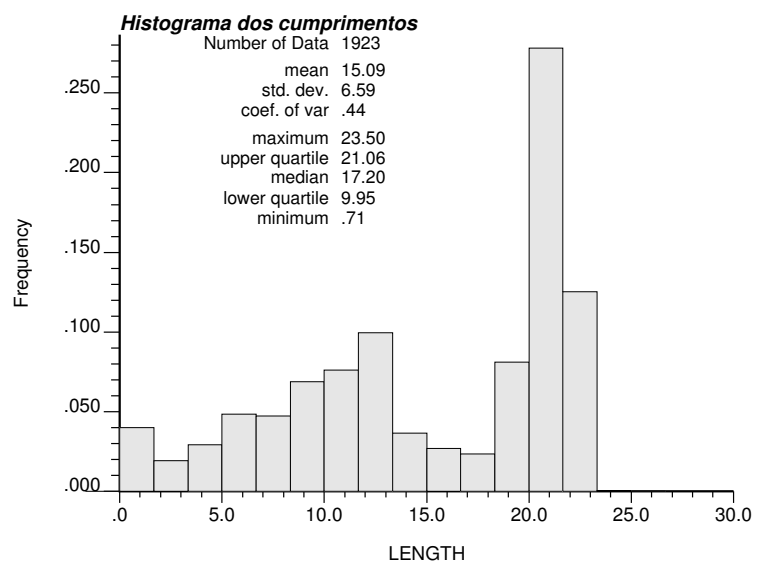

Figura 6.1: Histograma dos comprimentos dos furos de desmonte

Este mesmo banco de dados é composto por amostras de $P_{2} O_{5}$, obtidas através de uma análise química mineralógica. A Figura 6.2 apresenta uma distribuição normal dos dados. 


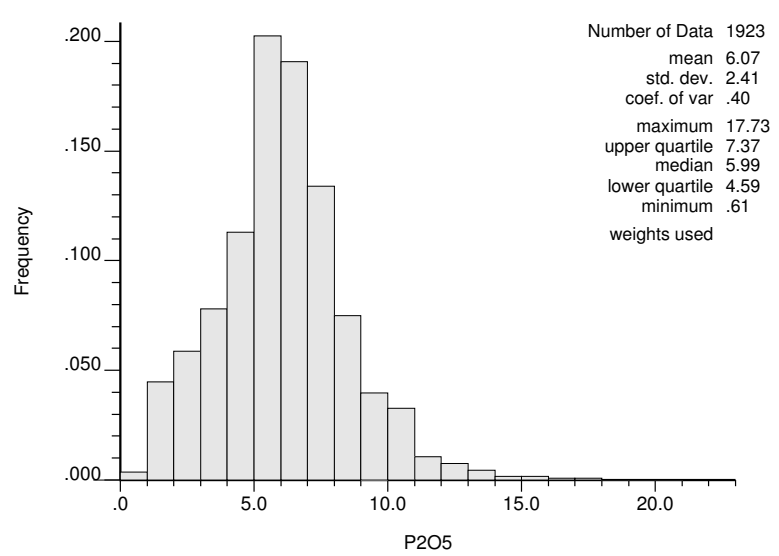

Figura 6.2: Histograma do $\mathrm{P}_{2} \mathrm{O}_{5}$ proveniente do pó do desmonte

\subsubsection{Análise exploratória dos dados de desmonte e sondagem por bancadas}

A primeira alternativa para incorporar a informação proveniente dos furos de desmonte com as sondagens foi juntar os dois bancos num só banco de dados, para o que foi necessário, inicialmente analisar os histogramas das médias agrupadas e desagrupadas do teor de $P_{2} O_{5}$ por bancada para ver se existe uma relação entre as duas informações e assim agrupá-las, embora a diferença de comprimentos de cada banco de dados seja distinta.

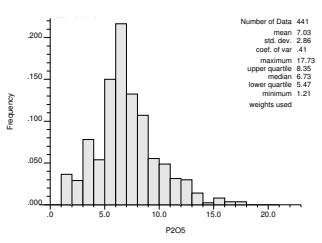

(a)

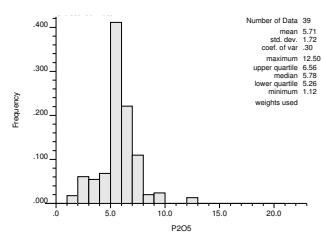

(b)

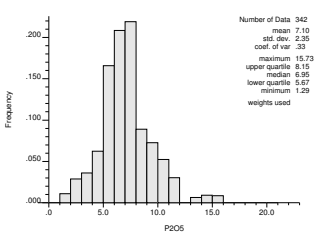

(c)

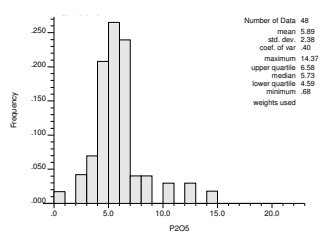

(d)

Figura 6.3: Comparativos entre os níveis -30 a 10

Do nivel -30 a -10. ((a) desmonte, (b) sondagem) e do nivel -10 a 10 ((c) desmonte, (d) sondagem).

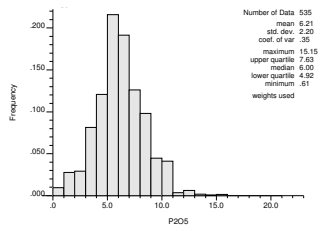

(a)

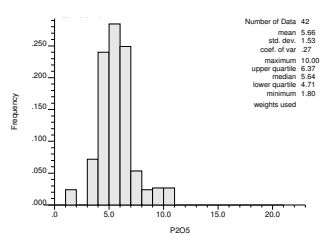

(b)

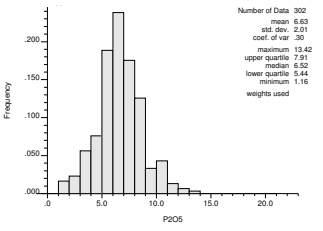

(c)

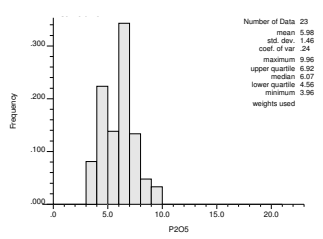

(d)

Figura 6.4: Comparativos entre os níveis 10 a 50

Do nivel 10 a 30 ((a) desmonte, (b) sondagem) e do nivel 30 a 50. ((c) desmonte, (d) sondagem). 


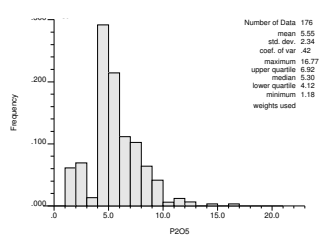

(a)

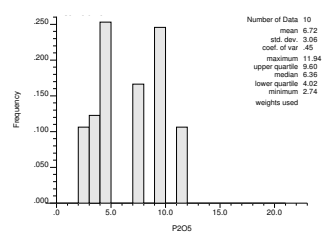

(b)

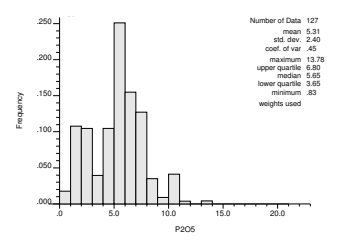

(c)

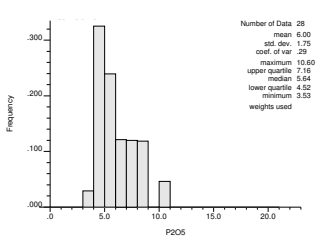

(d)

Figura 6.5: Comparativos entre os níveis 50 a 100

Do nivel 50 a 70 (a) desmonte, (b) sondagem e 70 a 100. (c) desmonte, (d) sondagem.

Os comparativos dos dados entre os níveis -30 a 100 (englobando todos os níveis) são mostrados nas Figuras 6.6 a (agrupados) e 6.6 b (desagrupados)

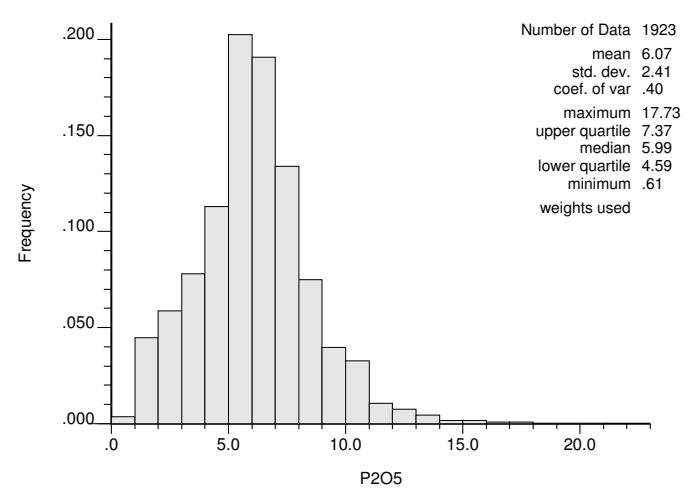

(a)

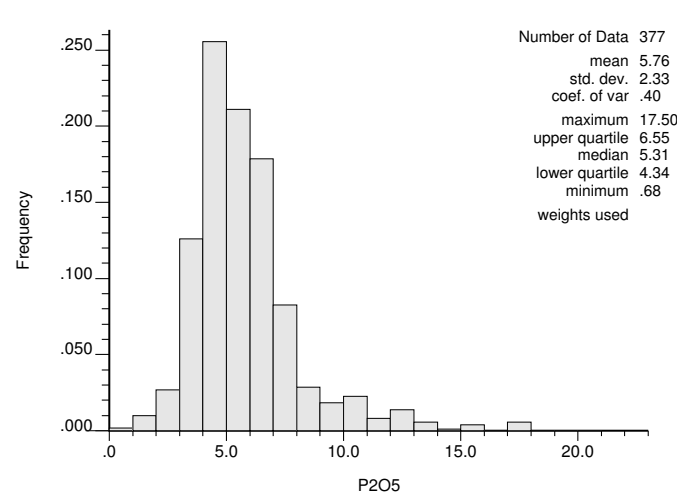

(b)

Figura 6.6: Comparativos entre os níveis -30 a 100

(a)desmonte, (b)sondagem

O resumo da análise estatística entre os níveis -30 a 100 é apresentado na Tabela 6.1.

Desta forma, de acordo com o levantamento estatístico, conclui-se que não é possível misturar as informações de sondagem e desmonte de forma direta pelo fato de terem diferentes teores médios, tanto nas bancadas como no global (Tabela 6.2), o que pode ser atribuído à diferença da metodologia de amostragens.

\subsubsection{Mudança do suporte amostral}

O tamanho de blocos escolhido para avaliar a incerteza em torno das estimativas foi de 10 X 5 m. Este tamanho de blocos foi determinado visando uma boa discretização da área (com respeito às variações locais) e uma perda relativamente pequena de variância devido à mudança de suporte e também pela praticidade operacional em relação ao tempo de processo e armazenamento computacional. Portanto, a variância deve ser corrigida por meio do processo de mudança de suporte (Capítulo 3). Para isto, foram utilizadas duas rotinas desenvolvidas por Deutsch, 1999: gammabar.exe (Glib). 


\begin{tabular}{|c|c|c|c|c|c|}
\hline Tipo & Nível & N. Amostras & Média & \multicolumn{2}{|c|}{$\begin{array}{c}\text { Desv.padrão Coef. } \\
\text { Var }\end{array}$} \\
\hline Desmonte & $-30 a-10$ & 441 & 7.03 & 2.86 & 0.40 \\
\hline Sondagem & $-30 a-10$ & 39 & 5.71 & 1.32 & 0.30 \\
\hline Desmonte & $-10 a 10$ & 342 & 7.10 & 2.35 & 0.33 \\
\hline Sondagem & $-10 a 10$ & 48 & 5.89 & 2.58 & 0.40 \\
\hline Desmonte & 10a30 & 535 & "6.21 & 2.20 & 0.35 \\
\hline Sondagem & 10a30 & 42 & 5.66 & 1.53 & 0.27 \\
\hline "Desmonte & $30 \mathrm{a} 50$ & 302 & 6.63 & 2.01 & 0.30 \\
\hline Sondagem & $30 \mathrm{a} 50$ & 23 & 5.96 & 1.46 & 0.31 \\
\hline Desmonte & $50 \mathrm{a} 70$ & 176 & 5.56 & 2.34 & 0.42 \\
\hline Sondagem & $50 \mathrm{a} 70$ & 10 & 6.72 & 3.06 & 0.45 \\
\hline Desmonte & $70 a 100$ & 127 & 7.03 & 2.40 & 0.45 \\
\hline Sondagem & 70a100 & 28 & 6.00 & 1.75 & 0.29 \\
\hline
\end{tabular}

Tabela 6.1: Resumo de estatísticas por níveis.

\begin{tabular}{|l|l|l|c|c|r|}
\hline Tipo & Nível & N. Amostras & Média & Dv.Padrão & Coef. Var \\
\hline Desmonte & $-30 a 100$ & 1293 & 6.07 & 2.41 & 0.40 \\
\hline Sondagem & $-30 a 100$ & 373 & 5.78 & 2.33 & 0.40 \\
\hline
\end{tabular}

Tabela 6.2: Resumo total das estatísticas por níveis

Assim, para blocos de 10 X $5 \mathrm{~m}$, a variância de dispersão calculada a partir do variograma é 0,005209. e o fator de redução da variância, f é 0,9363.

A Figura 6.7 seguinte mostra a correção do suporte amostral:

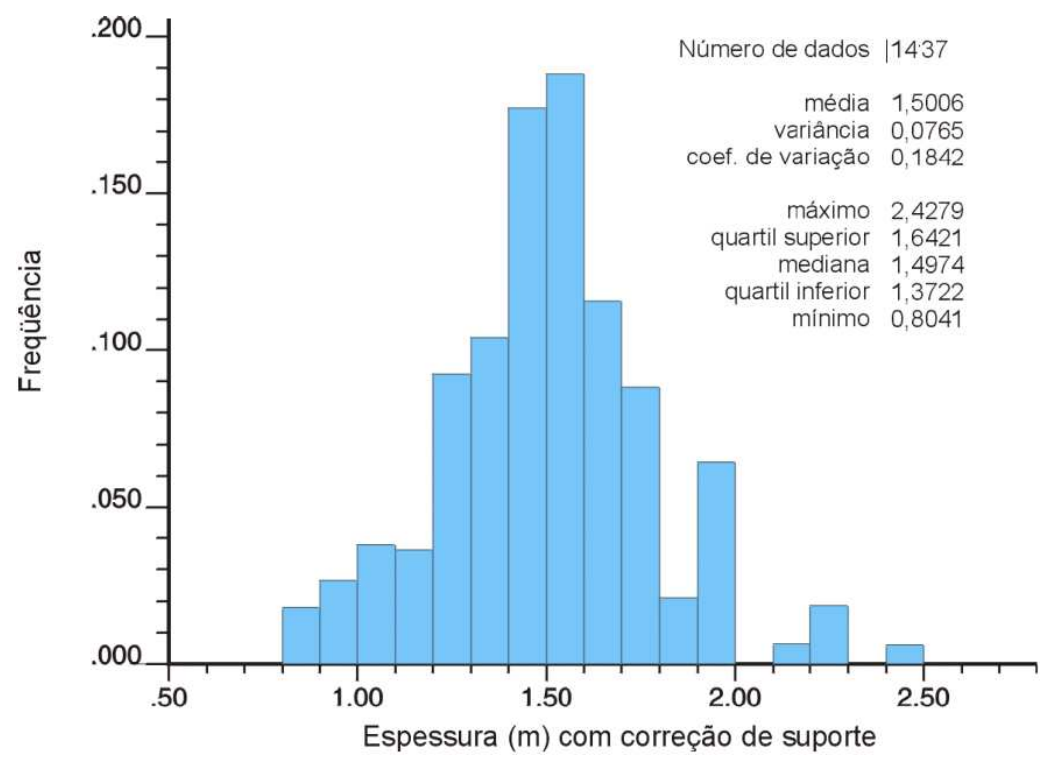

Figura 6.7: Histograma da mudança de suporte amostral do modelo krigado 
$\operatorname{Var}($ original - desagrupada $)=0,814 \Longrightarrow \operatorname{Var}($ corregida $)=0,765$.

\subsection{Análise da continuidade espacial do teor de $\mathrm{P}_{2} \mathrm{O}_{5}$ dos furos de desmonte}

Com o intuito de visualizar a correlação dos dados dos furos para desmonte, gerou-se um variograma direcional que representa a correlação das amostras. Após esta primeira análise foi identificada a direção de maior continuidade representada na Figura 6.8 (a). O variograma de maior continuidade foi indentificando na direção 86 graus, utilizando-se os seguintes parâmetros: passo $=6,0 \mathrm{~m}, \operatorname{subpasso}=2,0 \mathrm{~m}$ e largura de banda $=2,0 \mathrm{~m}$. Na Figura 6.8 (b) utilizou-se a informação dos furos de sondages pelo fato de não haver suficiente amostras na vertical.

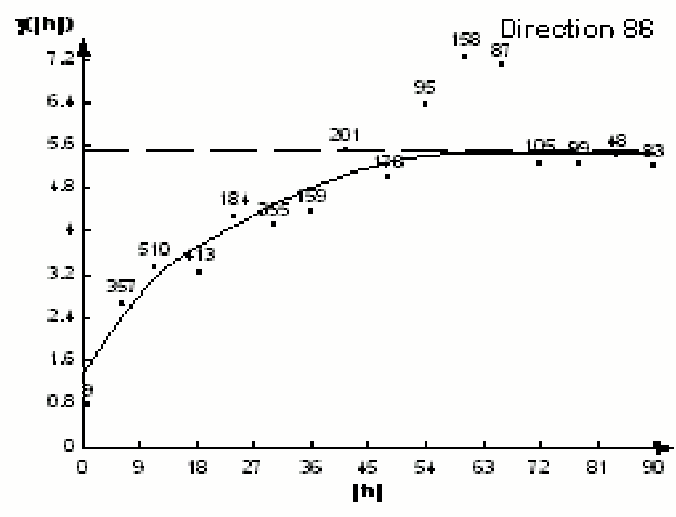

(a)

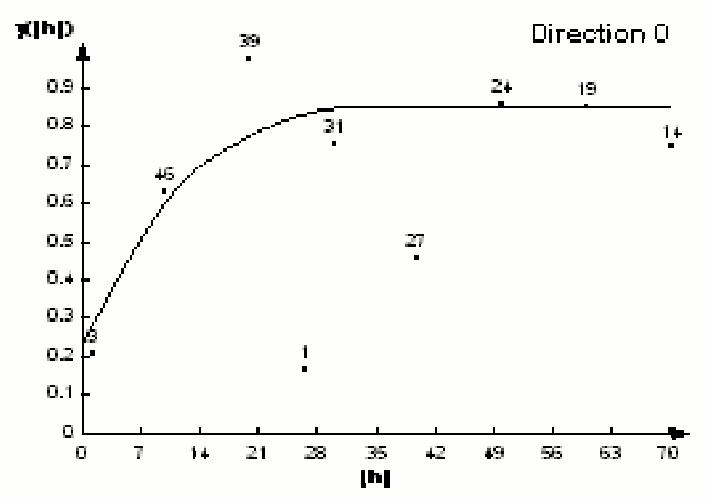

(b)

Figura 6.8: Variograma direcional na direção de 86 graus

(a) variograma horizontal na direção de maior continuidade, (b) variograma vertical com furos de sondagens.

A validação cruzada foi realizada para determinar a aderência do modelo ajustado, e o espalhamento do erro. Esses são mostrados nas Figuras 6.9 (a) e 6.9 (b) respectivamente.

A Equação 6.1 é o resumo dos parâmetros do ajuste do variograma na horizontal.

$$
\gamma_{2}(h)=1.104+1.584 \operatorname{Sph}\left(\frac{N_{86}}{19}+\frac{N_{172}}{13}\right)+2.496 \operatorname{Sph}\left(\frac{N_{86}}{38}, \frac{N_{172}}{23}\right)
$$

A Figura 6.10 mostra o modelo krigado, utilizando-se unicamente os furos de desmonte e os alcances do elipsóide de busca da krigagem a 90 por cento do alcance do variograma. A Figura 6.10 b mostra a variância da estimativa. 


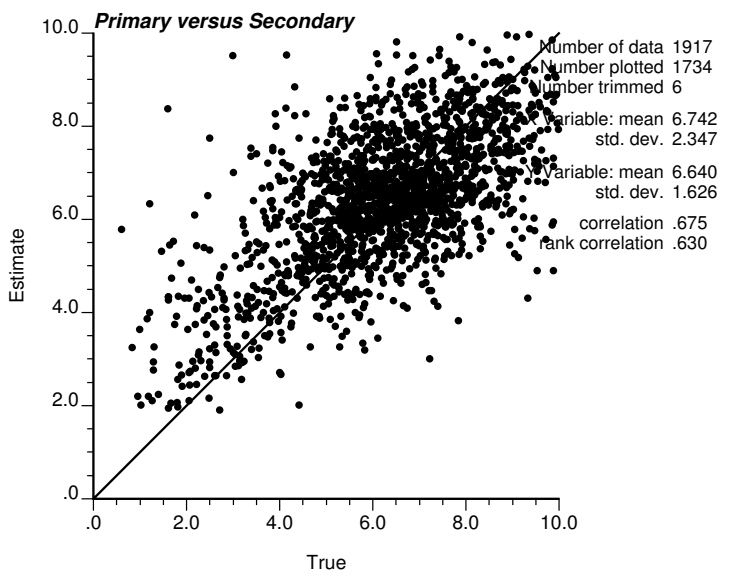

(a)

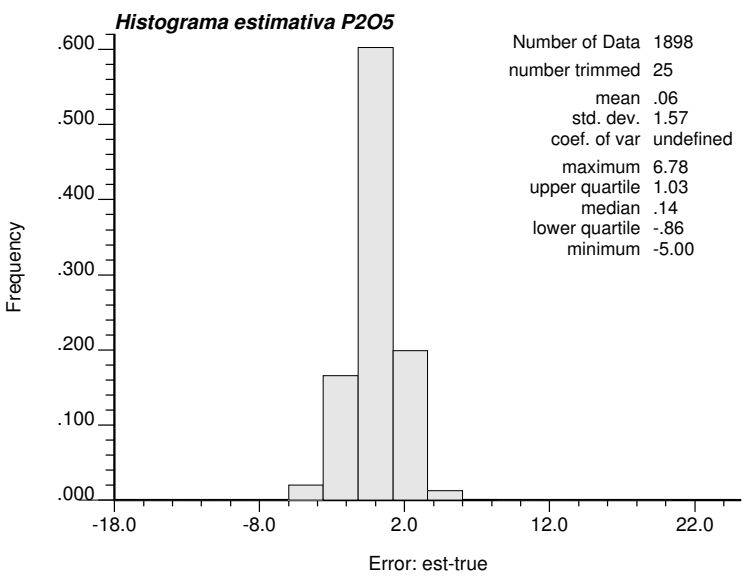

(b)

Figura 6.9: Validação cruzada e erro.

(a) Histograma e Espalhamento da validação cruzada do variograma na direção de 86 grãos, (b) erro da estimativa.

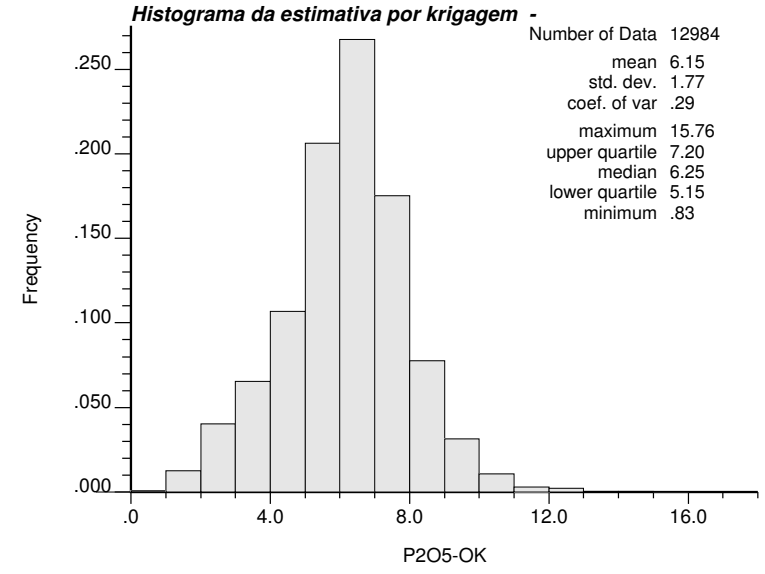

(a)

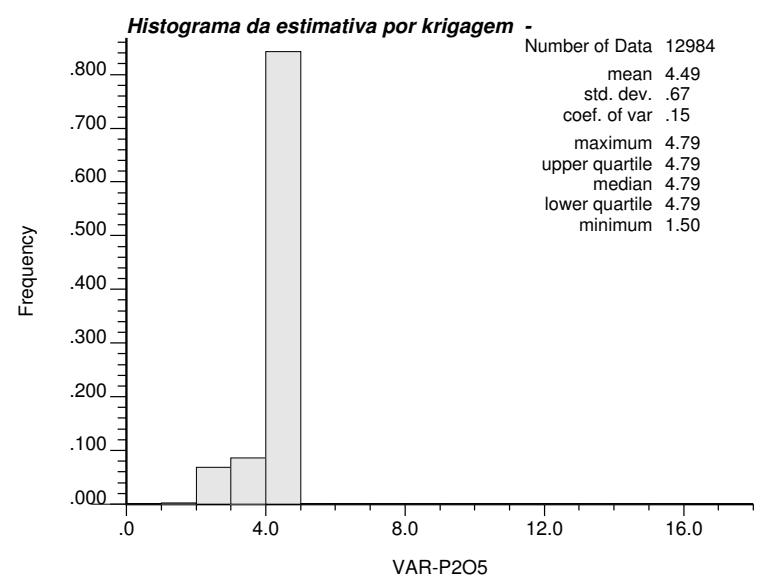

(b)

Figura 6.10: Histogramas do modelo krigado usando os furos de desmonte (a)histograma do modelo de blocos krigado, (b)histograma da variância da estimativa.

No processo de validação da estimativa utilizou-se a variância da estimativa de krigagem, a análise de deriva que representa comparativos em fatias de $10 \mathrm{~m}$, os quais relacionam por meio de curvas os dados originais e blocos estimados como mostrados na Figura 6.11(A) na direção $X$, e na Figura 6.12 (B) na direção $Z$.

A variância de interpolação mostra un intervalo de 1 a 16 de acordo ao mostrado na Figura 6.13(a), Figura 6.13(b), Figura 6.13(c), e Figura 6.13(d) e o método do slope mostra a categoria das estimativas nas Figura 6.14(a), Figura 6.14(b), Figura 6.14(c) e Figura 6.14(d). 
Todos estes comparativos são realizados em função das bancadas, nas quais destinguise as diferença tanto na configuração dos blocos estimados como nas variâncias das estimativas.

O método de Slope esta baseado na equação 6.2 de regressão do programa "Kriging Park" (Programa desenvolvido no laboratorio de planejamento e operação de lavra LAPES-URFGRS), considerando o seguinte critério:

$p$ medidos $>=80$ indicados $=0.60-0.80$ inferidos $<0.60$

$$
p=\frac{\operatorname{Cov}\left[Z_{v}, Z_{v}^{*}\right]}{\operatorname{Cov}\left[Z_{v}, Z_{v}^{*}\right]-u}
$$

onde $Z_{v}^{*}$ é o valor estimado e $Z_{v}$ é o valor real dos dados.

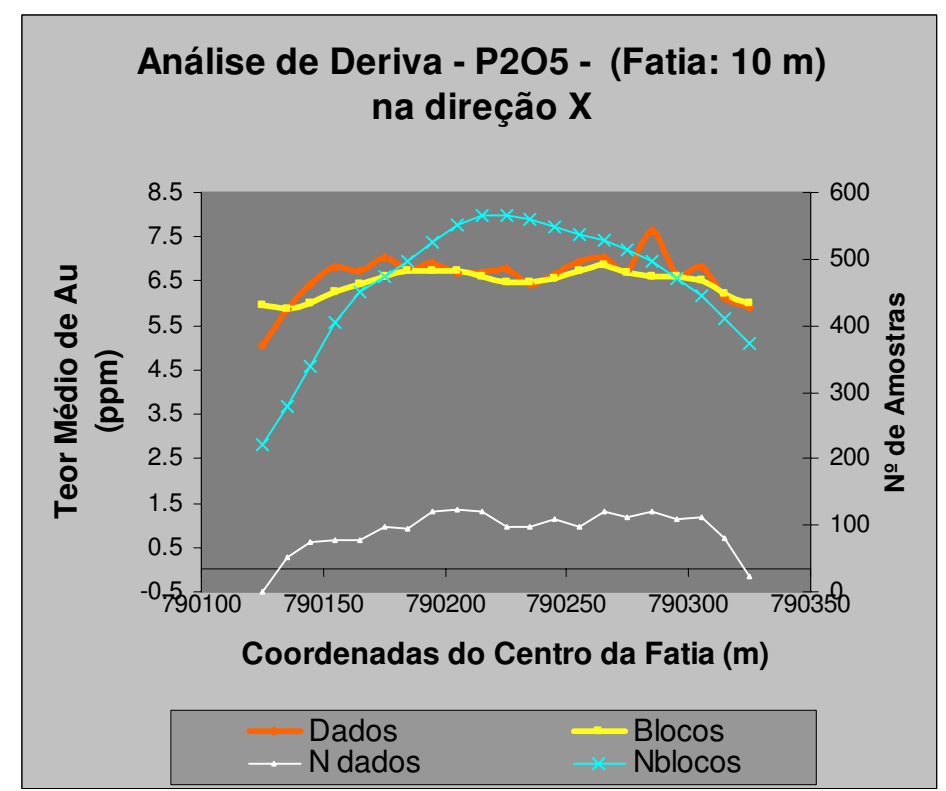

Figura 6.11: Análise de deriva em $\mathrm{X}$ da estimativa usando o desmonte em fatias de $10 \mathrm{~m}$.

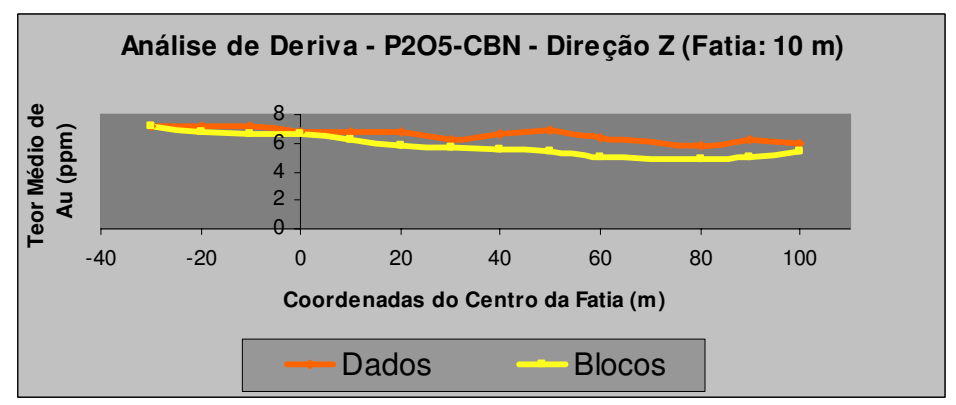

Figura 6.12: Análise de deriva em $\mathrm{Z}$ da estimativa usando o desmonte em fatias de $10 \mathrm{~m}$. 


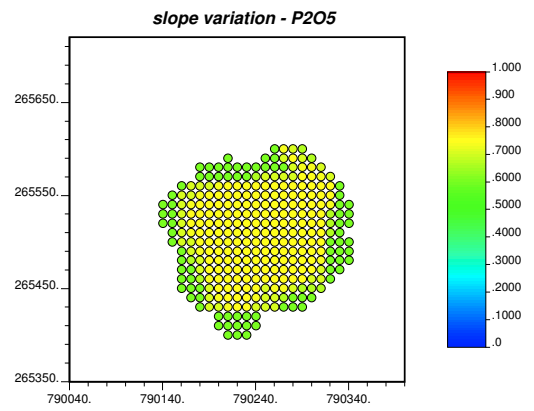

(a)

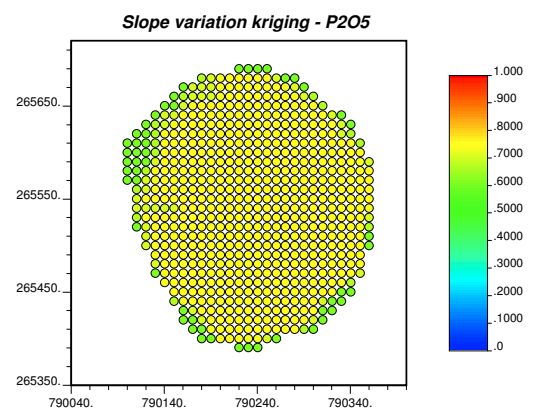

(c)

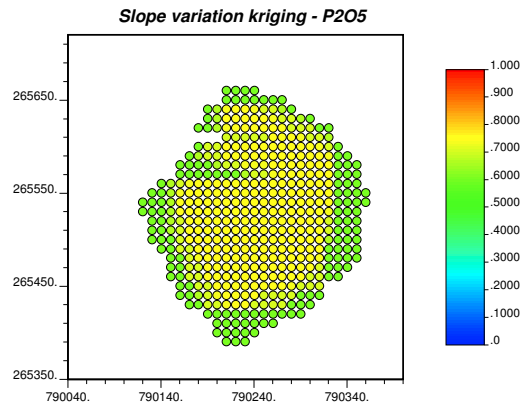

(b)

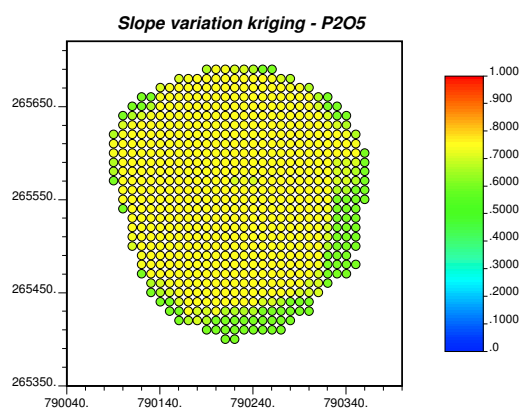

(d)

Figura 6.13: Avaliação pelo método de slope

(a)na bancada -50, (b)na bancada -30, (c)na bancada 10, (d)na bancada 40.

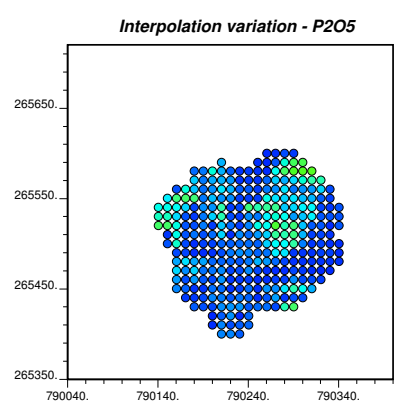

(a)

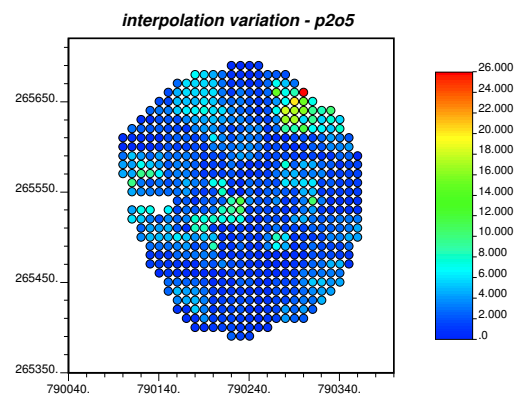

(c)

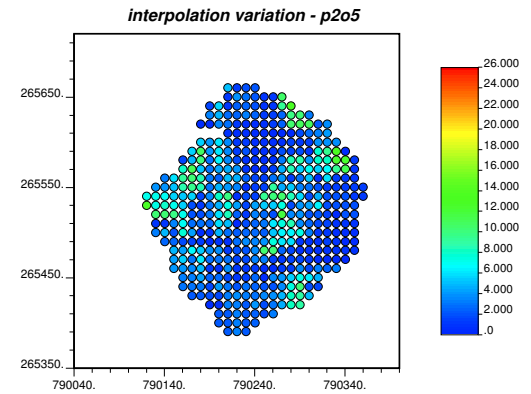

(b)

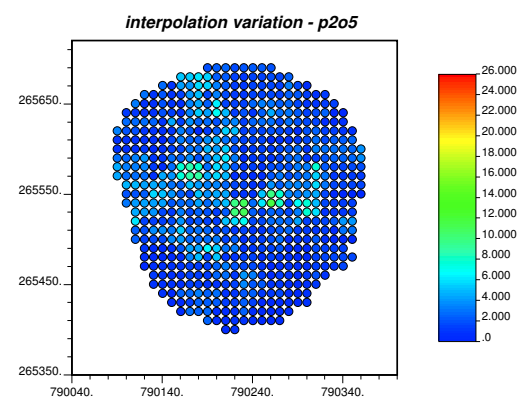

(d)

Figura 6.14: Avaliação da variância de interpolação

(a)na bancada -50 , (b)na bancada -30, (c)na bancada 10 (d)na bancada 40. 


\subsection{Banco de dados de sondagens}

O banco de dados da litología de interesse é composto por 377 amostras, adquiridas pela amostragem das sondagens em diferentes campanhas. Das amostras contidas no banco de dados, não foi descartada nenhuma, principalmente pelo fato de haver um reduzido número destas amostras para a área que representa. A Figura 6.15 apresenta a forma da distribuição do histograma dos furos com comprimento de $5 \mathrm{~m}$.

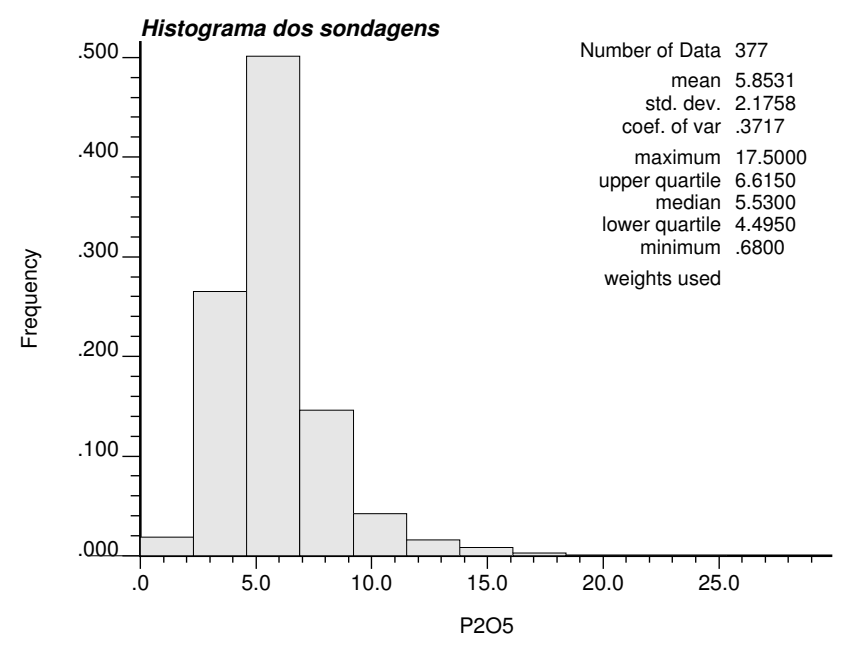

Figura 6.15: Histograma do desagrupamento da variável $\mathrm{P}_{2} \mathrm{O}_{5}$ do sondagem

\subsubsection{Análise da continuidade e krigagem}

Para determinação da continuidade espacial da variável $P_{2} O_{5}$, foi considera o variograma gerado a partir da a informação dos furos de desmonte, por estes terem uma boa densidade para fornecer uma estrutura do variograma. A Figura 6.16 representa os variogramas na direção vertical.

A validação cruzada foi realizada para determinar a aderência do modelo ajustado e o espalhamento do erro mostrados nas Figuras 6.17 (a) e 6.17 (b).

A equação 6.3 é o resumo dos parâmetros do ajuste do variograma.

$$
\gamma_{2}(h)=1,104+1,584 \operatorname{Sph}\left(\frac{N_{90.0}}{19}+\frac{N_{90.0}}{19}\right)+2,496 \operatorname{Sph}\left(\frac{N_{90.0}}{38}, \frac{N_{90.0}}{38}\right)
$$



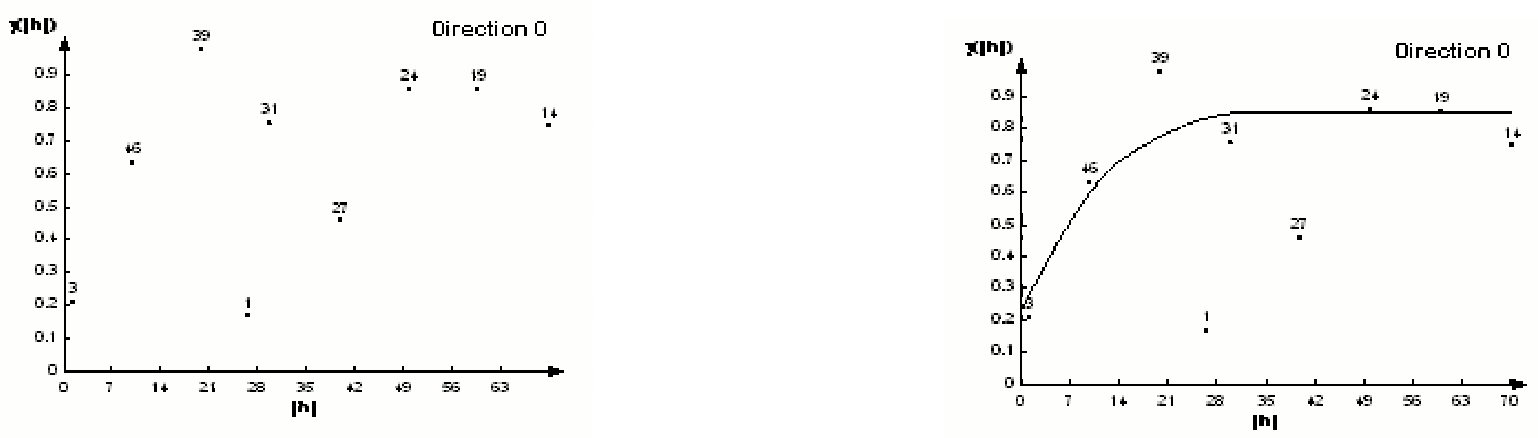

(a)

Figura 6.16: variogramas na vertical utilizando os furos de sondagens (a) variograma na vertical mostrando a variância, (b) variograma ajustado.

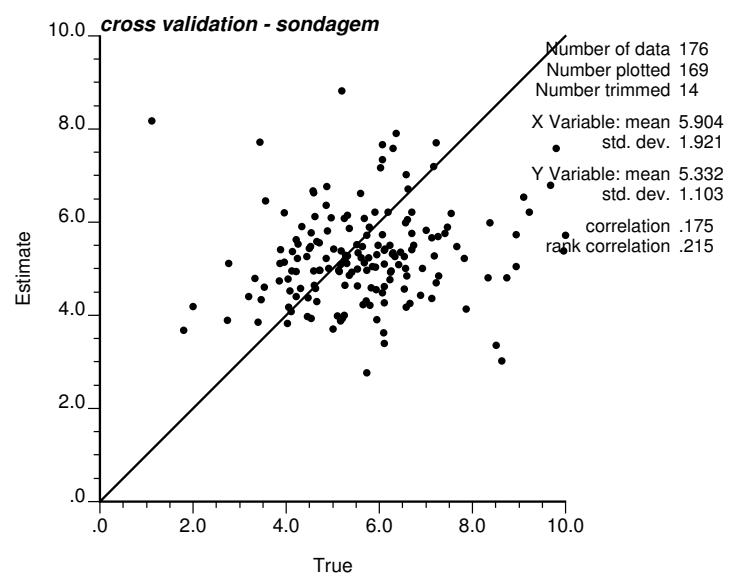

Figura 6.17: Validação cruzada e erro.

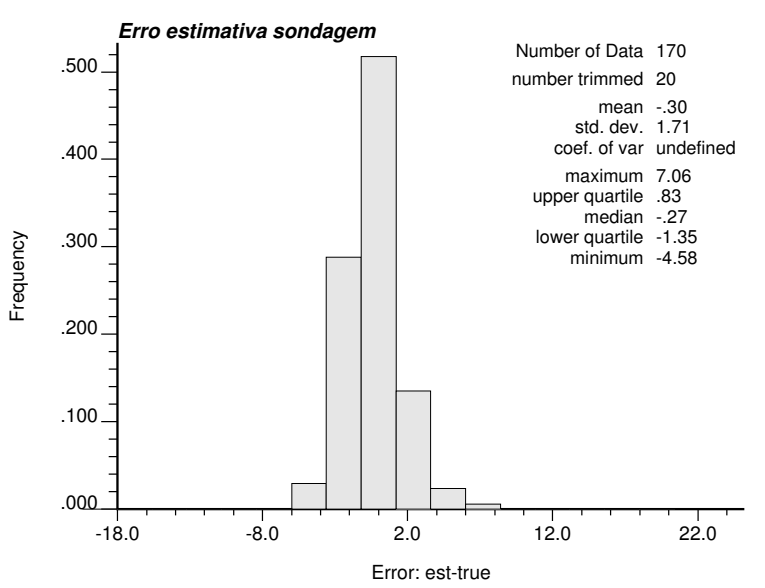

(a)

(a) histograma e espalhamento da validação cruzada do variograma na direção de 86 graus, (b) erro da estimativa.

A densidade de amostragens na horizontal é irregular, pois estas amostragens foram realizadas com o objetivos de delimitar o corpo do minério. Desse modo, não foi possível conseguir variogramas com bõa continuidade na horizontal. Portanto, o variograma horizontal é calculado usando os furos de desmonte por representar a mesma litologia. As Figuras 6.18 (a) e 6.18 (b) mostram o histograma do modelo krigado e a variância da krigagem.

No processo de validação da estimativa utilizou-se a variância da estimativa de krigagem com a análise de deriva em fatias de 10 m na direção $X$ (Figura 6.19), e na direção $Z$ (Figura 6.20) a variância de interpolação (Figura 6.21) e o método do slope (Figura 6.22). No caso da análise pelo método de deriva na direção $Z$, conseguiu-se observar uma boa estimativa dos blocos quando eles são relacionadas com os dados originais: 


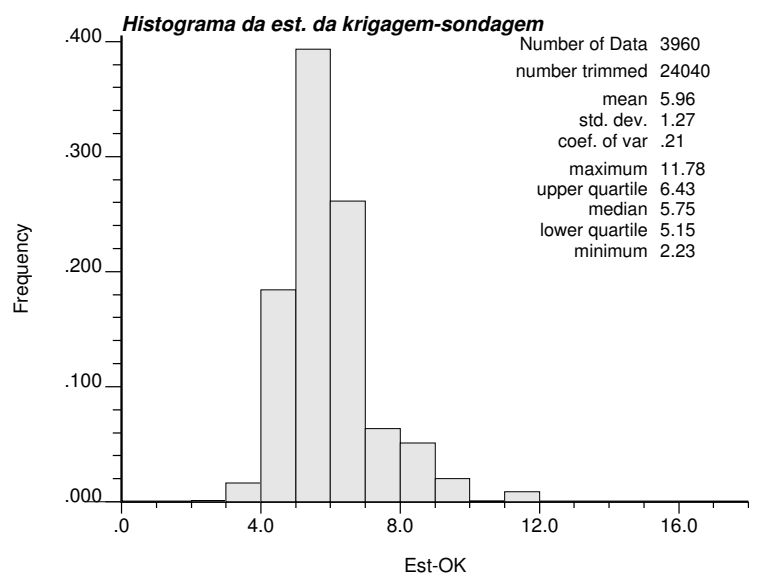

(a)

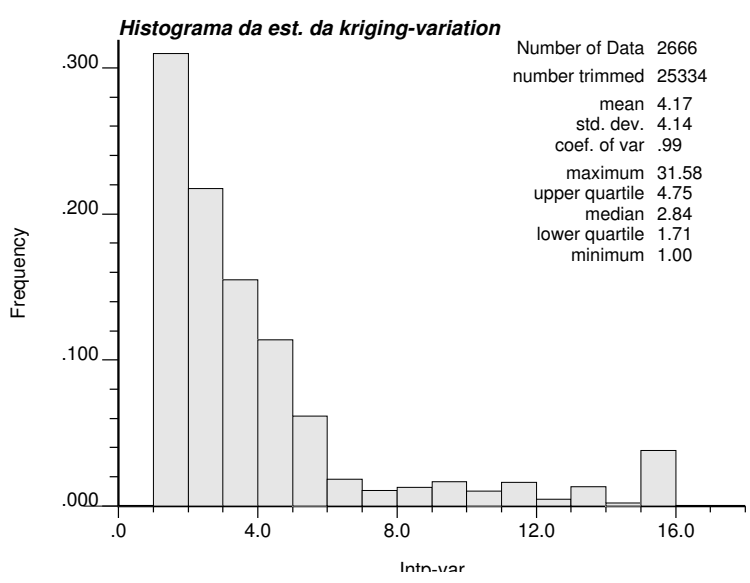

(b)

Figura 6.18: Estimativa do modelo por krigagem ordinária de $\mathrm{P}_{2} \mathrm{O}_{5}$ do sondagem (a) histograma do modelo krigado , (b) Variância da estimativa.

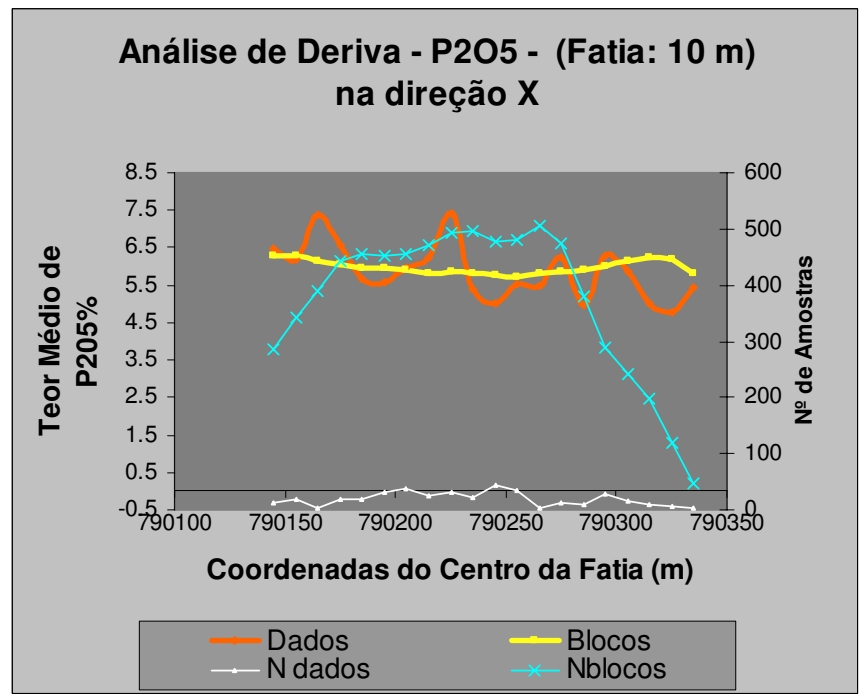

Figura 6.19: Análise de deriva da estimativa usando as sondagens na direção $X$ em fatias de $10 \mathrm{~m}$.

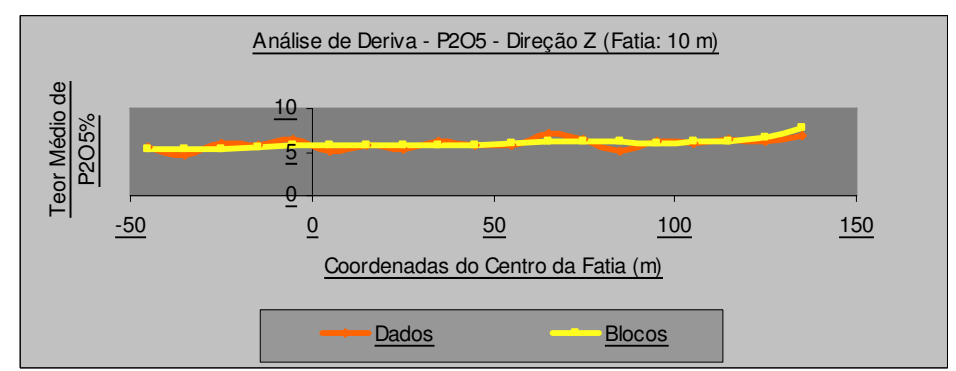

Figura 6.20: Análise de deriva da estimativa usando as sondagens na direção $Z$ em fatias de $10 \mathrm{~m}$. 


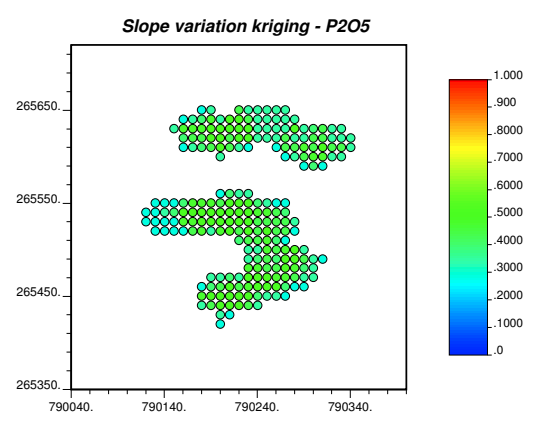

(a)

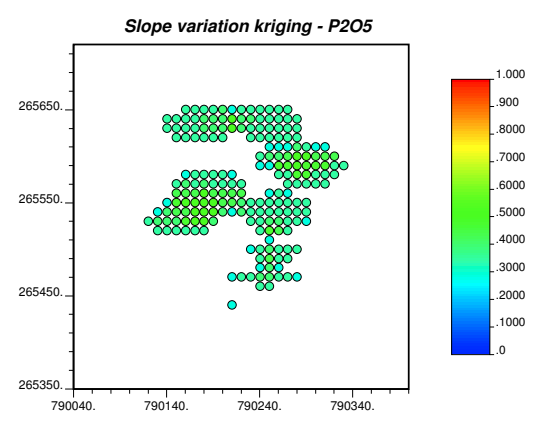

(c)

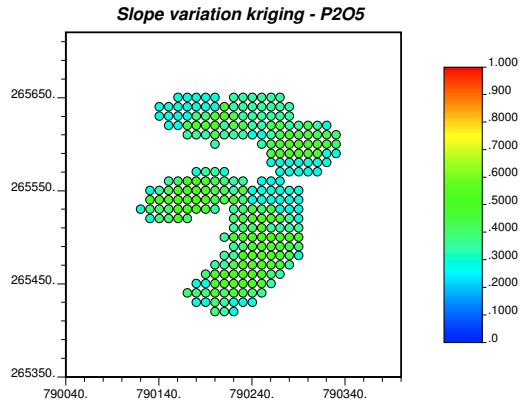

(b)

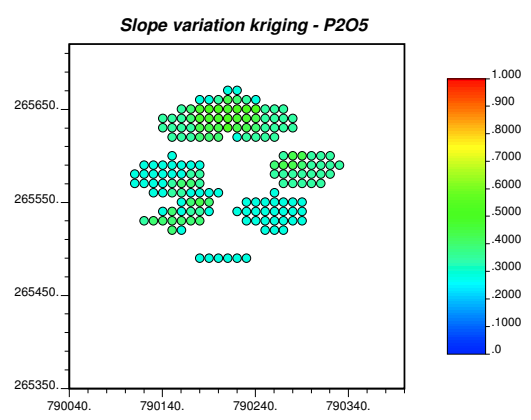

(d)

Figura 6.21: Avaliação pelo método de slope do modelo gerado por sondagens (a) na bancada -20, (b) na bancada 10 , (c) na bancada 40, (d) na bancada 70.

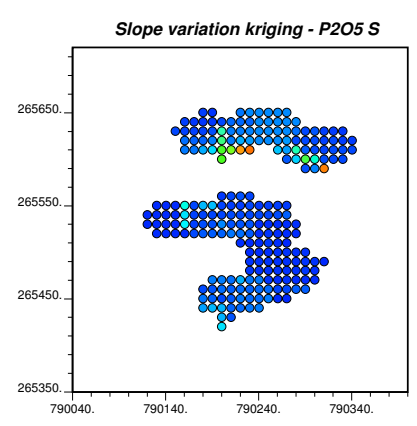

(a)

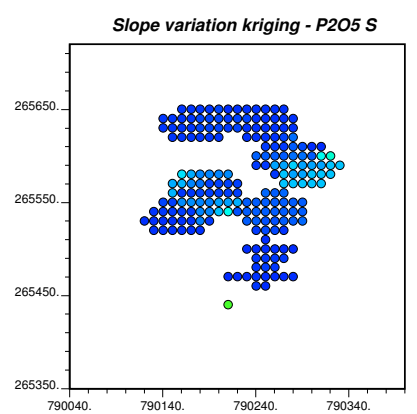

(c)
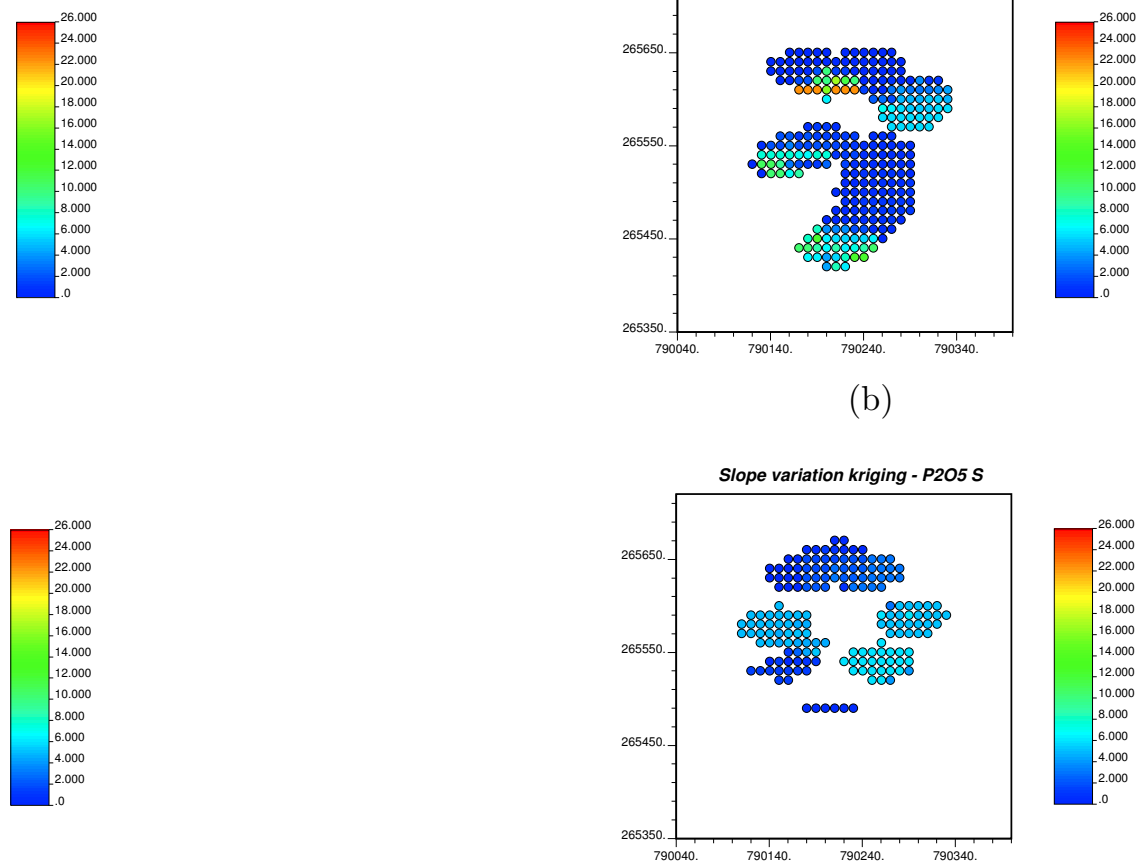

(d)

Figura 6.22: Avaliação da variância de interpolação modelo gerado por sondagens (a) na bancada -20, (b) na bancada 10, (c) na bancada 40, (d) na bancada 70. 


\subsection{Deslocamento dos pontos}

Uma das condições do método de co-krigagem é ter pontos comuns com diferentes atributos. Por isso decidiu-se adaptar deslocamentos das amostras com um modelo de blocos de 5,0 X 5,0 X 5,0 metros. Assim, o centro da amostra é deslocado para o centro do bloco. Esta adaptação é realizada com o intuito de obter nós com variáveis de $P_{2} O_{5}$ contendo as análises dos furos de desmonte e dos furos de sondagem como dois atributos diferentes. Esta adaptação dos bancos de dados é mostrada na Figura 6.23(a) que representa a distribuição dos furos de desmonte e a Figura 6.23(b), que representa o modelo de blocos deslocados incluindo o teor da amostra. A Figura 6.24(a) representa a distribuição espacial dos furos de sondagem e a Figura 6.24(b) representa os blocos deslocados incluindo o teor da amostra com a nova coordenada no centro do bloco.

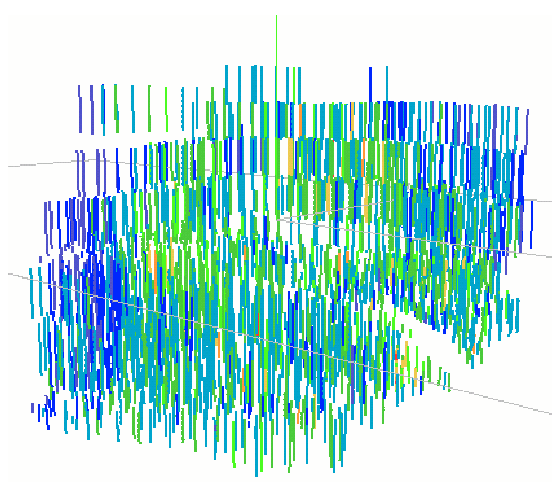

(a)

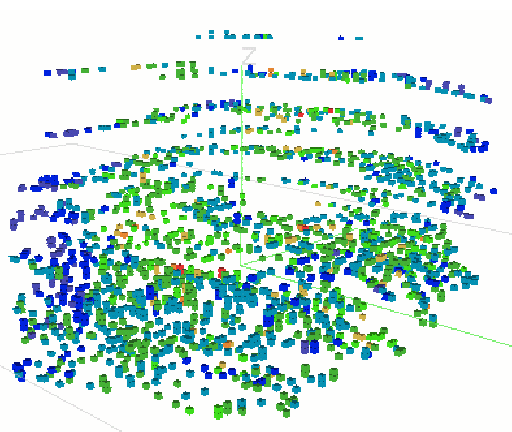

(b)

Figura 6.23: adaptação para o deslocamento das amostras de desmonte (a)furos de desmonte, (b)blocos contendo o teor da amostra mais próxima.

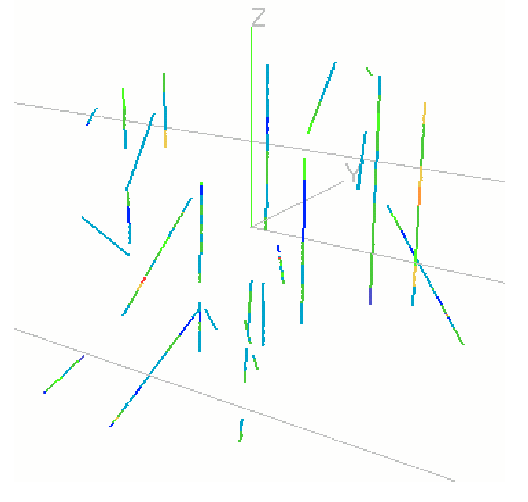

(a)

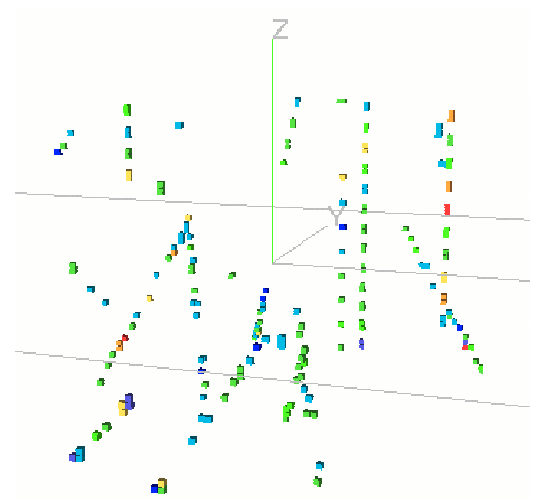

(b)

Figura 6.24: Adaptação para o deslocamento das amostras de sondagem (a)furos de sondagens, (b)blocos contendo o teor da amostra mais próxima. 
O modelo resultante tem duas variáveis, e isto quer dizer que para um mesmo ponto, tem-se um teor $T_{1}$ de $P_{2} O_{5}$ de sondagem e outro teor $T_{2}$ de $P_{2} O_{5}$ do desmonte. Após esta adaptação, foram obtidos 18 pontos comuns conforme mostrado na Figura 6.25.

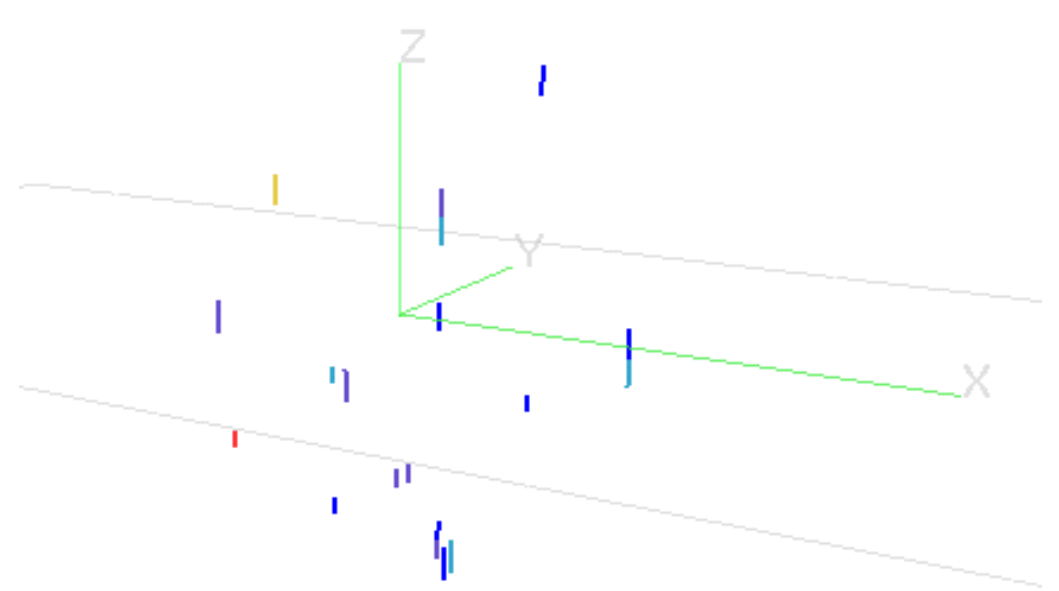

Figura 6.25: Furos adaptados contendo as duas informações primárias e secundárias

\subsubsection{Cálculo dos índices de correlação}

Para o cálculo dos coeficientes de correlação foi empregada a rotina "scatplt.exe" (DEUTSCH; CLAYTON; JOURNEL, 1998). Essa rotina cálcula o coeficiente de correlação $\rho$. Os gráficos de dispersão e os respectivos índices de correlação são apresentados na Figura 6.26.

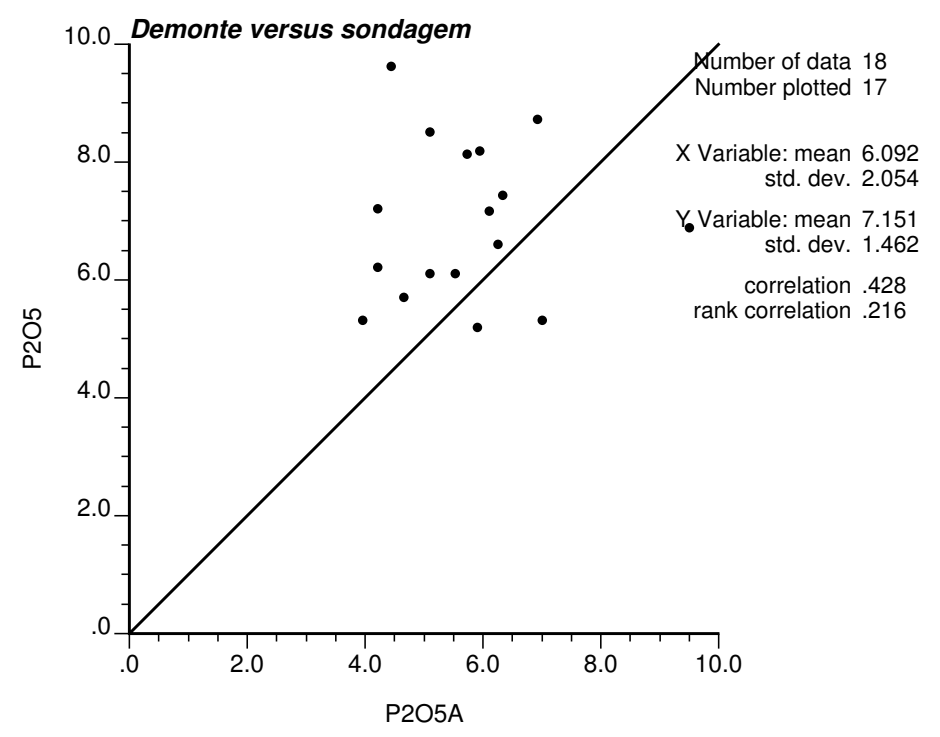

Figura 6.26: Coeficiente de correlação dos nós comuns do desmonte e sondagem 
Pela avaliação da Figura 6.26, conclui-se que existe uma relação entre as amostras, mesmo tendo sido utilizadas diferentes metodologias na coleta e variados comprimentos da informação do desmonte. Assim foi aplicado o modelo MM2 que requer somente a inferência e modelagem da covariância direta da variável primária (sondagem). Este método requer também o coeficiente estatístico entre as variáveis primária e secundária.

\subsubsection{Utilização do modelo Markoviano MM2 na construção do modelo}

Para a utilização da co-krigagem colocada neste estudo, foram feitas adaptações devido à configuração dos dados amostrais. Foi considerada como variável secundária a informação de $P_{2} O_{5}$ do desmonte. A co-krigagem requer que se estime o valor da variável secundária $\left(\mathrm{P}_{2} \mathrm{O}_{5}\right)$ em todos os pontos da malha que se quer estimar. Este procedimento foi realizado através da krigagem ordinária. Somente desta forma esta variável pode estar presente nos pontos da malha onde se deseja fazer a co-estimativa da variável de $\mathrm{P}_{2} \mathrm{O}_{5}$.

Assim, a krigagem ordinária da variável de $P_{2} O_{5}$ (desmonte) serviu para a variável secundária em todos os colocados em todos os pontos da malha. Para tal estimativa de co-krigagem, é utilizado o programa expandido do Geoslib com o comando específico MM2: Newcokb3d.exe.

\subsubsection{Determinação da continuidade espacial cruzada entre o teor de $\mathrm{P}_{2} \mathrm{O}_{5}$ (sondagem) e teor de $\mathrm{P}_{2} \mathrm{O}_{5}$ (desmonte).}

Conforme mostra a equação 4.12, o cálculo do variograma cruzado fica condicionado à qualidade de ambos os bancos de dados. O banco de dados que contem as duas variáveis, para o caso da variável $\mathrm{P}_{2} \mathrm{O}_{5}$ apresenta apenas 18 informações, as quais servem para obter o coeficiente de correlação. O variograma cruzado foi calculado para a co-krigagem. A cokrigagem colocada utilizando o MM2 necessita a inferência do variograma construído utilizando a informação secundária (desmonte) e o coeficiente de correlação entre os dados colocados pela $\mathrm{KO}$ em cada nó. Tendo como requisito a inferência do variograma do resíduo, foram usados o variograma experimental da variável primária e o variograma experimental da variável secundária.

A Figura 6.27 apresenta o resumo do ajuste do correlograma cruzado das variáveis $\mathrm{P}_{2} \mathrm{O}_{5}$ (sondagem) e $\mathrm{P}_{2} \mathrm{O}_{5}$ (desmonte), isto respeitando as exigências do modelo de coregionalização da co-krigagem. Os alcances, direções e modelos são proporcionais à variancia das amostras tanto de sondagem como de desmonte nas Figuras 6.28a e 6.28b. 


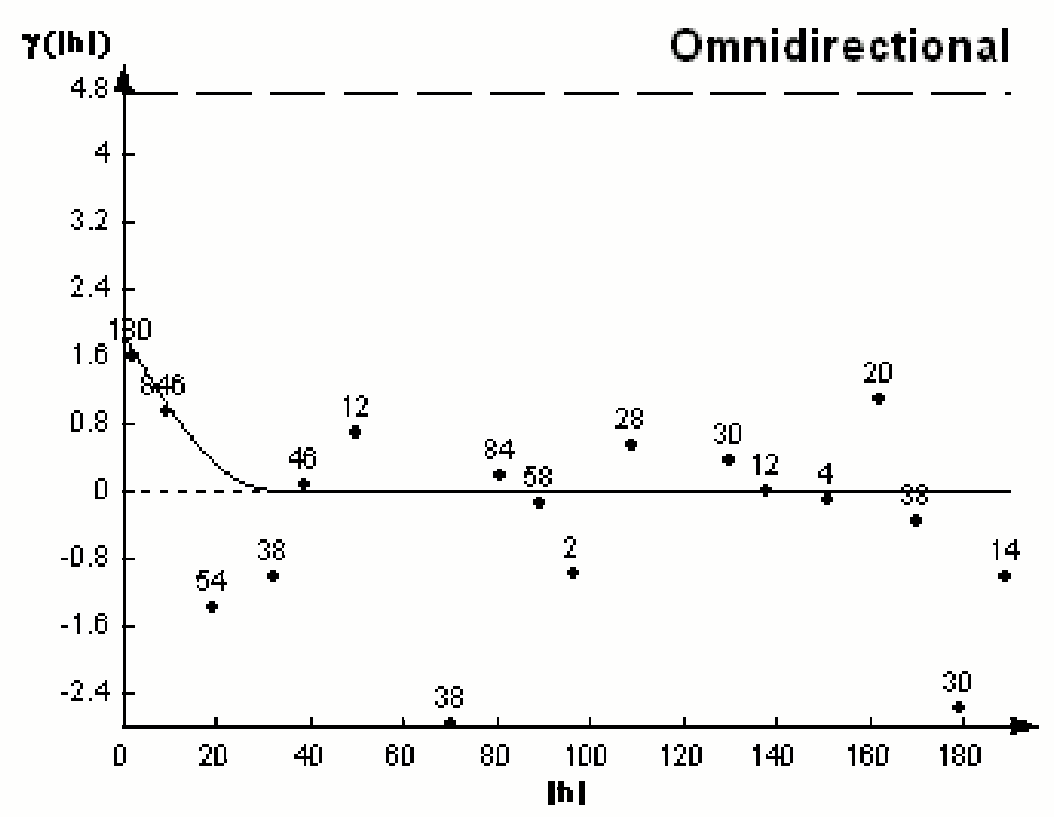

Figura 6.27: Variograma cruzado ominidirecional

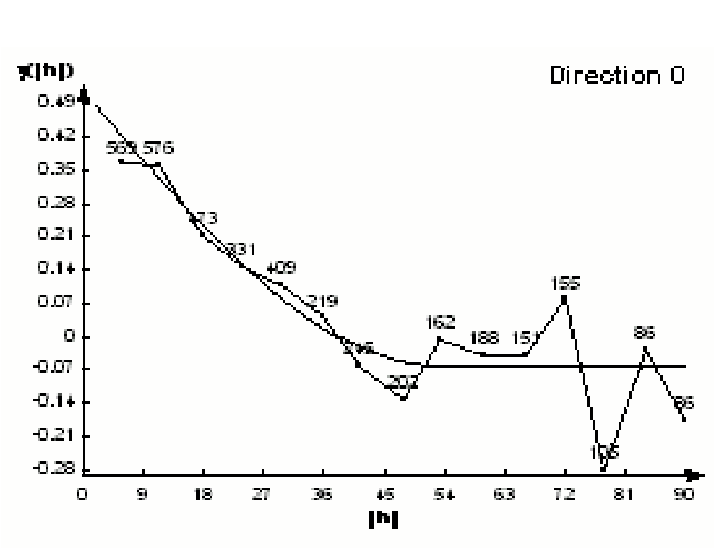

(a)

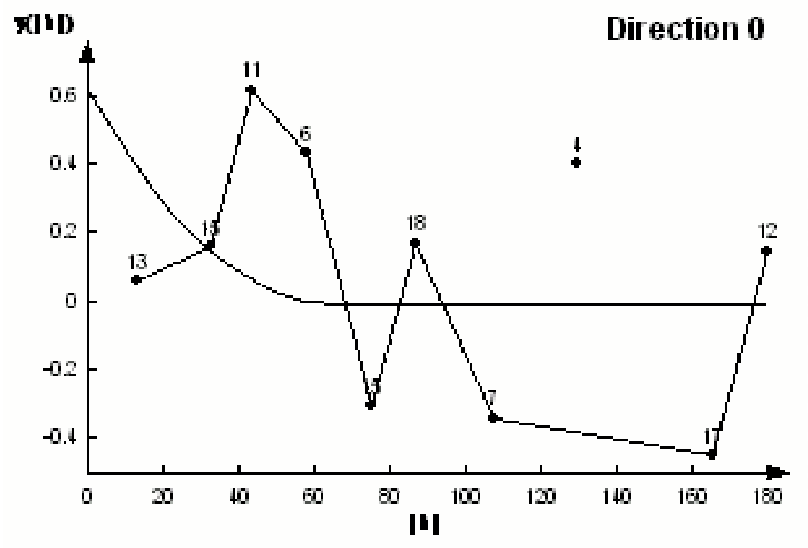

(b)

Figura 6.28: Correlogramas das variáveis primária e secundária (a)Correlograma ajustado da variável secundária de $\mathrm{P}_{2} \mathrm{O}_{5}$ (desmonete) (b)Correlograma ajustado da variável primária de $P_{2} O_{5}$ (sondages)

A Equação 5.4 resume os parâmetros de ajuste do variograma:

$$
\gamma_{2}(h)=1.88-0.88 \operatorname{Sph}\left(\frac{N_{162}}{23}+\frac{N_{86}}{38}\right)+1.02 \operatorname{Sph}\left(\frac{N_{162}}{19}, \frac{N_{86}}{29}\right)
$$

A Figura 6.29 mostra o histograma da estimativa da co-krigagem. 


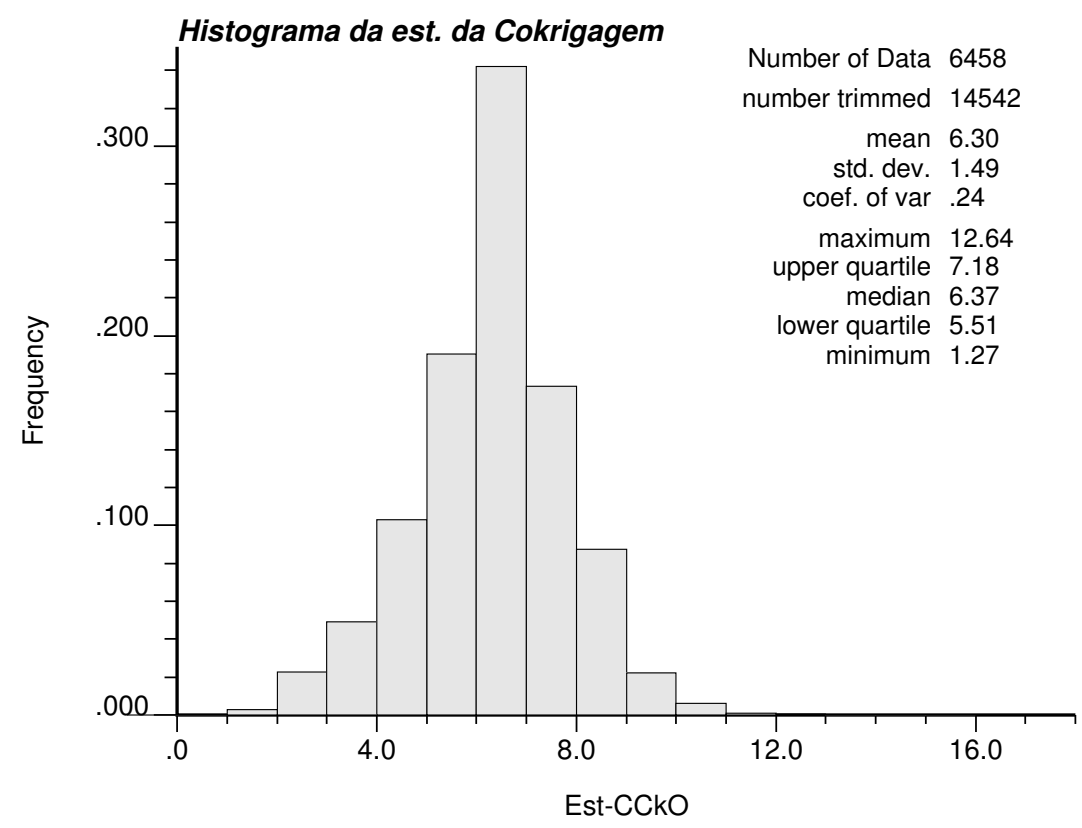

Figura 6.29: Histograma da estimativa por co-krigagem no modelo MM2

No processo de validação da estimativa, pela análise de deriva conforme as Figuras 6.30, 6.31 (B), e 6.32, são representados os resultados dos comparativos da co-krigagem em relação às amostras originais em fatias de 10 metros, pelo qual a dispersão dos dados estimados é razoável quando comparadas aos dados originais. A análise pelo método do slope é apresentado nas Figuras 6.33(A), 6.33(B), 6.33 (C), e 6.33(D). A análise pelo método da variância de interpolação mostra menor variancia em relação ao mesmo análise com o desmonte conforme as Figuras 6.33(A), 6.33(B), 6.33(C), e 6.33(D).

Na tabela 5.3 são apresentados os resumos estatísticos das estimativas de $P_{2} O_{5}$ pela OK (sondagens e desmonte) e co-krigagem (CCKO). 
Análise de Deriva CCKO- P2O5 - (Fatia: $10 \mathrm{~m}$ ) na direção $X$

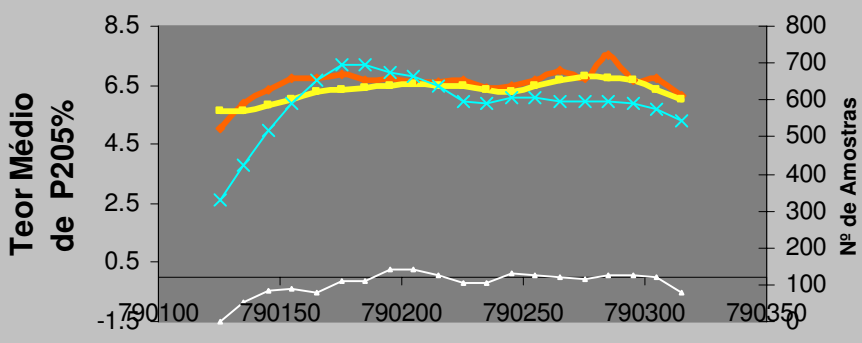

Coordenadas do Centro da Fatia (m)

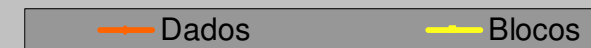

NDados $\quad$ N Blocos

Figura 6.30: Análise de deriva da estimativa por co-krigagem na direção $X$

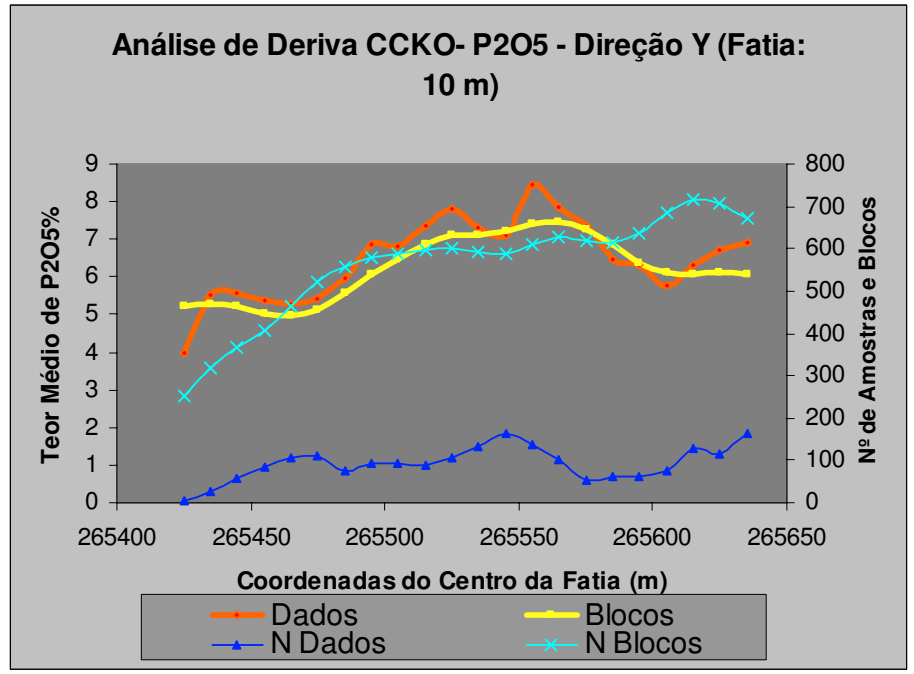

Figura 6.31: Análise de deriva da estimativa por co-krigagem na direção $Y$

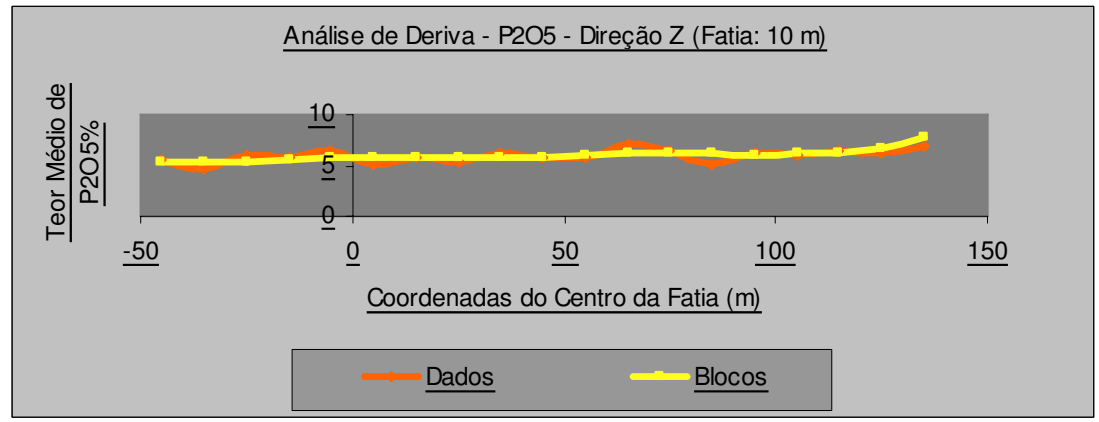

Figura 6.32: Análise de deriva da estimativa por co-krigagem na direção $Z$ 


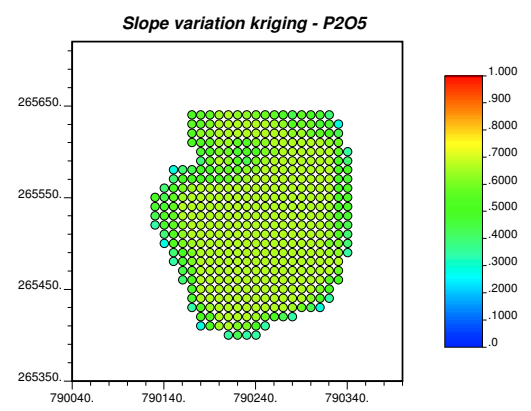

(a)

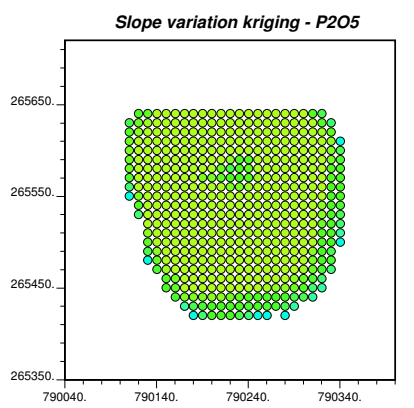

(c)

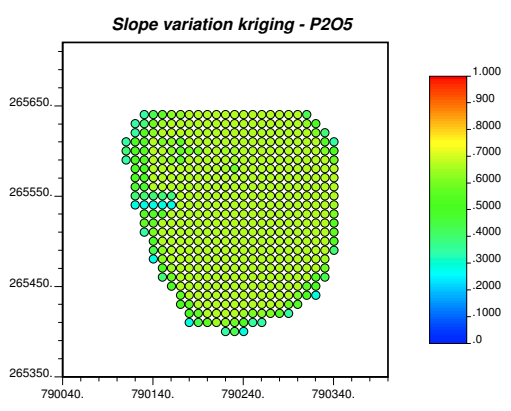

(b)

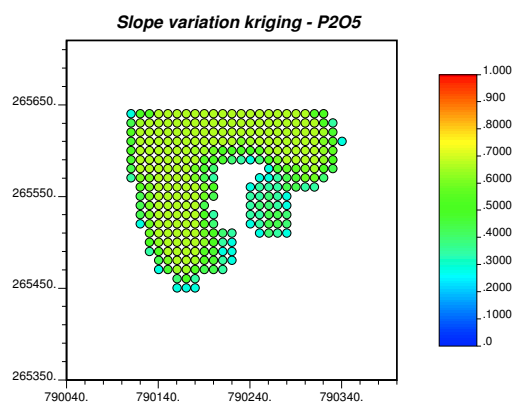

(d)

Figura 6.33: Avaliação pelo método de slope da estimativa modelo MM2 (a)na bancada -20, (b)na bancada 10 , (c)na bancada 40, (d)na bancada 70 .

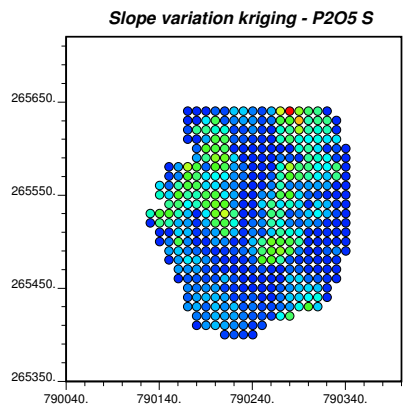

(a)

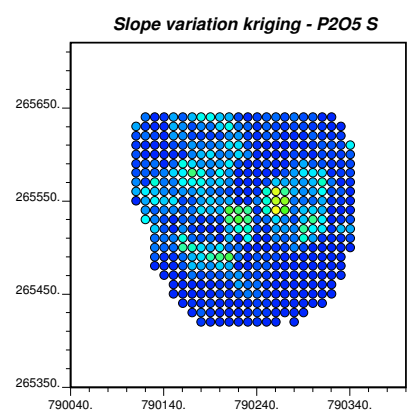

(c)
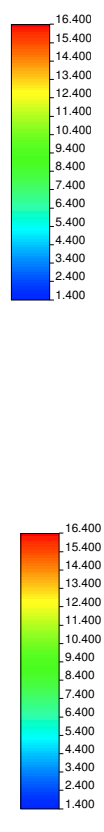

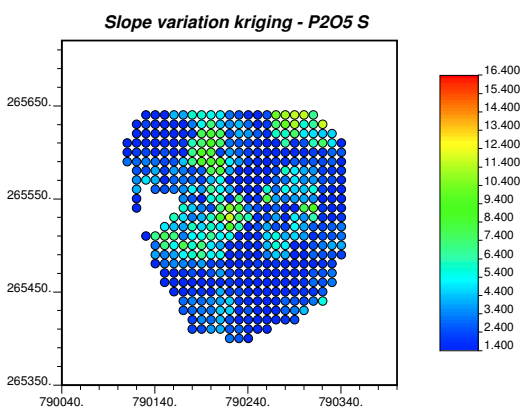

(b)

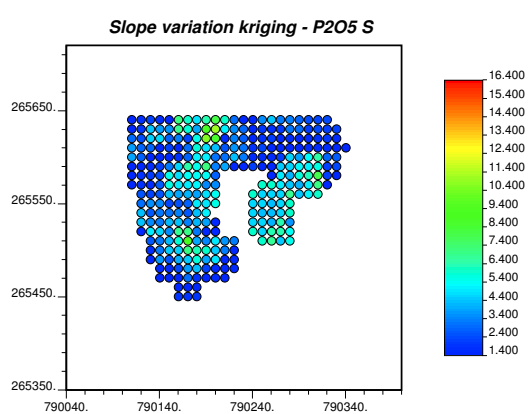

(d)

Figura 6.34: Avaliação da variância de interpolação da estimativa do modelo MM2 (a)na bancada -20, (b)na bancada 10 , (c)na bancada 40, (d)na bancada 70. 


\begin{tabular}{|l|l|l|l|l|l|l|}
\hline $\begin{array}{l}\text { Variável de } \\
\boldsymbol{P}_{\mathbf{2}} \boldsymbol{O}_{\mathbf{5}}\end{array}$ & $\begin{array}{l}\text { Desm. } \\
\text { KO }\end{array}$ & $\begin{array}{l}\text { Variância } \\
\text { de inter- } \\
\text { polação }\end{array}$ & $\begin{array}{l}\text { Sond. } \\
\text { KO }\end{array}$ & $\begin{array}{l}\text { Variância } \\
\text { de inter- } \\
\text { polação }\end{array}$ & CCKO & $\begin{array}{l}\text { Variância } \\
\text { de inter- } \\
\text { polação }\end{array}$ \\
\hline$N^{0}$ de dados & 12984 & 12984 & 3960 & 3960 & 6458 & 6458 \\
\hline Média & 6,15 & 2,91 & 5,96 & 4,17 & 6,30 & 3,15 \\
\hline $\begin{array}{l}\text { Desvio- } \\
\text { Padrão }\end{array}$ & 1,77 & 2,58 & 1,27 & 4,14 & 1,49 & 2,28 \\
\hline $\begin{array}{l}\text { Coeficiente de } \\
\text { Variação }\end{array}$ & 0,29 & 0,89 & 0,21 & 0,99 & 0,24 & 0,72 \\
\hline Máximo & 15,76 & 26,70 & 11,78 & 31,58 & 12,64 & 16,43 \\
\hline $3^{0}$ Quartil & 7,20 & 3,79 & 6,43 & 4,75 & 7,18 & 4,21 \\
\hline Mediana & 6,25 & 2,21 & 5,75 & 2,84 & 6,37 & 2,64 \\
\hline $1^{0}$ Quartil & 3,99 & 1,11 & 5,15 & 1,71 & 5,51 & 1,49 \\
\hline Minimo & 0,83 & 0,03 & 2,23 & 1,00 & 1,27 & 0,01 \\
\hline
\end{tabular}

Tabela 6.3: Resumo estatístico das estimativas de $P_{2} O_{5}$ pela $\mathrm{KO}$ e CCKO

\subsection{Aplicação no planejamento de curto prazo}

Com a modelagem de $\mathrm{P}_{2} \mathrm{O}_{5}$ é possível obter a programação de produção mensal nos primeiros dois anos da operação da mina. Para atingir esta meta são considerados os seguintes parâmetros operacionais:

- A usina da mina foi projetada para uma produção anual de 5.110.000 toneladas do minério do tipo Concentrado para a produção de Foscálcio;

- A usina de mantém um equilíbrio entre a lavra do minério e o estéril que evita de exceder a capacidade da frota disponível do caminhões;

- A frota de caminhões pode dispor cerca de 9.000 horas por mês para o transporte do minério e de estéril.

- O objetivo da programação é a produção de 500.000 t por mês, com um teor médio de 5.0 por cento de $P_{2} O_{5}$;

- As unidades lavra são definidas por seus limites de tipo de litologia (perímetros);

- Os perímetros são definidos considerando os objetivos de tonelagem e controle de teores de $\mathrm{P}_{2} \mathrm{O}_{5}$;

- Os estágios operacionais são lavrados na ordem em que foram definidos (digitados ou importados). 
De acordo com os dados mostrados no diagrama da Figura 5.1 da metodologia, a atualização da modelagem geológica permite a lavra da mesma área, o que não formavam parte de um mesmo estágio, Isto é observado nas diferentes distribuições de teores tanto por KO (sondagem) como por CCKO, como mostrados nas Figuras 6.35 (a) e 6.35 (b).

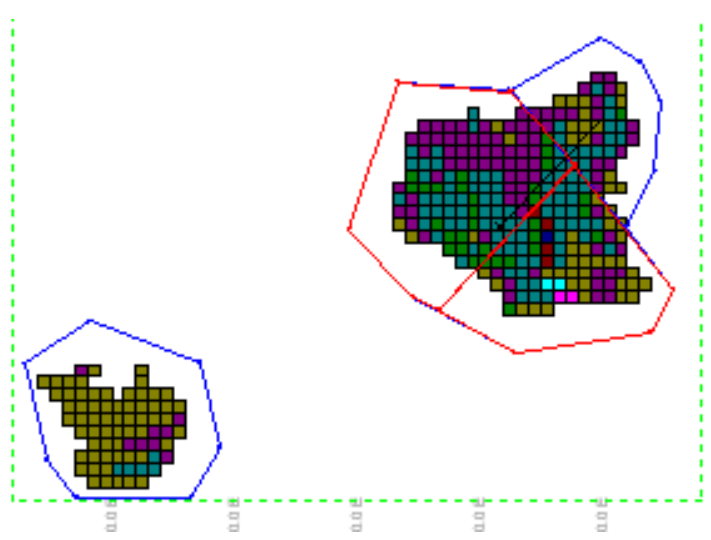

(a)

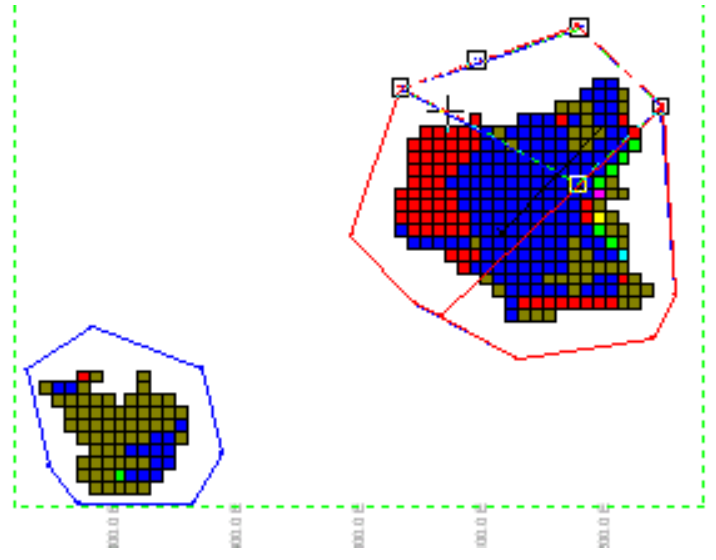

(b)

Figura 6.35: Dependências de fases operacionais da seqüência da programação (a) Modelo krigado com os furos de sondagem (b) modelo co-krigado pelo método de Marckov (MM2).

\subsubsection{Eleição das unidades de lavra}

A unidade de lavra é uma coleção de blocos estimados (krigagem e co-krigagem) na mesma bancada e dentro da mesma fase da mina que, por razões operacionais, devem ser lavrados juntos. Isto na parte operacional da Mina de Cajati é realizado de acordo a uma classificação de teor de mágnecio.

Estas unidades lavra, como são mostrados nas Figuras 6.36a e 6.36b, fornecem a solução que é acessível para subdividir estágios operacionais maiores em unidades menores para um número maior de cenários no controle de objetivos de produção.

\subsubsection{Definição das dependências}

Um critério importante considerado neste trabalho é a ordem que os estágios operacionais devem ser lavrados, os quais podem ser restringidos pelas dependências definidas. Estas dependências são definidas pelo planejador de modo que respeite a condição operacional como mostrados no comparativo da Figuras 6.37 (A) e 6.37 (B).

A definição de dependências é a parte relevante na escolha dos blocos operacionais, pois a seqüência implica no cumprimento de objetivos operacionais. Isto quer dizer, por 


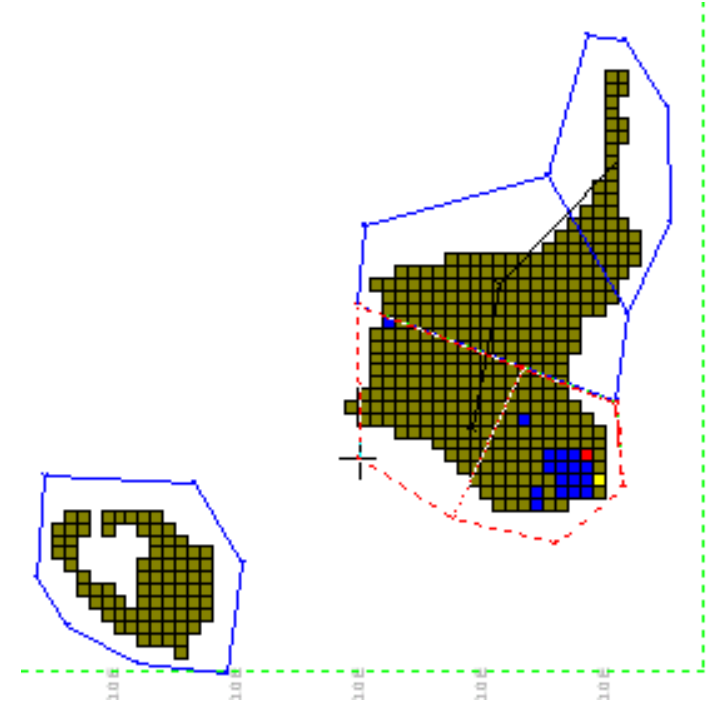

(a)

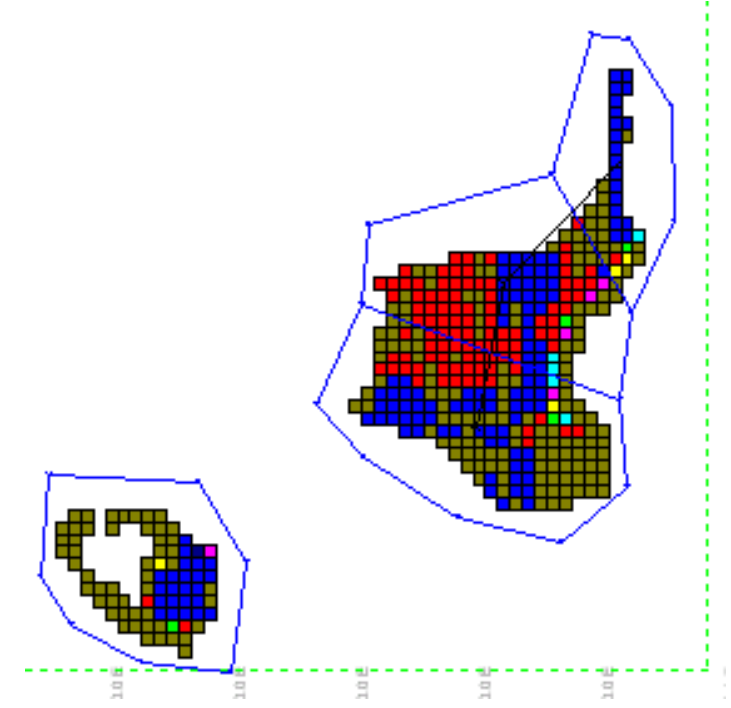

(b)

Figura 6.36: Blocos operacionais na seqüência de operacionalição

(a) Modelo krigado com os furos de sondagem (b) modelo co-krigado pelo método de Marckov (MM2)

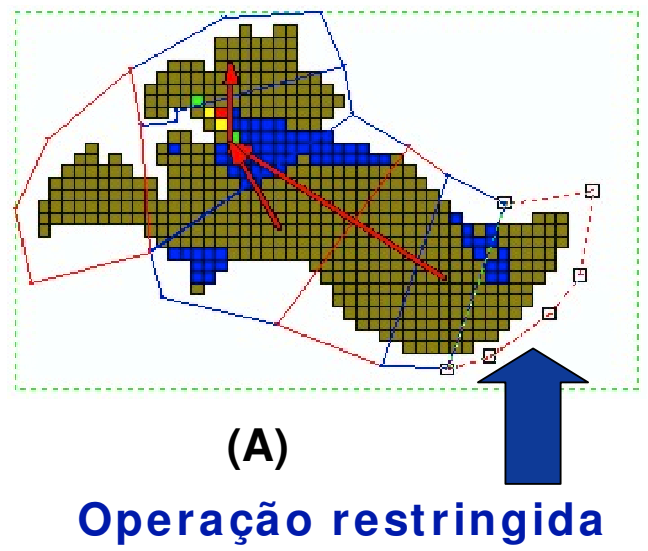

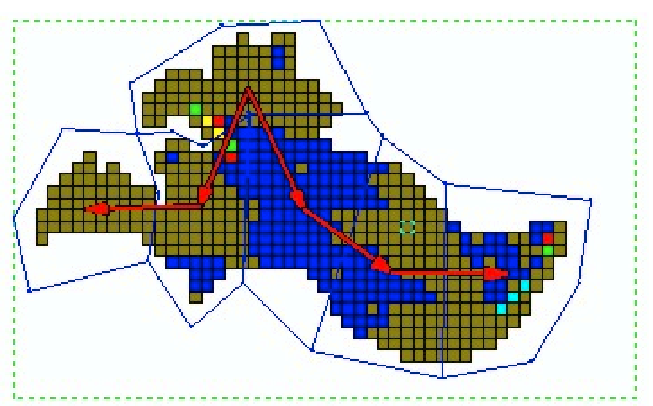

(B)

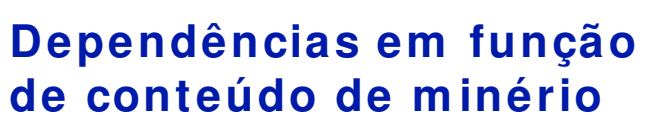

Figura 6.37: Programação operacional comparativa com restrições e dependências (A) Programação operacional usando as estimativas da krigagem dos sondagens (B) Programação operacional com as estimativas da Co-krigagem

exemplo, que o estágio operacional B depende do estágio operacional A como mostrado na Figura 6.37(a), onde as setas vermelhas indicam a seqüencia de lavra, na qual não há dependências de alguns conjunto de blocos com conteúdo de minério baixo, já a Figura 6.37(b) representa a forma diferente das dependências e seqüencia de lavra com menor incerteza, conseqüentemente permite maior detalhe no controle do estéril e do minério. 


\section{Conclusões}

Este estudo mostrou que é possivel aprimorar a aderência do planejamento de lavra de curto prazo mesmo utilizando informações com diferentesvariabilidades amostrais em relação dos dados originais.

Na parte geoestatística foi mostrado que o uso da informação de desmonte (secundária) melhorou a estimativa do atributo menos amostrado (sondagem). Isto tem relevância pela possibilidade de viabilizar a lavra de áreas menos sondadas, quando o objetivo foi estimar todos os blocos visando o seqüenciamento da mina.

Além disso, demonstrou-se que o método bivarial (co-estimativa) pode ser utilizado, desde que sejam conhecidas as limitações dos métodos de amostragens, principalmente a representatividade, avaliando os procedimentos de cada método. O método mostrou-se de grande valia, pois com uma adequada locação de amostras, podem ser inferidas áreas próximas das frentes de lavra com poucas de informações primárias atravez do uso de informações secundárias.

Apesar do método de co-estimativa fornecer vantagens sob um ponto de vista matemático, os resultados apresentados neste trabalho deverão ser validados nos procedimentos de reconciliação na própria mineração. Portanto, os resultados apresentados estão sujeitos à validação em função do suporte amostral não claramente definido que, por certo, poderá ser tema para futuras pesquisas.

No caso do método de análise de deriva, observando os comparativos as curvas dos dados originais e dos blocos estimados, ocorreu menor suavização na direção $X$ da $\mathrm{KO}$ usando as sondagens em relação à CCKO usando o desmonte e sondagem. Por outro lado, observou-se maior suavização na direção Z da CCKO em relação a KO porque a CCKO considera maior peso à variável secundária. No entanto, o método do slope mostra pequena diferença nas estimativas, o que significa que áreas as quais eram consideradas inferidas na estimativa da $\mathrm{KO}$ usando sondagem, na $\mathrm{CCKO}$ foram consideradas indicadas. $\mathrm{O}$ método da variância de interpolação mostrou que a CCKO tem menor variância em relação 
a $\mathrm{KO}$ usando o sondagem e a $\mathrm{KO}$ usando o desmonte. .Portanto, pelos tres métodos apresentados a CCKO mostra uma diminuição da incerteza mais evidente.

$\mathrm{Na}$ parte de planejamento de lavra foi mostrado que a programação operacional de curto prazo respeitando as fases do planejamento de longo prazo, onde se consideram todas as variáveis econômicas, geológicas, geotécnicas e ambientais, permite uma programação de lavra focada nos objetivos operacionais. Esta é uma questão ainda a ser estudada com mais detalhe em pesquisas futuras.

Uma consideração ainda não detalhada refere-se aos destinos do minério. No entanto, este é contexto de tomada de desições operacionais que poderá mudar se a distância de transporte tiver influência na escolha das áreas a se lavrar e não simplesmente por ter melhor controle de teores. 


\section{Referências}

ALMEIDA, A. Joint simulation of multiples variables with a Markov type Coregionalization Model. 2003 p. Tese (Doutorado) — Stanford University, Califórnia, 2003.

BARBOSA, P. M.; STURARO, J. R.; CALDEIRA, R.; MONTEIRO. Exemplos de aplicação da Co-krigagem. UNESP Rio Claro, 2002. Disponível em: <http: //www.rc.unesp.br/igce/aplicada/textodi.html acessa em: 25 set. 2005>.

BARROS, G. Reavalição Geoestatística dos Recursos Reservas de Fosfato da Mina de Cajati. 108 p. Tese (Mestrado) — Instituto de Geociências, Universidade de São Paulo, São Paulo, 2001.

BOEZIO, M. N. Métodos geoestatísticos para a incorporação da topografia como informação secundária no mapeamento do nível de água subterrânea. $292 \mathrm{p}$. Tese (Mestrado) - Engenharia de Minas, Materiais e Metalúrgica, Universidade Federal do Rio Grande do Sul, Porto Alegre, 2004.

BUSTILO, R. N.; JIMENO, C. L. Manual de evaluación y diseño de explotaciones minera. Madrid: Grafica Arías Montano, 1997. 705 p.

CALDER, P. N. Tópicos de ingeniería de minas a rajo abierto. Santiago de Chile: Universidad la Catolica, 2001. 267 p.

CHAUSSON, D. Otimização de cava por blendagem em minas de Calcário. 124 p. Tese (Mestrado) - Engenharia de Minas, Universidade de São Paulo, São Paulo, São Paulo, 2005.

CODELCO, G. Manual de planeamiento de Mina. Santiago de Chile, 2003.

COSTA, J. F. Simulação condicional aplicada ao planejamento de lavra. Escola Politécnica da USP,Lapol: [s.n.], 2003. Disponível em: < Notas de aula da disciplina PMI $5019>$.

DATAMINE. Reference Manual NPV. Londres, 2001. Disponível em: <www. datamine. com.br/soporte/manuaisacessa em: maio 2005>.

DAVIS, M. Geostatistical ore reserve estimation. In: Geostatistical ore reserve estimation. [S.l.]: Elsavier Sientific Publishing Company, 1977. v. 2, p. 364.

DE-FARIA, S. Controle de Qualidade na Lavra em Minas de Calcário para cimento. 124 p. Tese (Mestrado) - Engenharia de Minas, Universidade de São Paulo, São Paulo, São Paulo, 2003.

DE-TOMI, G.; CEOTTO, H. Gerenciamento integrado da cadeia de valor mineral. Lapol-Fapesp, 2003. Pedido de Auxilo à pesquisa - Projeto Regular "projeto ERP-CVN". 
DE-TOMI, G.; CEOTTO, H. Gerenciamento integrado da cadeia de valor mineral. Lapol-Fapesp, 2004. Relatorio científico parcial do projeto gerenciamento integrado da cadeia de valor mineral "Projeto ERP-CVM-I".

DE-TOMI, G. F.; CARRASCO, C. A.; FARIA, A. S. Incorporación de la incertidumbre geologica en la toma de decisions en el planeamiento de corto plazo y control de mineral. In: CONVENCION MINERA, XXVII., 2005, Arequipa-Perú. Ministerio de Energia de Minas del Perú. Anuario, 2005.

DEUTSCH, V.; CLAYTON; JOURNEL, G. GSLIB Geostatistical Software Library and Users Guide. New York: Oxford University Press, 1998. 345 p.

FARIA, A. J. de. Planejamento de lavra da mina de Cajati Bunge - Fertilizantes S/A em Cajati-SP. [S.1.], 2004. Disponível em: <http://www. bunge.com.br/pub.htm ou acervo do próprio autor $>$.

GOOVAERTS, P. Geostatistics for Natural Resources Evaluation. New York: Oxford University Press, 1997. 481 p.

ISSAKS, E.; SRIVASTAVA, M. An Introduction to applied geostatistics. New York: Oxford University Press, 1989. 561 p.

JOURNEL, A. G. Markov models for cross-covariances. International Association for Mathematical Geology, n. 1, 1999.

JOURnEL, A. G.; HUIJBREGTS, C. J. Mining geostatistic. London: Academic Press, 1978. $600 \mathrm{p}$.

JOURNEL, A. R.; ROSSI, M. E. When do we need trend model in kriging? Math. Geology, v. 21, n. 7, p. 561, sep/oct 1989.

MANUAL-OS. Manual de operation scheduler. Londres, 2006. Disponível em: $<$ www. datamine.com $>$.

MATHEERON, G.; ARMSTRONG, M. Geostatistical case studies. Dordreeht Holland: D.reidel publishing company, 1987. 247 p.

MEYERS, J. C. Geostatistical error management: quantifying uncertainty for enviromental sampling and mapping. New York: GVan Nostrand Reinhold, 1996. 545 p.

OLIVEIRA, L. J. de. Avaliação do uso da perfilagem geofísica para obtenção de informações secundárias para utilização em co-estimativas de variáveis geológicomineiras. 125 p. Tese (Mestrado) - Engenharia de Minas, Materiais e Metalúrgica, Universidade Federal do Rio Grande do Sul, Porto Alegre, 2005.

PERONI, R. de L. Análise da sensibilidade do seqüenciamento de lavra em função da incerteza do modelo geológico. 126 p. Tese (Doutorado) — Engenharia de Minas, Materiais e Metalúrgica, Universidade Federal do Rio Grande do Sul, Porto Alegre, 2002.

PILGER, G. G. Critérios para locação amostral baseado em simulação estocástica. 125 p. Tese (Dissertação (Mestrado)) — Engenharia de Minas, Materiais e Metalúrgica, Universidade Federal do Rio Grande do Sul, Porto Alegre, 2000. 
PLÁ, F.; MOYANO, I.; HERRERA, J.; ROSA, F. P. da. Curso de planificación y evaluación Minera. Madrid: Universidad Politécnica de Madrid, 2001. 219 p.

REMACRE, A. O uso do cokrigagem co-locada Collocated cokriging na integração de dados quimicos e mineralógicos no minério de ferro. Revista: Escola de Minas, Seilo Brasil, v. 21, n. 5, p. ISSN 0370-4467, sep/oct 2004.

ROCHA, M. Estudo comparativo entre os métodos computacionais de avaliação de reservas e controle de teores da Mina Capanema, Santa Catarina, MG. 78 p. Tese (Mestrado) - Instituto de Geociências, Universidade de São Paulo, São Paulo, 1999.

SCHNEIDER, V. C. S. Métodos de Declusterização. Porto Alegre-UFRGS: [s.n.], 2002. Disponível em: < Notas de aula da disciplina PMI 5019>.

SEWALD, F. Desenvolvimento de metodologia baseada em simulação geoestatística para incorporação da incerteza no planejamento de lavra. 135 p. Tese (Mestrados) Engenharia de Minas, Materiais e Metalúrgica, Universidade Federal do Rio Grande do Sul, Porto Alegre, 2000.

VALENTE, J. M. Geomatemática, lições de geoestística. Ouro Preto: Fundação Gorceix, 1989. 510-713 p.

YAMAMOTO, J. K. Avaliação e classificação de reservas minerais. São Paulo: Editora da Universidade de São Paulo, 2001. 226 p. 


\section{Anexo A - Rotina para o deslocamento esapacial para a adaptação do uso de co-krigagem}

\section{A.1 Exemplo de scrip para mudar coordenadas para a aplicação de co-krigagem}

Este anexo é a especificação organizacional em formato HTML (conforme utilizado na implementação do método de Marackov MM2)

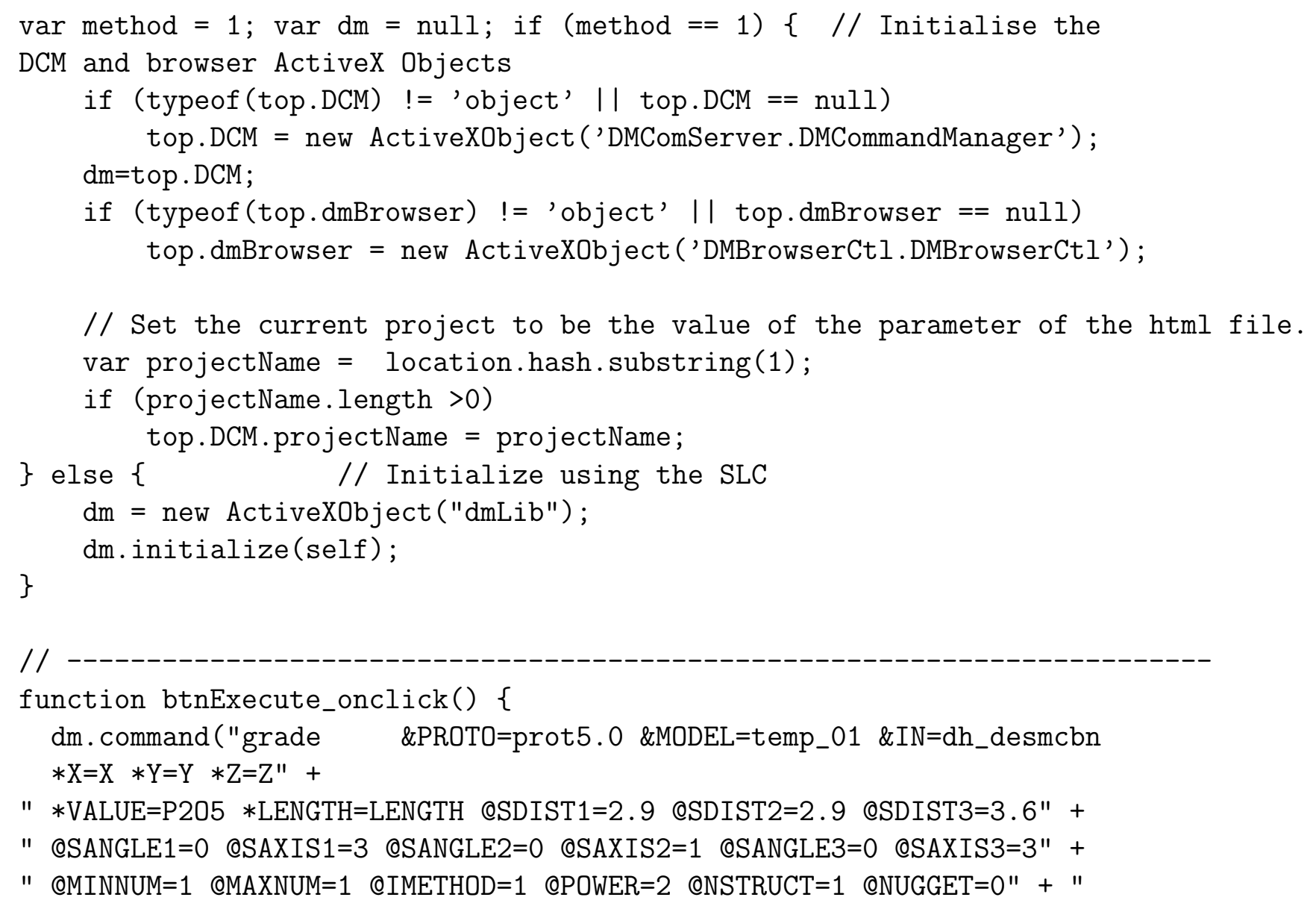




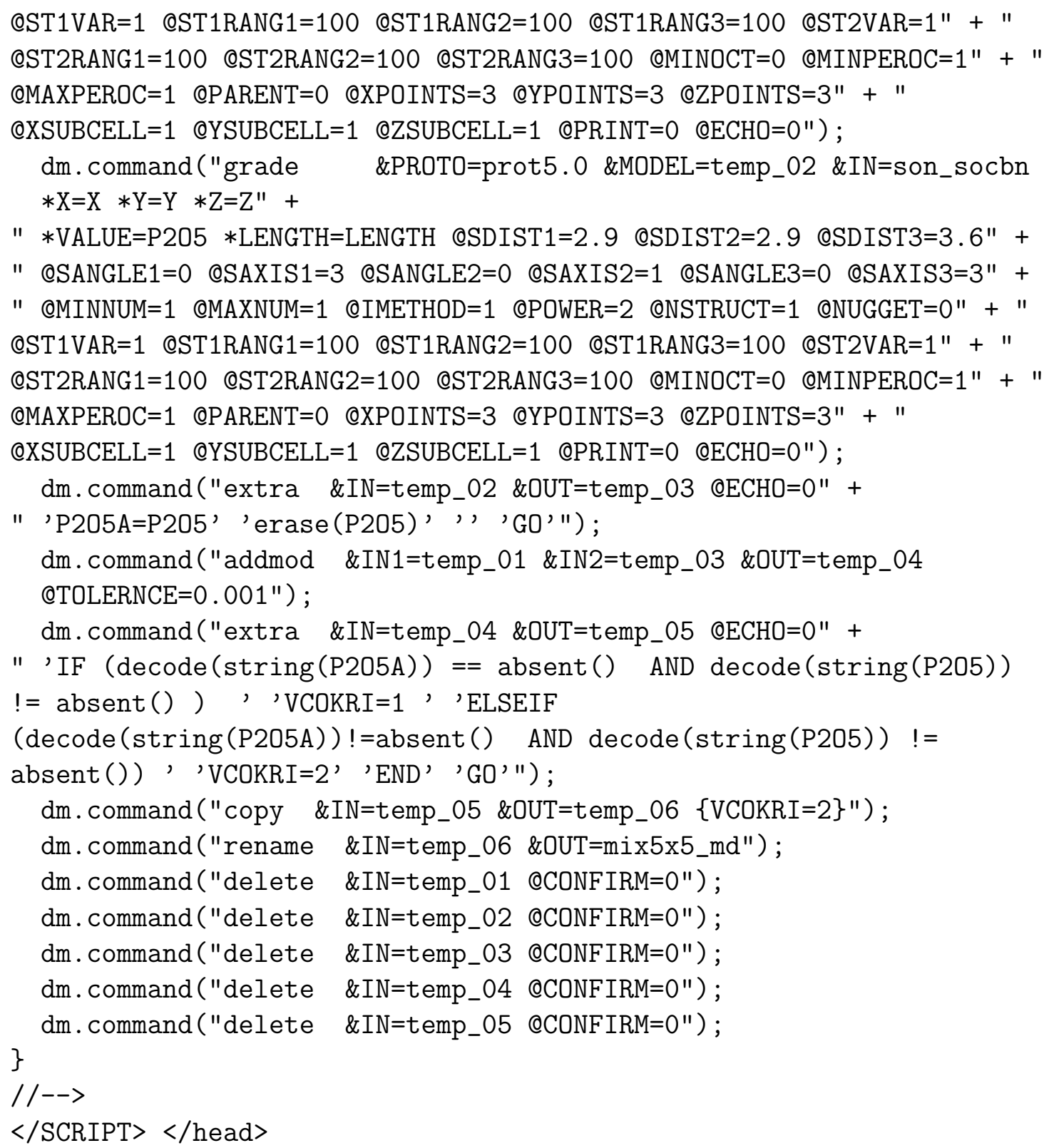

<body language="javascript" onunload="top.DCM = null; top.dmBrowser = null; $\mathrm{dm}=$ null;" style="font-family: MS Sans Serif; font-size: 8pt; background-color: threedface">

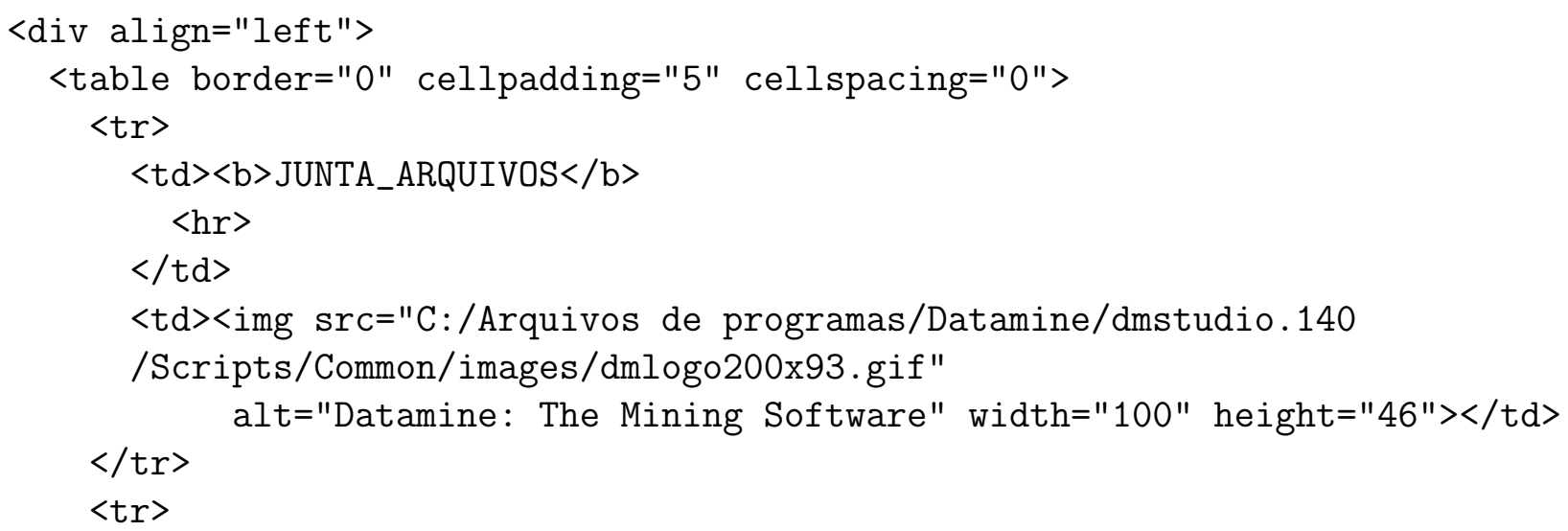




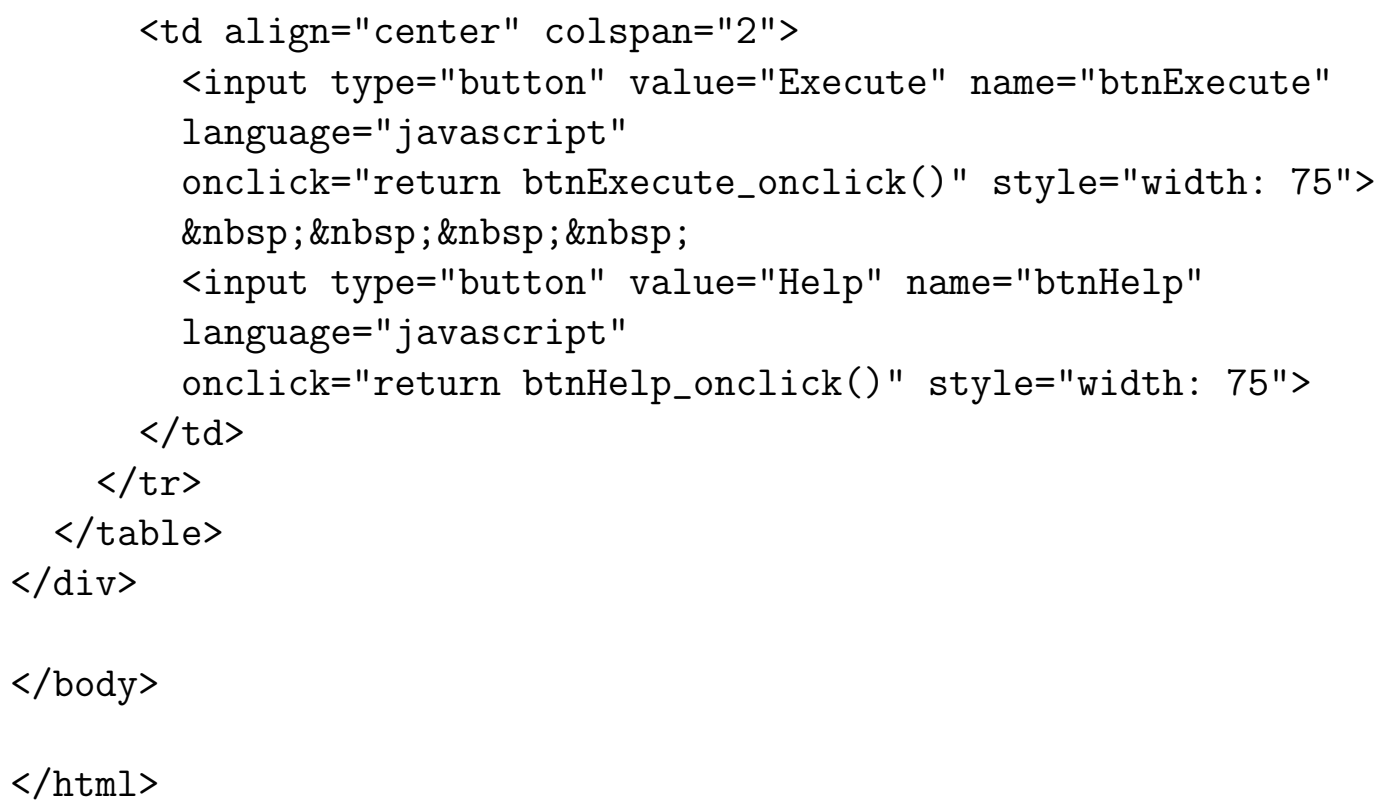




\section{Anexo B - Visão geral da co-krigagem co-locada}

\section{B.1 Co-krigagem simples colocada (CKSC)}

Inicialmente foi introduzida a krigagem simples variando médias locais (KSvml), sendo este um método de estimativa linear não tendencioso com a esperança matemática dos valores estimados subtraídos dos valores originais na posição $u$ igual a zero. A equação de krigagem simples é (GOOVAERTS, 1997):

$$
Z_{S K}^{*}(u)-m=\Sigma_{\alpha=1}^{n(u)} \lambda_{\alpha}^{S K}(u)\left[Z\left(u_{\alpha}\right)-m\right]
$$

onde $Z_{S K}^{*}(u)$ é o peso relativo ao dado $Z\left(u_{\alpha}\right)$ e $m$ é a média global. Respeitando a decisão de estacionariedade, a média m não depende da localização u, porém representa informação global comum para todos os pontos não amostrados.

Considerando uma informação secundária em cada ponto $u$, a média estacionária $m$, pode ser substituída por uma média local conhecida $m * S K(u)$.

A cokrigagem simples colocada de um atributo primário $Z_{1}$ locado em u é dada por:

$$
Z_{C K S C}^{(1)^{*}}=\sum_{\alpha 1=1}^{n(u)} \lambda_{\alpha 1}^{C K S C}(u)\left[Z_{1}\left(u_{\alpha 1}\right)-m_{1}\right]+\lambda_{2}^{C K S C}(u)\left[Z_{2}(u)-m_{2}\right]+m_{1}
$$

Os pesos de co-krigagem são obtidos a partir das equações abaixo:

$$
\left[\begin{array}{ll}
\sum_{\beta 1=1}^{n(u)}(u) \lambda_{\beta 1}^{C K S C} C_{11}\left(u_{\alpha 1}-u_{\beta 1}\right)+\lambda_{2}^{C K S C}(u) C_{12}\left(u_{\alpha 1}-u\right) & \\
=C_{11}\left(u_{\alpha_{1}}-u\right) & \alpha_{1}=1, \ldots ., n_{1}(u) \\
\sum_{\beta 1=1}^{n(u)}(u) C_{21}\left(u_{\alpha 1}-u_{\beta 1}\right)+\lambda_{2}^{C K S C}(u) C_{22}\left(u_{0}=C_{21}(0)\right. &
\end{array}\right]
$$


onde:

$\lambda_{\beta 1}^{C K S C}$ é o somatório dos pesos das informações da variável primária $Z 1(u 1)$,

$\lambda_{2}^{C K S C}$ é o peso destinado ao dado da variável secundária $\left.Z 2_{(} u\right)$ locado no ponto u que está sendo estimado,

$C_{11}\left(u_{\alpha 1}-u_{\beta 1}\right)$ covariância da variável primária entre os locais $u_{\alpha 1}$ e $u_{\beta 1}$

$C_{12}\left(u_{\alpha 1}-u\right)$ covariância cruzada entre a variável primária em u 1 e da variável secundária no ponto u que está sendo estimado,

$C_{11}\left(u_{\alpha 1}-u\right)$ covariância da variável primária entre os locais u 1 e o ponto u que está sendo estimado,

$C_{21}\left(u-u_{\beta 1}\right)$ covariância cruzada da variável secundária no ponto u que está sendo estimado com a variável primária em $u_{1}$

$C_{21}(0)$ covariância cruzada para o vetor de separação h igual a zero

$C_{22}(0)$ (co) variância dos dados da variável secundária

Diferentemente da co-krigagem, a co-krigagem colocada não emprega a covariância entre as variáveis secundárias para $|h|>0$.

\section{B.2 Co-krigagem ordinária co-locada (CKOC)}

O formalismo usual da cokrigagem ordinária, ao considerar o somatório os pesos dos dados secundários igual a zero, não pode ser aplicado em casos de dados secundários colocados. Em conseqüência disso, deve ser empregada a cokrigagem ordinária padronizada. Com isso, a cokrigagem ordinária colocada de um dado primário z1 locado em u é obtida por:

$$
Z_{C K O C}^{(1)^{*}}(u)=\sum_{\alpha 1=1}^{n(u)} \lambda_{\alpha 1}^{C K O C}(u) Z_{1}\left(u_{\alpha}\right)+\lambda_{2}^{C K O C}(u)\left[Z_{2}(u)-m_{2}+m_{1}\right]
$$

onde $Z_{C K O C}^{(1)^{*}}(u)$ é o dado primário estimado em $u$ com

$$
\sum_{\alpha 1=1}^{n(u)} \lambda_{\alpha 1}^{C K O C}
$$

e $\lambda_{2}^{C K O C}$ sendo os pesos das amostras associadas à variável primária $Z_{1}$ e com a secundária $Z_{2}$ respectivamente, $\mathrm{m} 1$ refere-se a média de $Z_{1}$ e $m_{2}$ a média de $Z_{2}$. A soma de todos os 
pesos deve ser igual a um:

$$
\sum_{\alpha 1=1}^{n(u)}(u) \lambda_{\alpha 1}^{C K O C}(u)+\lambda_{2}^{C K O C}(u)
$$

Os pesos de cokrigagem são obtidos a partir da solução das equações abaixo:

$$
\left[\begin{array}{lr}
\sum_{\beta 1=1}^{n(u)} \lambda_{\beta 1}^{C K S C}(u) C_{11}\left(u_{\alpha 1}-u_{\beta 1}\right)+\lambda_{2}^{C K S C}(u) C_{12}\left(u_{\alpha 1}-u\right)+U^{C K O C}(u) & \\
=C_{11}\left(u_{\alpha 1}-u\right) & \alpha_{1}=1, \ldots ., n_{1}(u) \\
\sum_{\beta 1=1}^{n(u)} \lambda_{\beta 1}^{C K O C}(u) C_{21}\left(u-u_{\beta 1}\right)+\lambda_{2}^{C K S C}(u) C_{22}(0)+U^{c k o c}(u)=C_{21}(0) & \\
\sum_{\beta 1=1}^{n(u)} \lambda_{\beta 1}^{C K O C}(u)+\lambda_{2}^{C K O C}(u)=1 &
\end{array}\right]
$$

onde : $\sum_{\text {beta } 1=1}^{n(u)} \lambda_{\beta 1}^{C K S C}(u)$ é o somatório dos pesos das informações da variável primária $Z 1\left(u_{1}\right)$,

$\lambda_{2}^{C K O C}$ é o peso destinado ao dado da variável secundária $Z 2(u)$ locado no ponto u que está sendo estimado,

$C_{11}\left(u_{\alpha 1}-u_{\beta 1}\right)$ covariância da variável primária entre os locais $u_{1}$ e $u_{1}$,

$C_{12}\left(u_{\alpha 1}-u\right)$ covariância cruzada entre a variável primária em $u_{\alpha 1}$ e da variável secundária no ponto $u$ que está sendo estimado,

$C_{11}\left(u_{\alpha 1}-u\right)$ covariância da variável primária entre os locais u 1 e o ponto u que está sendo estimado,

$C_{21}\left(u-u_{\beta 1}\right)$ covariância cruzada da variável secundária no ponto $u$ que está sendo estimado com a variável primária em $u_{1}$

$C_{21}(0)$ covariância cruzada para o vetor de separação h igual a zero.

$C_{22}(0)(\mathrm{co})$ variança dos dados da variável secundária

$U^{\text {ckoc }}$ parâmetro Lagrangeano para incorporar a condição da soma dos pesos de $Z_{1}$ e $Z_{2}$ ser igual a 1.

\section{B.3 Modelo de Markov 1 (MM1)}

O MM1 foi aceito na prática, pois não necessita do sistema linear de co-regionalização diretamente, porém esta facilidade tem seu preço. Tudo que o MM1 precisa é a covariância primária C11(h) e a covariância cruzada C12(h).(ALMEIDA, 2003) sugere o seguinte tipo 
de aproximação para a covariância cruzada:

$$
C_{12}(h) \approx \frac{C_{12}(0)}{C_{11}(0)} C_{11}(h)
$$

onde a covariância cruzada $C_{12}(h)$ é ajustada pela covariância da variável primária $C_{11}(h)$, os índices $C_{12}(0)$ e $C_{11}(0)$ é a covariância cruzada e da variável primária para $h=0$ respectivamente. A equação (3.23) escrita sob a forma de correlograma é dada por:

$$
\rho_{12}(h)=\rho_{12}(0) \cdot \rho_{1}(h)
$$

onde o correlograma cruzado para $h \neq 0 \rho_{12}(h)$ é igual a multiplicação do correlograma cruzado para $h=0 \rho_{12}(0)$ pelo correlograma da variável primária $\rho 1(h)$.

Reescrevendo a equação anterior em termos de variograma:

$$
\gamma_{12}(h)=\frac{C_{12}(0)}{C_{11}(0)} \gamma_{11}(h)
$$

onde o variograma cruzado $\gamma_{12}(h)$ é ajustado pela covariância da variável primária $C_{12}(0)$ e $C_{11}(0)$ para $h=0$ e pelo variograma da variável primária $\gamma_{11}(h)$.

Uma limitação do MM1 é de que os dados secundários $Z_{2(u)}$ são dependentes dos dados primários colocados $Z_{1(u)}$ o que filtra a influência dos dados primários mais afastados $Z_{1\left(u^{\prime}\right)}$.

O MM1 é empregado quando o correlograma cruzado experimental for proporcional ao correlograma experimental da variável primária (GOOVAERTS, 1997).

O MM1 é um modelo aceitável se $Z_{1}(u)$ apresentar o mesmo ou um maior volume de suporte que $Z_{2}(u)$, permitindo que isto projete a influência de dados mais afastados de $Z_{1}\left(u^{\prime}\right)$ (JOURNEL, 1999).

Em várias aplicações práticas, no entanto, a variável primária $Z_{1}(u)$ é definida como um suporte muito menor que a variável secundária $Z_{2}(u)$. Por essa razão o MM1 não é um modelo indicado, pois, o ajuste variográfico da variável secundária (menos abundante) pode ser menos preciso.

Finalmente, devido aos dados secundários $Z_{2}$ serem tipicamente mais abundantes, a inferência de $\rho_{2}(h)$ é mais fácil que $\rho_{1}(h)$. Então, em casos semelhantes, um modelo revertendo às posições de $Z_{1}$ e $Z_{2}$ no modelo MM1 proposto poderia ser mais apropriado. 